University of Louisville

ThinkIR: The University of Louisville's Institutional Repository

Electronic Theses and Dissertations

$12-2017$

\title{
Educating critically : challenging the familiar contours of literacy teacher education.
}

Bianca Nightengale-Lee

University of Louisville

Follow this and additional works at: https://ir.library.louisville.edu/etd

Part of the Curriculum and Instruction Commons, Curriculum and Social Inquiry Commons, Elementary Education Commons, Language and Literacy Education Commons, and the Scholarship of Teaching and Learning Commons

\section{Recommended Citation}

Nightengale-Lee, Bianca, "Educating critically : challenging the familiar contours of literacy teacher education." (2017). Electronic Theses and Dissertations. Paper 2824.

https://doi.org/10.18297/etd/2824

This Doctoral Dissertation is brought to you for free and open access by ThinkIR: The University of Louisville's Institutional Repository. It has been accepted for inclusion in Electronic Theses and Dissertations by an authorized administrator of ThinkIR: The University of Louisville's Institutional Repository. This title appears here courtesy of the author, who has retained all other copyrights. For more information, please contact thinkir@louisville.edu. 
EDUCATING CRITICALLY: CHALLENGING THE FAMILIAR CONTOURS OF LITERACY TEACHER EDUCATION

\author{
By \\ Bianca Nightengale-Lee \\ B.S., Eastern Michigan University, 2004 \\ M.Ed., University of Louisville, 2012 \\ A Dissertation \\ Submitted to the Faculty of the \\ The College of Education and Human Development \\ in Partial Fulfillment of the Requirements of the University of Louisville \\ for the Degree of \\ Doctor of Philosophy \\ in Curriculum \& Instruction \\ Department of Curriculum \& Instruction \\ University of Louisville \\ Louisville, Kentucky
}

December, 2017 
Copyright 2017 by Bianca Nightengale-Lee

All Rights Reserved 

EDUCATING CRITICALLY: CHALLENGING THE FAMILIAR CONTOURS OF LITERACY TEACHER EDUCATION

\author{
By \\ Bianca Nightengale-Lee \\ B.S., Eastern Michigan University, 2003 \\ M.Ed., University of Louisville, 2012 \\ A Dissertation Submitted on
}

November 10, 2017

to the following Dissertation Committee:

\begin{tabular}{c}
\hline Lori Norton-Meier Co-Chair \\
\hline Mikkaka Overstreet Co-Chair \\
\hline Shelley Thomas \\
\hline Meera Alagaraja \\
\hline
\end{tabular}

Ray Haynes

James Chisholm 


\section{DEDICATION}

This work is dedicated to Brielle, Clinc and Mom. Thank you for all you are and all you do. I love you each with my whole heart. 


\section{ACKNOWLEDGEMENTS}

I would like to thank my dissertation co-chairs Drs. Lori Norton-Meier, and Mikkaka Overstreet, for their relentless support, and patience as I advanced on this journey. Secondly, I must thank my committed dissertation committee, for their continued support. I strategically chose each individual on the committee because of their humanizing approach to leadership, that predicates on mutual respect, and collegiality. I truly appreciate each of you for the unique perspectives and contributions that you have applied to my work.

Outside of my committee, I'd like to thank those professors who were not obligated to support me, but took a vested interest my success. Therefore I extend a thank you to Drs. Id-Deen, Washington, Laman, Carter, Ingle, Immekus, Jean-Marie, Dumas, Kumi, Compton, Gattis, Jett, Finch, Brown, Johnson, Rowland, Foster, and Jean Wolph. I also must recognize and thank the very supportive and humble staff of the College of Education who have been a constant light during this process, especially, Wanda, Paula, Melody, Christine, Steve, Desrie, and Alice.

I of course could not have made it through this process without the support of my colleagues and friends therefore I would especially like to thank, Simone, Nyree, Tara, Lisa, Tytianna, Emily, Ashley, Irina, Kimberly, Kobena, Picandra, Brandon, Portia and Jarrod. 


\section{ABSTRACT \\ EDUCATING CRITICALLY: CHALLENGING THE FAMILIAR CONTOURS OF LITERACY TEACHER EDUCATION \\ Bianca Nightengale-Lee}

November 10, 2017

The shifting cultural ecologies of U.S. classrooms emphasize acknowledging difference, accepting diversity, and sustaining both cultural and linguistic plurality (Banks \& Banks, 2009; hooks, 1994; Paris 2014). Teacher education programs play an integral role in preparing Pre-Service Teachers (PSTs) with skills, knowledge, and dispositions necessitated by a growing Culturally and Linguistically Diverse (CLD) student population (Cruz, Ellerbrock, Vasquez \& Howes, 2014). To enact equitable teaching practices reflective of $21^{\text {st }}$ century students, PSTs need to demonstrate a level of cultural awareness that acknowledges the racially, socially, and politically charged societal structures that shape education for CLD students (Hall \& Carlson, 2016). However, for Teacher Preparation Programs (TPPs), this task is complicated by the racial, cultural, and linguistic divide amid CLD students and their White teacher counterparts (Ball \& Forzani, 2009). Research suggests cultural dissonance can result in a lack of knowledge and understanding about diverse students and how socio-historical oppression can affect their achievement (Brock, Case, \& Taylor, 2013; Grossman \& McDonald, 2008; Lazar, 2007). Thus, if White PSTs are expected to cultivate equitable classrooms, responsive of 
the socio-cultural, linguistic, and educational needs of CLD students, then TPPs need radical alterations in curriculum and instructional design to not only deliver practical applications of classroom practice, while also providing critical understanding of literacy as "a cultural resource that can be used to challenge systems of domination" (Janks, p. 35, 2000). This idea is amplified through the current study, when exploring three strands of curricular inquiry: critical pedagogy, literacy education, and intersectional positionality. Specifically, the researcher examines how teacher candidates conceptualize curriculum that blends elementary literacy methods content and critical perspectives that critique, resist, and re-design traditional literacy practices. Utilizing a qualitative case study, multiple forms of data analysis reveal that critically oriented instruction must be taught explicitly and in multiple formats to support teachers in taking anti-hegemonic stances. 


\section{TABLE OF CONTENTS}

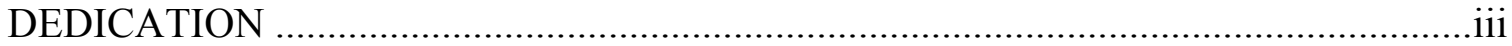

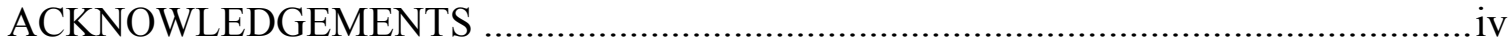

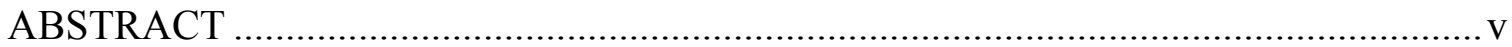

LIST OF FIGURES ............................................................................................. vii

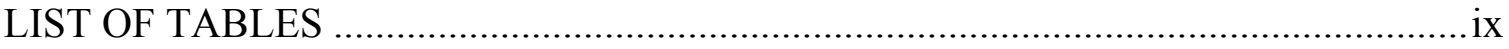

RETAINED LABELED \& TRACKED .................................................................... 1

CHAPTER 1: INTRODUCTION ......................................................................... 4

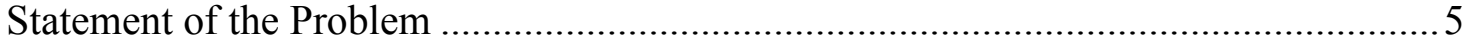

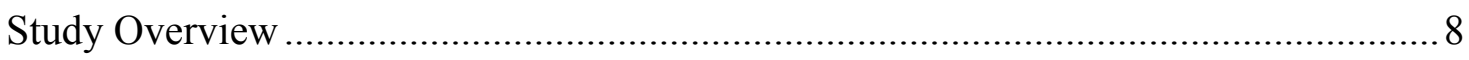

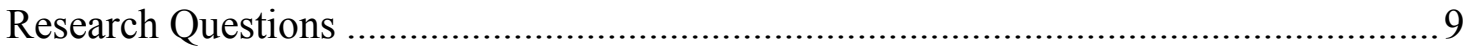

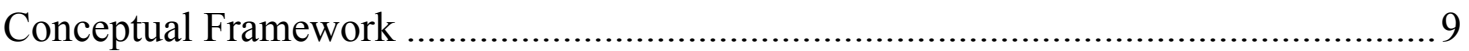

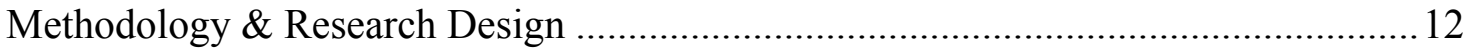

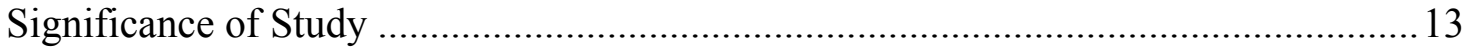

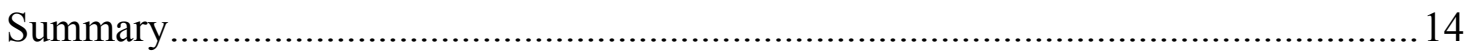

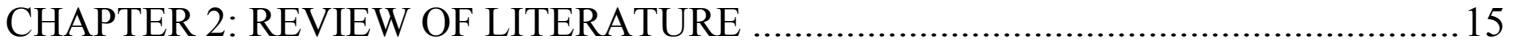

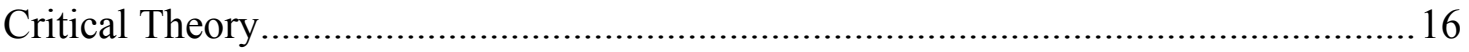

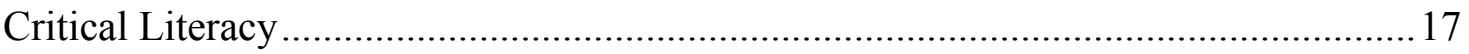

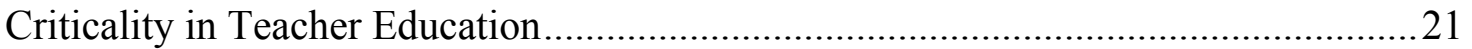

Pre-Service Teachers \& Cultural Dissonance .......................................................2 24

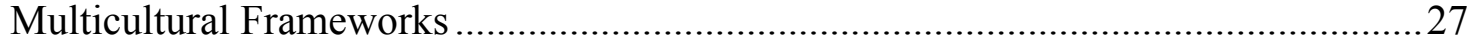

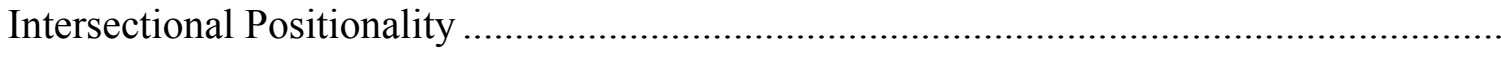

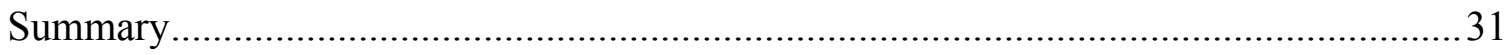

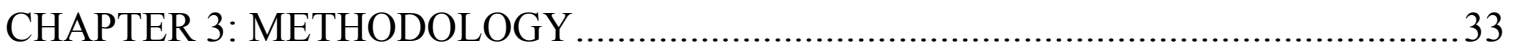


Study Overview

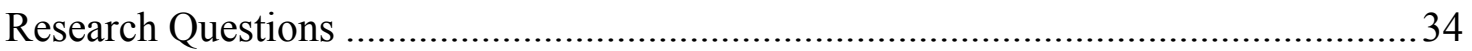

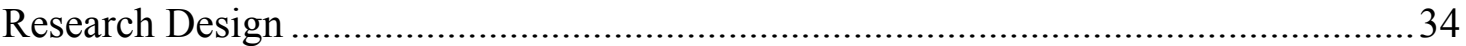

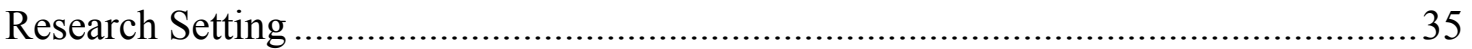

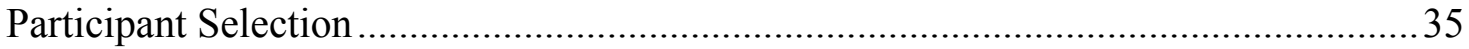

Data Collection, Instruments \& Procedures .............................................................. 38

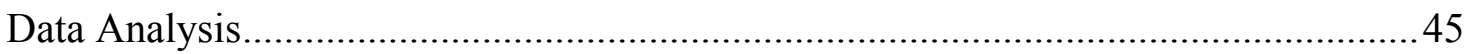

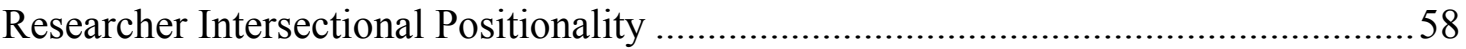

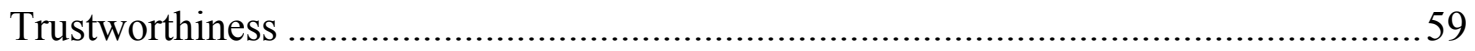

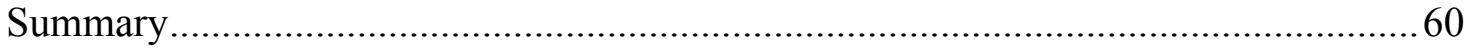

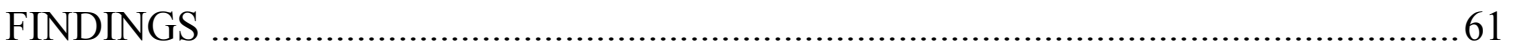

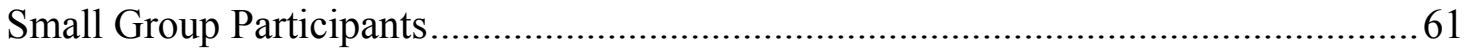

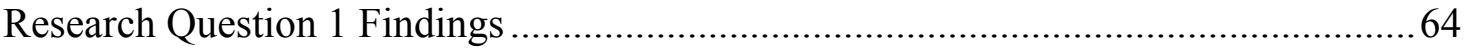

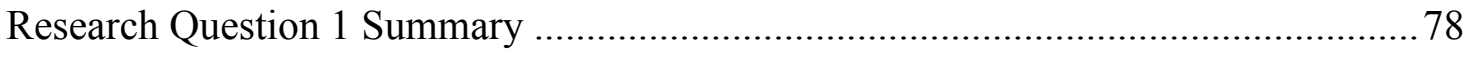

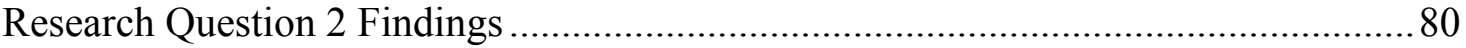

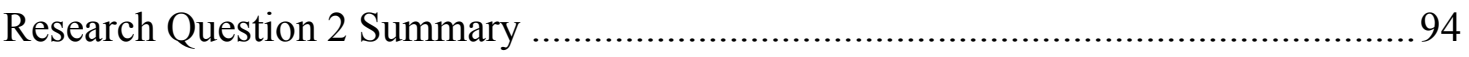

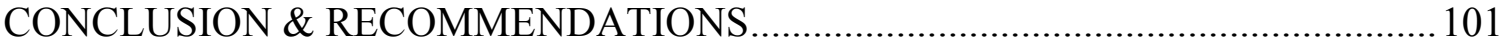

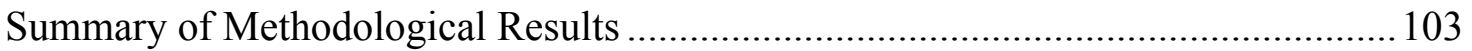

Overview of Research Findings \& Insights....................................................... 114

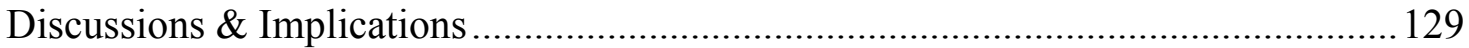

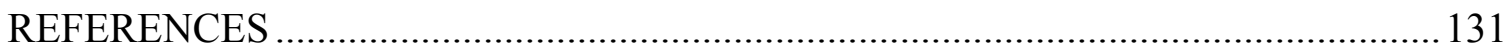

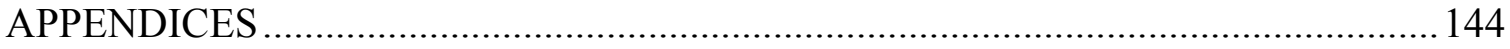




\section{LIST OF TABLES}

1. Literature Review Search Terms .......................................................................... 17

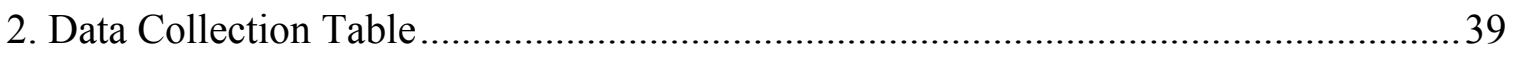

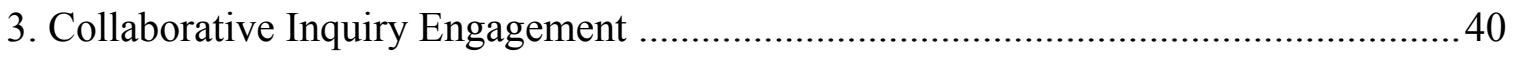

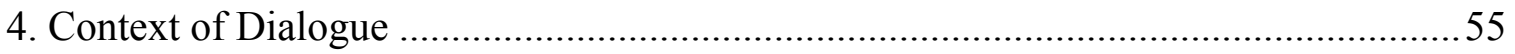

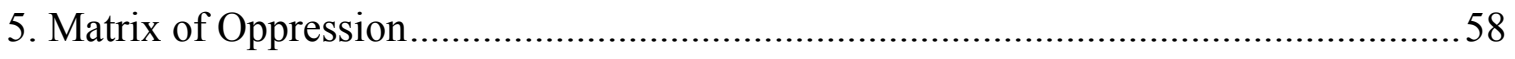

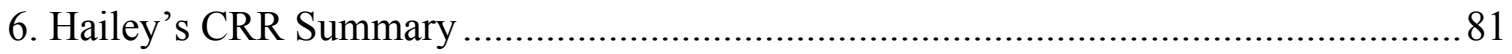

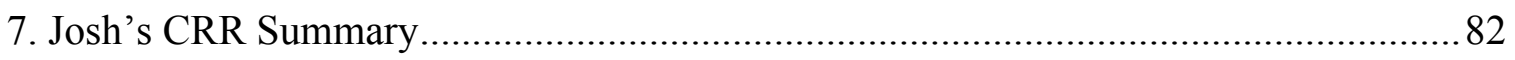

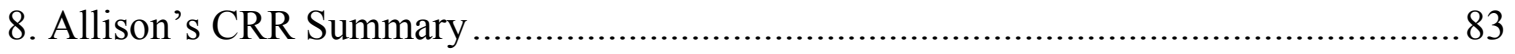

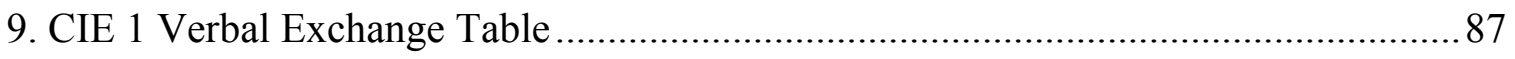

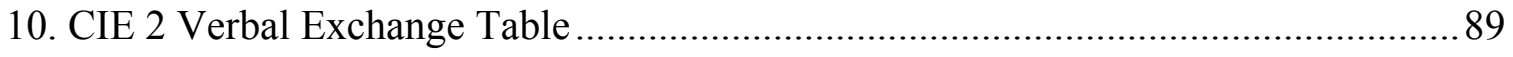

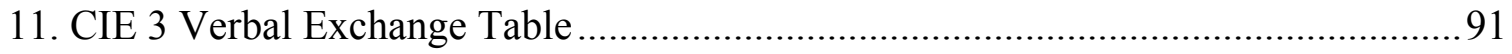

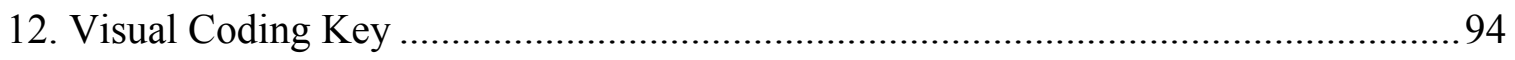

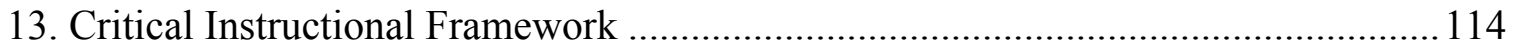




\section{LIST OF FIGURES}

1. Critical Intersectional Model .................................................................................. 13

2. Contextualized Considerations of Analysis Flow Chart .......................................... 49

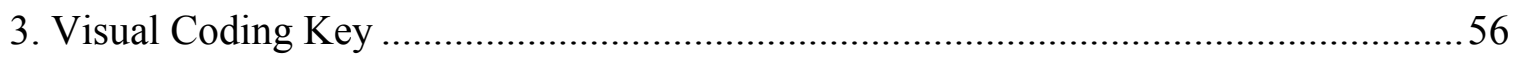

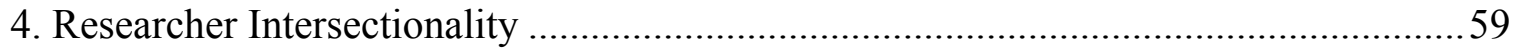

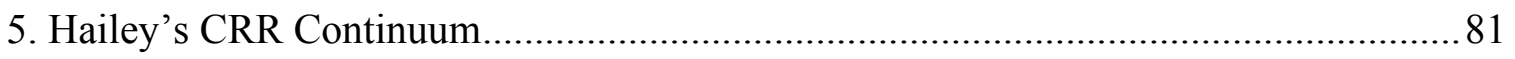

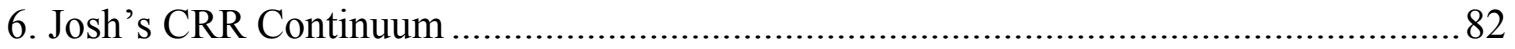

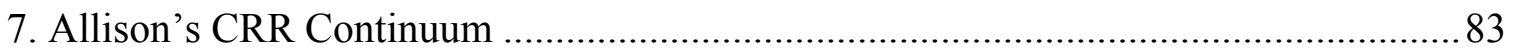

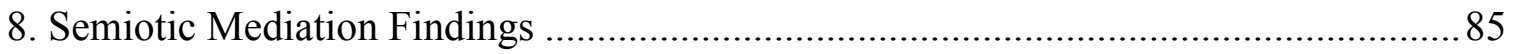

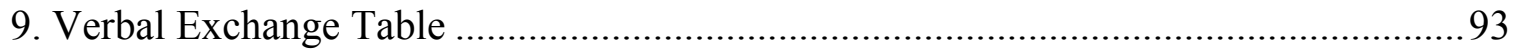

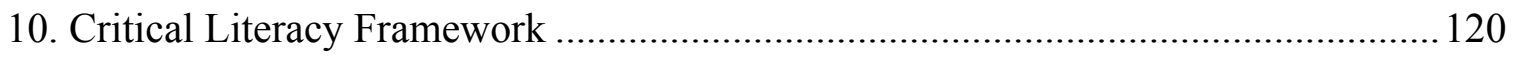

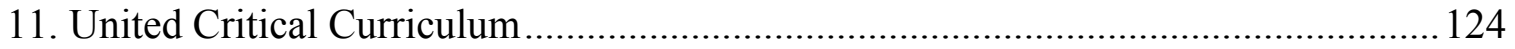




\section{RETAINED LABELED \& TRACKED: DILEMMAS IN FINDING A WRITER'S VOICE}

"Voice is the literal expression of one's identity, the echoing of the self. If you can't talk about what you believe in a way that feels natural, you can become alienated from your inner self. You're no longer able to express who you truly are."

-Jones \& Shorter-Gooden (2003)

By age six, I knew I was dumb. I still have clear memories of being placed in the corner by my kindergarten teacher, Mrs. Hannigan, because I couldn't "color within the lines". I didn't recall information as quickly as the other kids, and easily became confused with trying to remember the order of my ABCs. Mrs. Hannigan made sure to remind me that I wasn't quite good enough, by comparing my reading abilities with other students. I sat alone most days in kindergarten, but I'm unsure why. My mother and Mrs. Hannigan had a meeting about me, which ended with mom grabbing my hand, and storming out of the classroom. On our walk to the car, mom's hand firmly clutching mine, we were silent. After the car door slammed, mom sat quietly for a while, and I could see small tears fall from her eyes. I was never sure why mom was so upset, but I knew it wasn't good, and I knew it was because of me. I soon found out that Mrs. Hannigan didn't feel I was ready for first grade, and that she wanted me to be "held back". Mrs. Hannigan said that I needed to be tested for something called a learning disability. Though I didn't know the meaning of a learning disability, I heard these words a lot from my teachers, and I knew it was the reason why I had to go to a "special" class during reading time. I was six, and I knew I was dumb.

This vignette, though short and simplistic, speaks to my introduction to literacy learning. If I was retained in kindergarten, labeled in first grade, and tracked in second, why would I think achievement was a possibility for me? Carrying this burden of shame and incompetence, I traveled through elementary school calmly awaiting failure and mediocrity. Couple this with a 1980s literacy curriculum predicated on prescriptive pedagogy (Reither, 1985) that reflected only Eurocentric ideologies, and you have the recipe for a voiceless student. Gay asserts, "Educators must develop and deliver curriculum and instruction in ways that do not silence the cultural voices of diverse students" (2010, p. 122). My 
definition of a voiceless student is one who is subjugated to modes of inequitable educational practice that devalue their worth and marginalize their voice and experience. The message of inadequacy reflected by my early educational experience was blaringly evident and carried debilitating consequences as I traveled through the world voiceless. Combating the projected realities of how teachers perceived me through the lens of my disability was challenging to reconcile psychologically and emotionally.

However, my deficit narrative was interrupted within my first college level writing course. My professor, Dr. Orloff, didn’t see me as an "LD student". In her eyes I was a capable being, with valid thoughts and conjectures. She provided learning experiences that allowed me to speak my truth, through expressive writing exercises, in which she validated my perspective and challenged my thinking. Though Dr. Orloff still stands as one of my most challenging professors, her tutelage and belief in me helped re-conceptualize who I was as a student, as a learner, and as a writer. Smith says that "All learning pivots on who we think we are, and who we see ourselves as capable of becoming" (1998, p. 11). This significant moment in my career helped me realize the powerful platform that writing could provide. It was in this space that I began to find myself; it was in this space I began to find my voice.

I share my journey not to invoke pity, but to promote promise. Promise of a revolutionized educational system, responsive to the diverse needs of all students, that fosters transformative learning experiences, and supports marginalized students into becoming critically conscious citizens who use their 
voice for social action and change (Christensen, 2000; Dewey, 1938; Freire, 1970). This optimistic lens is antithetical to my K-12 educational experience, and although my tale was unfortunate, it illuminates cracks that still exist in the educational landscape of U.S. classrooms today.

My conceptual interpretation of literacy in the elementary classroom is heavily influenced by my primary educational experiences. I use these experiences as catalysts to resist dominant forms of standardized curricula that undermine my professional expertise and ignore the "rich cultural and linguistic legacies of diverse student populations" (Kinloch, p.15, 2013). Thus my educational path has helped establish my quest as a literacy educator and fortify my love of teaching literacy because I understand its potential in transforming reluctant students into active learners who may find their voice and change the world.

Considering the ever-increasing opportunity gap between high and low socio-economic students (Gay, 2010) and the lack of culturally responsive curricula (Ladson-Billings, 1995), this study seeks to amplify classroom practices which make literacy education equitable for students of cultural and linguistically diverse backgrounds. This modality of thought sanctions analysis of how explicit constructions of knowledge are legitimized or delegitimized by dominant cultures. By using a critically oriented approach to teacher education and literacy learning, my research aims to provide avenues of agency for teacher candidates that enable them to enact forms of critical awareness in their pedagogical practices. The following chapters discuss my plan for this study of research. 


\section{CHAPTER I}

\section{INTRODUCTION}

"When you go at life with a question and simply try to follow the trail of answers, when all the familiar contours of culture begin to shift. Everything is connected to everything else, and the web shakes with any touch at the farthest margins" Mary Rose O-Reilly, The Peaceable Classroom (1993, p. 37).

In 1932, progressive educational theorist George Counts insisted that education should play a fundamental role in making positive social and political reforms. Though Counts' work entitled, "Dare the School Build a New Social Order?," received criticism for pontificating an overly optimistic view of the American school system, this hopeful rendering acknowledged the potentiality of schools in re-shaping society. Critically inclined academics, such as Dewey, Freire, and hooks, carry a unified belief that, "education systems on the one hand, are highly influenced by social structures, and on the other hand, can contribute to the improvement of the status quo" (Abednia \& Izadinia, 2013 , p. 1). Though theorists approach criticality in various ways, their shared understanding contextualizes schooling as a social construction, operationalized by hierarchical manifestations of privilege and power (Giroux, 1988; McLaren, 1989; McLaren, 1993; Shor \& Pari, 1999).

Counts (1938) work reminds of us of the importance of teachers who "lead society rather than follow it” (p. 5). Working from this notion, I agree with Bartolome (2000), that educators cannot assume a position of neutrality that absolves them from recognizing the socio-political constructions of dominance, which shape our society, nor 
can they ignore their role in reproducing or rejecting these structures in the classroom. Educators, as disseminators of knowledge, are afforded the opportunity to engage in consciousness-raising practices, which promote student action by reading and reacting to the world (Bartolome, 2004; Freire, 1970). However, this level of emancipatory education is stymied if teachers are unable to remove the veil of societal blindness, which relieves them from recognizing the racially, socially, and politically charged structures that shape education. Therefore, this study aims to challenge the contours of familiarity by cultivating pre-service teachers who critique, resist, and re-design traditional literacy education practices to promote equitable literacy instruction.

\section{Statement of the Problem}

The shifting cultural ecologies of U.S. classrooms emphasize acknowledging difference, accepting diversity, and sustaining cultural and linguistic plurality (Banks \& Banks, 2009; hooks, 1994; Paris 2014). Teacher education programs are responsible for preparing Pre-Service Teachers (PSTs) with the skills, knowledge, and dispositions necessitated by a growing Culturally and Linguistically Diverse (CLD) student population (Cruz, Ellerbrock, Vasquez \& Howes, 2014). To employ responsive teaching practices reflective of the current cultural landscape, PSTs require a level of critical awareness that acknowledges the societal constructs that shape education for CLD students (Hall \& Carlson, 2016), and the equitable teaching practices that reflect their needs. However, this equity-based outlook is hindered if PSTs are not provided the space to explore critical perspectives that interrogate inequitable literacy practices and their significance in an increasingly multicultural society (Ladson-Billings, 2007; Sleeter, 2008). 
Promoting multicultural, critical, and culturally responsive pedagogies exist in stark contrast to traditional approaches to learning which predicate on hegemony and White mainstream norms. Research emphasizes the role of TPPs in directly influencing what PSTs learn about themselves, and about teaching students who differ from them (Gomez, Black, \& Allen, 2007; Hollins, 2011). Researchers in teacher education and diversity agree that multicultural commitments first depend upon PSTs dispositions, social values, and beliefs (Ball, 2009; Hollins, 2011).

However, preparing PSTs to endorse critical pathways to teaching, can be challenged by varying factors. One potential barrier is the racial, cultural, and linguistic divide between White mainstream PSTs and CLD students (Ball \& Forzani, 2009). Research suggests that this dissonance can result in a lack of knowledge and understanding about diverse students and how socio-historical forms of oppression affect their academic achievement (Brock, Case, \& Taylor, 2013; Grossman \& McDonald, 2008; Lazar, 2007). Further, King (1991) asserts, that while some PSTs may adopt multicultural perspectives, they still maintain ideologies that nest within structural racism, and White privilege. This cultural misalignment is problematic considering that $82 \%$ of all educators entering the field of education are White and middle class (NCES, 2016).

From a curricular standpoint, embedding critical orientations into curriculum is challenging when many gaps remain as to how teacher educators can develop courses that build PSTs instructional knowledge, alongside critical consciousness. Narrowing the focus to literacy education, very few effective models exist, which blend methods-based content and critical approaches to literacy learning in teacher education (Bartolome, 2007; Dooley, Exley \& Comber, 2011; Janks, 2000; Rogers, 2013; Williamson, 2013). 
Williamson suggests that, "In addition to core competencies for accomplished literacy instruction, candidates must also become critical consumers of the instructional resources that are available to them and evaluators of the environments where they teach" (2013, p. 138). This idea is even more important when you consider that many PSTs adopt traditional and linear approaches to reading, which reduces the practice to a purely technical skill that overlooks its socially constructed nature. Janks (2000) suggests that $21^{\text {st }}$ Century literacy preparation needs to extend beyond narrow conceptions of decoding and comprehension of text. She urges, "What is needed now is a critical understanding of language as a cultural resource that can be used to challenge or maintain systems of domination" (Janks, 2000, p. 45).

Intuitively, helping PSTs access exemplary literacy methods for classroom practice is essential. However, resting on the ideas of Counts (1938), who believed education can transform the social order of our world, teacher preparatory programs have the space and latitude to not only deliver practical applications of classroom instruction, but advance democratic ideologies, which promote critical consciousness and dismantle historicized notions of neutrality (Cochran-Smith 2003; Compton-Lilly 2002; Freire, 1970; Giroux, 1988). Therefore, if PSTs from White, mainstream backgrounds are expected to cultivate equitable classrooms, responsive to the socio-cultural, linguistic, and educational needs of CLD students, then TPPs need progressive and non-traditional alterations to disrupt curriculum that fails to honor the "rich cultural and linguistic legacies of diverse student populations" (Kinloch, p.15, 2013). 


\section{Study Overview}

This exploratory case study examined how four pre-service teachers conceptualized critical literacy when embedded in a literacy methods course. For this study, participants were enrolled in a literacy methods course, which meet once a week for three hours. This course was housed within an urban elementary school of high need. Prior to this study, permission was granted by the department chair and the instructor of record to work closely with this literacy methods course to influence curriculum development indicative of course objectives and my research agenda. The course that was the site for this study was structured to provide a balance of literacy theory and instructional practice for PSTs. For study purposes, the curriculum was altered to embed literature activities and experiences that fostered a critical orientation to literacy.

Though critical perspectives in literacy instruction are beneficial to all educational contexts, the focus of this study is on culturally and linguistically diverse classrooms and students, which are defined by Ball (2008) as classrooms serving students from two or more cultural and linguistic groups. For this investigation, a systematic analysis of both writing reflections and small group discourse were examined.

Specifically I created seven curricular engagements that merged the literacy methods course syllabus with critically based learning activities. The curricular engagements called Collaborative Inquiry Engagements, were implemented seven times throughout the semester, for a duration of 60 to 90 -minutes within the 180-minute course day. In addition, the researcher attended class weekly and acted as a co-teacher alongside the instructor of record as a means to develop meaningful relationships with the students. Weekly conversations with the instructor were integral to successful implementation of 
the research plan, which required constant contact via e-mail, phone, and in-person conversation. The following research questions ground my study, and provide the framework for all data collection and analysis:

\section{Research Questions}

1) What do reflective writings, reveal about the ways pre-service teachers construct meaning around critical perspectives in literacy education?

2) How do pre-service teachers use collaborative discussion to construct meaning around critical perspectives in literacy education?

\section{Research Question Rationale}

To better understand how PSTs made sense of critical literacy in a literacy methods course, I decided to examine their reflective writings, and their collaborative discussion. I specifically chose to investigate these forms of PST data based on Vygotsky's sociocultural learning theory, and Mezirow's transformative learning theory that reveals the power of discussion, reflection and writing as vehicles for deeper meaning and comprehension construction; (Mezirow, 2000; Vygotsky, 1978). Framed by Lev Vygotsky (1978), sociocultural theory acknowledges the inextricable link between knowledge construction and the socially shaped contexts in which it exists. The power of this methodological outlook predicates on the interconnectedness between individual learner and social mediators in the process of meaning construction. Vygotsky (1978) applies the notion of semiotic mediation to define how semiotic tools (language, text, writing, gestures, collaboration) mediate social and individual functioning to connect the 
external and internal, and the social and the individual. The role of abstract and concrete tools based on Vygosky's (1978) definition of semiotic mediation is used as a conceptual framework to delineate how PST participants made meaning of critical literacy throughout this study.

Research in the area of reflective writing is vast and spans the past fifty years. Numerous studies reveal that the process of writing can be instrumental in sculpting our understanding of new learning (Britton, 1970; Hover, 1994). Specifically, writing can be superior to talk in shaping our thinking through deliberation and word choice, which can lead to more explicitness in expression (Britton, 1993). By articulating our rationales for actions through writing, by uncovering our beliefs and examining our actions in light of those assumptions, we engage in inquiry or knowledge generating. (Hoover, 1994). For this study I have chosen to approach reflective writing from a transformative learning perspective in which meaning structures are further developed and understood through reflection (Mezirow, 2000).

Discussion as a mode for deeper understanding has been researched extensively in the area of education. Specifically, James Britton (1970) describes the importance of language in developing thought and as a means of organizing a representation of the world:

Events take place and are gone; it is the representation that lasts and accumulates and undergoes successive modification.... We habitually use talk to go back over events and interpret them, make sense of them in a way we were unable to while they were taking place. (p. 18) 
However, for this study I am viewing collaborative discussion through a sociocultural lens which considers how the interaction between, my instruction, the critical curriculum, along with collaborative discussion, worked together to help PSTs make meaning of new learning.

\section{Conceptual Framework}

\section{Critical-Intersectional Framework}

When teachers nest instruction within a critical framework, they foreground classrooms of possibility (hooks, 1994). As a critical educator, I teach literacy through a critical lens, in which power, politics, and the presence of self is examined, analyzed, and countered (Kamler, 2001). Considering the complexities of teaching literacy within a critical framework, I conceptualized an approach to criticality through the criticalintersectional framework. This dyadic model attempts to illustrate the balanced nature of intersectional awareness and critical pedagogy, as complimentary mechanisms for teaching critical literacy in teacher education.

The critical-intersectional model is my interpretation of the interaction equivalency theorem posited by Anderson (2003), situated in distance education it provides a theory-based rationale for the roles in which equivalent interactions between student-teacher, student-student, and student-content play in supporting deep and meaningful learning. Leaning upon Wagner's (2010) definition of interaction as interactions that occur when objects and events mutually influence each other. I adapted Anderson's model to represent the balanced interaction between intersectionality theory (Collins, 1990) and critical literacy (Freire, 1970). Anderson (2003) suggests that "deep and meaningful formal learning is supported as long as one of the forms of interaction 
(student-teacher; student-student; student-content) is at a high level"' (p. 1).

The link between critical literacy and intersectionality rests within research that focuses on social manifestations of hierarchical forms of power and privilege (PurdieVaughns \& Eibach, 2008; Rios \& Stewart, 2013). As critical literacy works to amplify critical consciousness (Freire \& Macedo, 1987; hooks, 1994), a foundational aspect of this stance nests within a deeper understanding of self (Freire, 1970). Freire (1970) posits that self-awareness is the entry point to which cultural action and liberating education can begin. Working from this idea, a critical orientation to literacy is challenged if PSTs fail to recognize their own assumptions, biases, and positions in society. Critically conscious educators "seek to gain a better understanding of their own culture, their students' culture, and the historical relationship between the two" (Irizarry, 2007, p. 27).

The power of intersectional positionality recognizes identity as a matrix of socially assigned privileges and oppressions determined by gender, social class, race, sexual orientation, and ability (Case, 2016). Single axis conceptions of identity deny PSTs the opportunity to examine how "both privileged and oppressed social identities interact to create systemic inequalities, which alter lived experiences" (p. 9). An intersectional framework to literacy acts as a mirror from which PSTs can locate themselves as simultaneously privileged and oppressed, and provides a window to see how these divergent social locations position them as literate beings.

Because many PSTs lacked critically based instructional practices during their K12 experience, some are unaware of the socio-historical context in which literacy is situated. Unaware of this critical framework, some PSTs are oblivious of how literacy is negotiated through intersectional identities, which provide the lens from which readers 
make sense of text, and henceforth make sense of their world (McCormick, 1996). The primary theme of intersectionality examines "the experiences and struggles of disenfranchised groups to broaden and deepen understandings of human life and behavior (Collins \& Bilge, 2016 p. 36).

I argue that intersectionality lays the foundation for critical literacy by enabling PSTs to identify the duality of their own identity as being privileged and marginalized (Williamson, 2013). This perspective allows PSTs to realistically situate themselves in the world and counter reductionist-based notions that rely only on race and gender to define identity. This level of critical self-awareness is foundational in helping to acquire the self-assessment and consciousness necessary to access, acknowledge, and accept critical conceptions of the world (Grant \& Sleeter, 2007). Figure 1 represents how I conceptualize the critical-intersectional model and the major concepts which establish both theories.

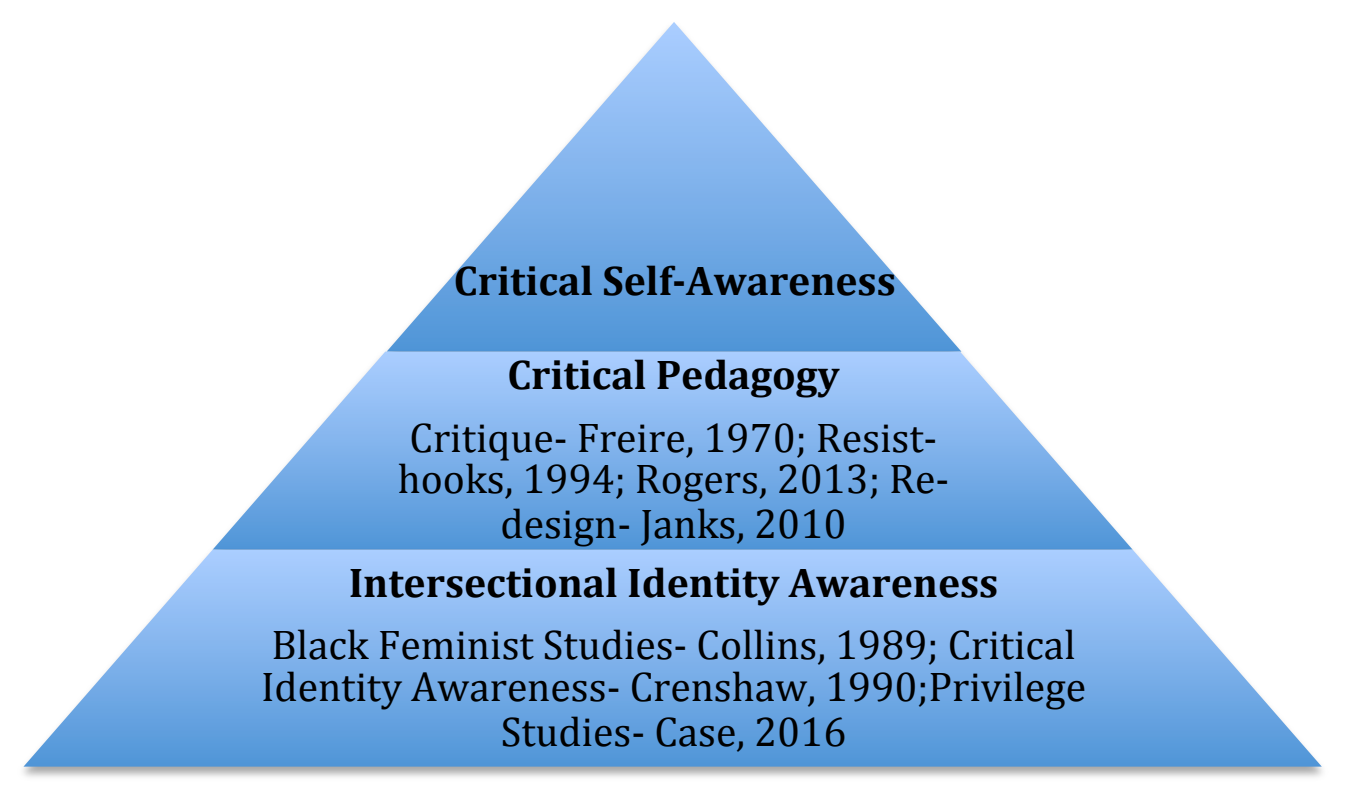

Figure 1. Critical-Intersectional Model 


\section{Levels of Criticality- Stance, Design, Curriculum}

This study defines criticality as the state of being critical, and employs this orientation to teaching and learning in three different ways: criticality as researcher stance, criticality as research design, and criticality as curriculum. Criticality as researcher stance represents the ways I maintained a high level of inquiry, reflectivity and reflexivity to continuously raise new questions about myself, and about my pedagogy, throughout the study.

Criticality as research design represents the critical theories and outlooks, which ground this study which include critical pedagogy, intersectionality, sociocultural theory, and transformative learning theory. These four concepts were used as anchors that provided the foundation for which all chapters were conceptualized and created.

Criticality as curriculum speaks to the construction of the Collaborative Inquiry Engagements (CIEs), which were shaped by an intermingling of two different approaches to curriculum, centered on a critical curricular lens, and a transformative instructional lens. Conceptualized by Freire (1970), Janks (2010), and Rogers, (2013) the critical curricular lens, molded each CIE learning session to connect to a critical literacy focus which pushed PSTs to critique, resist, or re-design a traditional literacy practice. The critical curricular lens influenced the curricular approach and activities in which I developed for the literacy methods classroom

The transformative instructional lens was grounded by Mezirow's (2000) Transformative Learning Theory, and adhered to the theory's three domains, (disorienting dilemma, rational discourse, and critical reflection) as scaffolds to support 
PSTs new learning. Specifically this lens influenced the foundational structures of my instruction by providing a balance of explicit modeling, small and whole group discourse, and written reflection. This structure was used as a guide that helped me provide instructional consistency during each CIE learning session.

\section{Methodology \& Research Design}

This exploratory study was conducted within the tradition of two different qualitative methodologies, in order to provide a more robust understanding of how teacher candidates conceptualized critical literacy when embedded into a literacy methods course. Specifically, this work borrowed methods from ethnographic and case study traditions. The utility of these methods provided two lenses to examine my data.

Exploratory case studies "are used to explore those situations in which the intervention being evaluated has no clear, single set of outcomes" (Yin, 2003, p. 35). Since exploratory case studies are often applied in a research context that is not clearly specified and still requires data for the formulation of valid hypotheses, theoretical propositions or assumptions are not created prior to the study. The broad themes, which emerge from an exploratory study, are positioned to open the door for further examination of the phenomenon observed (McDonough \& McDonough, 1997; Yin, 1984). While the study design and data collection were not restricted by the confines of an established theory, the literature base relative to the conceptual framework, provided a broad foundation from which study design, analysis and findings were constructed.

\section{Significance of the Study}

Research suggests that PSTs lack critically based experiences in their teacher 
education programs. Many markers in the literature contribute this to teacher educators who lack the knowledge to support PSTs on their journey to critical awareness (Chubbuck, 2010; Neumann, 2013). This study draws on the tenets of critical literacy in the methods classroom, to provide teacher educators with a framework that moves PSTs beyond simply processing received knowledge, into a realm of critical questioning that explores unresolved assumptions about traditionalized literacy teaching and learning (Giroux, 2004; Simon, 2011). An overarching goal of this work seeks to translate critical literacy knowledge into practice to provide PSTs with the skills to acknowledge inclusive and equitable educational practices that speak to the intersectional needs of CLD students (Ladson-Billings, 1994; Seidl, 2007).

\section{Summary}

Thus far I have provided the purpose of the research study, why it is important, and the foundations which undergird its conceptualization. The remainder of this study is comprised of four chapters, appendices, and a reference section. Chapter 2 will explain the expansion of literature related to critical theory, teacher education, and intersectionality. Chapter 3 will provide a description of my methodology and research design. Chapter 4 will provide an analysis of data findings and a discussion. Finally, Chapter 5 will delineate conclusions, implications and recommendations of this work. 


\section{CHAPTER II}

\section{REVIEW OF LITERATURE}

To initialize my literature review search, I conducted a broad search using ERIC

\section{EBSCO host.}

\begin{tabular}{|l|l|}
\hline 1. Critical literacy & 2. Pre-service Teacher \\
\hline 3. Critical Pedagogy & 4. Critical Consciousness \\
\hline 5. Teacher Candidates & 6. Teacher Education \\
\hline 7. Literacy Education & 8. Intersectionality \\
\hline 9. Urban Readiness & 10. Whiteness Studies \\
\hline 11. Privilege Studies & 12. Social Justice Education \\
\hline 13. Multi-Cultural & \\
\hline
\end{tabular}

Table 1. Literature Review Search Terms

This search garnered a wide spectrum of articles; however, some did not pertain directly to my research interests. Therefore, another search was conducted using Web of Science. Using the same key word indicators I noticed that the article pool aligned well with my research agenda. Fifty-five articles were then selected that related to my topic of study. These fifty-five articles were cross-referenced based on each bibliography page. Next, common authors found in the articles were highlighted and recorded on a separate piece of paper. Thirty-five names resulted from my initial coding sequence. To narrow and differentiate each, three categories were created: a) theory, b) research, and c) practice. From here, I began locating each work produced by the author within a twentyyear time span by using Google Scholar and Ekstrom Library search engines. Once all articles were located, they were printed and placed within two binders. One binder was 
specifically for critical literacy, while the second binder was for critical literacy in teacher education, Whiteness, and intersectionality. These research binders housed the majority of research used for this literature review.

\section{Critical Theory}

\section{Freirian Approach}

The revolutionary work of Brazilian educator Paulo Freire stands as one of the most prolific contributions to critical literacy (Giroux, 2003; McLaren, 2000). Freire's interpretation of critical literacy rests upon emancipatory practices, which reject the notion of curricular stratification that serve to maintain the status quo (1970). Freire posits that when "an awareness of self and others through critical consciousness can be developed students can begin to reflect on themselves and the world in which they live to uncover hidden biases and imbalanced power structures" (1970, p. 94). Nurturing critical awareness can open the door for what Freire refers to as praxis. Praxis is the power and the knowledge to act against oppressive practices, and is fundamental in transforming the social realities that shape our world.

Fostering agency to enact action, or what Freire refers to as praxis, is crucial in cultivating conscious individuals who own their power, potential and possibility (hooks, 1994). Though some refer to Freire's approach as empowering education (Allen \& Rossatto, 2009), Freire was deliberate in delineating the difference between agency and empowerment, through emphasis of the inextricable teacher-student, student-teacher connection (Freire, 1970). The dynamic interaction, which can exist between teachers and students can take on one of two forms according to Freire (1970). One mode of interaction known as the "banking concept of education", considers knowledge as a gift 
"bestowed by those who consider themselves knowledgeable upon those whom they consider to know nothing" (Freire, 1970, p. 35).

The second mode of interaction has a libertarian outlook on education. This stance is predicated on reconciling the power differential between teacher and student, which rejects the role of teacher as knowledge depositor and student as knowledge receiver. Instead, Freire speaks to the intersectional relationship between teacher and student, by stating that educators must project a "mutual humanization," which equalizes the classroom environment so that both teacher and student are partners in the learning process. This reconciliation allows the teacher as student, student as teacher dynamic to emerge, enacting the co-construction of knowledge (McLaren, 2000).

\section{Critical Literacy}

A number of critical researchers and practitioners (McLaughlin \& DeVoogd, 2006; Vasquez, 2014; Wink, 2013) explain critical literacy in terms of pedagogical practice, however, this term has a broader meaning. Critical literacy is rooted in a philosophical approach, which views literacy as a vehicle to challenge power, privilege and the status quo (Giroux, 2012; hooks, 1995). Adopting a critical perspective to knowledge dissemination means that teaching and learning must be linked "to understand why things are the way they are, and how they got to be that way; to make the familiar strange and the strange familiar" (McLaren, 1986,p. 32).

To fully grasp the utility of such an abstract concept, it is crucial to understand how "literacy" is shaped in traditional and critical domains. Traditional conceptions of literacy describe an individual's ability to read, write, communicate, and comprehend. This view of literacy is considered functional literacy. Functional literacy places 
emphasis on technical aspects of literacy including, canonized literature, word recognition, spelling, and sound-letter correspondence (Luke \& Freebody, 1997). According to Endes (2006), functional literacy prepares students for interactions that are based on workplace efficiency and productivity. Curriculum and instruction that only focus on functional literacy fail to prepare students to think in critical ways that help them make sense of themselves and society.

Luke and Freebody (1997) contextualize the foundation of reading in relation to its social implications, emphasizing its purpose within schools, politics, and society. They suggest that critical literacy uses competencies that expand the act of reading outside of perfunctory tasks. Luke \& Freebody (1997) summarize this by stating:

What this has meant in many classrooms is that there has been a shift away from the passive reception of information and skills as the core of the reading classroom experience, toward an apparently more active and oral construction of ideas that relate to a text, and pedagogies that aim to develop the individuals meaning making capabilities through talk, and allow the individual to respond to works of literature at a personal level. (p. 190-191)

The quote above denounces the notion of literacy as simple knowledge transmission, and encompasses a broader spectrum of the practice. Contrary to traditional literacy models, critical literacy critiques the process, content, and purpose of literacy, which helps readers situate words and how they relate to the world (Freire, 1970; Luke, 2012).

Critical literacy can take on various definitions based on the educational setting and audience. However, a universal tenet considers "learning to read and write as a part of the process of becoming conscious of one's experience as historically constructed within specific power relations" (Anderson \& Irvine, 1993, p. 82). The highly socialized and politicized nature of critical literacy examines power by asking: who has the power, by what means, and within what definitions of equity (Price-Dennis, 2009). Though a 
Freirian perspective to critical literacy posits ideological and pedagogical stances, critical researchers suggest that this framework lacks specificity of how teachers and students can utilize this structure within real-world contexts (Luke, 2012). Therefore, more practical models, which focus on problem posing, critical discourse analysis, and textual re-design, have emerged.

\section{Problem Posing}

Foundational strategies for building a critically conscious classroom promote critique by using the problem-posing method. Problem-Posing is an inductive questioning process that fosters inquiry through a guided series of questions that assists students in literary comprehension. Problem-Posing is situated in a three-step process of naming, critically reflecting, and consciously acting on the text messages which students' encounter (Wink, 2003). Problematizing and questioning authors' messages is a form of liberating praxis per Freire, because it enables readers to "develop their power to perceive critically the way they exist in the world in relation to the word" (1970, p. 34). This critical strategy provides a complimentary structure, which allows students to actualize their agency to challenge and question text in a critical way, supported by the guidance of the teacher.

\section{Critical Discourse Analysis}

Another practical method for critical literacy is language construction or deconstruction. Linguistic researchers (Janks, 2010; Rogers, 2013) prescribe critical discourse analysis (CDA) as a method to support learners by using language as a mediational tool for learning (Rogers, 2002; Vygosky,1938). Predicated on the assumption that language is never a neutralized construct, this facet of critical literacy 
helps students understand how texts function. From a teaching and learning perspective CDA teaches students how to analyze a range of texts by examining their functional, academic, literary, socio-linguistic, and ideological structures (Luke, 2012). Assisting students to become critically literate deals with "enabling them to detect and handle the inherently ideological dimension of language and literacy" (Lankshear, p.46, 1997). This critical perspective focuses on the grammatical and dialogic choices made by the author, to understand what these choices say about the author, how these words position the reader, and the larger socio-political implications of the text (Cervetti, Pardales, \& Damico, 2001).

\section{Textual Re-design}

Janks (2010) speaks to the potential of critical literacy as a form of re-design, which allows students to deconstruct language as a source of power. When student conceptualize literacy as socially constructed, they can understand the transformability of words and how as readers they have the power to re-imagine and re-work messages to counter dominant narratives. Janks (2015) states, "because all texts are constructed from a range of semiotic options, they can be deconstructed, unmade, unpicked and then reconstructed to offer a different representation of the world" (p. 4). In her interdependent model for critical literacy, she refers to design as a concept used to critique multi-modal text production. Janks' interpretation of re-design parallels a Freirian perspective in that "to exist humanly is to name the world, to change it. Once named, the world in its turn reappears to its namers as a problem and requires then a new naming" (Freire, 1972, p. $32)$. 
A critical approach to literacy studies is distinctive from other forms of curriculum and instruction because it commits to making unjust and inequitable conceptions of reality more salient. Through a thoughtful examination of text analysis, language construction, and critique, critical literacy provides leverage, which allow students to problematize the messages they receive on a daily basis. Nested in critical consciousness and praxis (Freire, 1970), critical literacy has the power to increase selfawareness, which can then lead to student reflection, voice, and agency (Giroux, 1985).

\section{Criticality in Teacher Education}

Bassey (1999) suggests that PSTs should learn to apply critical literacy early in their field experiences to promote democratic and empowering classrooms of change. However, teaching from a critical perspective is no small endeavor. Teacher education is up against several barriers that impede the progress of a critically oriented program of studies. The sections that follow touch upon these obstacles and illustrate why a critical stance is needed in teacher education today.

The National Council for Accreditation of Teacher Education standards state (NCATE, 2008) that teacher education programs should prepare teachers with the essential knowledge, skills and dispositions for teaching all learners and in particular, diverse learners. The Association for Supervision and Curriculum Development (ASCD) defines diverse learners as students from "racially, ethnically, culturally, and linguistically diverse families and communities of lower socioeconomic status" (2008). Considering that classroom ecologies are reflecting a much more diverse student population (NCES, 2016) TPPs are tasked with preparing a predominately White, 
female, and middle class pre-service teaching pool to understand diverse students, and deliver instruction relative to their needs (Bartolome, 2006; Gomez, 1994).

The racial, cultural, and linguistic dissonance between students and teachers is an important one. Research shows that this cultural dissonance ${ }^{2}$ (Allen, 2003) can result in a lack of knowledge and understanding, about diverse students, and how their social identities in the world can affect their achievement (Cross, 2005; Grossman \& McDonald, 2008). Lazar (2007) states:

At issue is the cultural dissonance between primarily White or middle class preservice teachers, who represent about $90 \%$ of those in teacher education programs, and a growing population of culturally and linguistically diverse children (Ziechner \& Hoeft, 1996). In many school districts, African-American and Hispanic Americans now represent the majority. It is likely that pre-service teachers will work with children whose cultural and social backgrounds are different from their own (p. 413).

This is further complicated when attempted at predominantly white institutions (PWIs) with White, mainstream PSTs who have not had the opportunity to interact with individuals of color (Ullucci \& Battey, 2011). Lazar (2007) states:

The majority of pre-service teachers are cultural outsiders with respect to urban, high poverty-communities. Many do not fully recognize the inherent literacy abilities of children in these communities even though this belief is fundamental to setting high expectations for them in the classroom. (p. 412)

Finding effective strategies that support a critical agenda is a continual source of study in teacher education (Cochran-Smith, 2001; Collins, 2003; Ladson-Billings, 1994; Rose \& Potts, 2011). Literature points to learning about candidates' perceptions, values, and beliefs as a primary step in aiding them to take an increased critical stance to teaching and learning. Meaningful forms of candidate analysis require exploring their

\footnotetext{
${ }^{2}$ Cultural dissonance- an uncomfortable sense of discord, disharmony, confusion, or conflict experienced by people in
} 
constructions of race, equity, and merit, which expose the ways in which they value and judge the world (Howard, 2006; Rios \& Lindley, 2004). Further Rose and Potts (2001) suggest, "power relations exist in the classroom, and teachers' actions toward students are influenced by teachers' perceptions regarding multiple socio-cultural factors” (p. 2). Since ideology is a necessary component to the ways in which teachers conceptualize society, a closer examination of PSTs perceptions of CLD students is required.

Understanding the challenges that PSTs face in adopting critical stances, Chubbuck (2010) argues that teacher educators wishing to foster such commitments should work to scaffold pre-service teachers' learning by acknowledging the emotional work necessary to cultivate equitable classrooms. This demands that teacher educators acknowledge and affirm the value of teachers' often-implicit knowledge and beliefs about teaching and schools (Neumann, 2013). Once teacher educators acknowledge PSTs foundational dispositions, they can begin to introduce elements of critical dissonance to disrupt pre-service teachers' intellectual status quo and cultivate a critical awareness that produces a potential shift of traditionalized educational practice.

\section{Pre-Service Teachers and Cultural Dissonance}

\section{Deficit Perspectives}

Research in teacher education suggests that some pre-service teachers espouse deficit perspectives in relation to teaching CLD students (Delpit, 1995). Negative presuppositions about diverse students could result in underserving these learners, therefore, further perpetuating the achievement gap (Delpit, 1995; Gay, 2010). Bartolomé's $(2004,2007)$ work asserts that teacher educators need to guide pre-service teachers to begin with the critique of dominant or mainstream ideologies such as the myth 
of meritocracy. She states, "coursework and field placement must include explicit critique of ideology and supports for pre-service teachers to learn how to take counter hegemonic stances" (p. 118). Supporting PSTs in understanding CLD students may help them re-conceptualize their deficit stances, and allow them to begin breaking down their own hegemonic interpretations of society.

Research suggests that many deficit perspectives derive from myths about race (Gay, 2000). Seidl (2007) argues that students need to work on "acknowledging the role and history of race and racism in our society and the ways in which this history affects relationships between communities" (p. 8). Integral to her study is the idea that links race and culture as a part of one's identity. Therefore, it's important to locate the role that race plays in PSTs perceptions of CLD students. However, PSTs who align with a White, middle class identity are rarely taught to discuss race or culture. Therefore "race and racism come to occupy a deafening silence in many spaces, including classrooms" (Seidl, 2007, p. 8). This notion begs the question posed by Ladson-Billings, which asks "how do White, middle class teacher candidates make the transition from being unaware of their culture to a critical understanding of the role of culture, power, and oppression?" (1994, p. 54). Unfortunately, this complex question cannot be answered simply. This is especially true when many White PSTs espouse colorblind ideologies.

\section{Colorblind Ideologies}

Pre-service teachers who lack racial awareness can perpetuate deficit thinking through colorblindness (Ullucci \& Battey, 2011). According to Rosenberg (2004), colorblindness allows people to deny that "race, especially skin color, has consequences for a person's status and well-being and that blindness to skin color and race remains a 
‘privilege' available exclusively for White people" (p. 257). Sleeter (2001) provides a critique of how PSTs used colorblindness as a mechanism to subvert the uncomfortable areas of race, equity, and diversity in a college education course. Sleeter's commentary suggests the importance of "working through resistance, and exploring privilege before pre-service teachers receive their initial teacher license and enter the profession" (PriceDennis, 2009, p. 32). Ullucci and Battey, who in a 2011 study sought to challenge colorblind orientations, further support this idea. The authors state:

As we attempt to prepare teachers to work with children from diverse backgrounds, a critical first step is a willingness to see how discrimination functions in society. Teachers cannot see racial inequities if they position race as insignificant in schooling and see racism as a historical artifact (2010, p. 196). Unchallenged notions of a colorless world blur the boundaries of cultural difference and create a homogenized view of society. With the minority majority report of 2014 , which shows $51 \%$ of the U.S population being from culturally diverse backgrounds, PSTs who fail to acknowledge and appreciate "color" stand to further perpetuate the failure of the American school system. In his book, Racism Without Racists, Bonilla-Silva (2006) espoused the detrimental effects of colorblindness, as a new form of racism. Bonilla-Silva suggests that this construct manifests as a "kinder, gentler" type of racism that is covert in nature, and does not rely on obtrusive forms of oppression, but utilizes methods that are "subtle, institutional, and apparently nonracial" (p. 3). Therefore, an understanding of color and cultural awareness is important, because it speaks to the ways in which PSTs extend educational opportunity and interact with students, families, and communities divergent from their own (Galman, Pica-Smith \& 
Rosenberger, 2010). Seidl and Jaekel (2012) advocate for White pre-service teachers to develop a greater understanding of the historical and political legacy of race, starting with a greater awareness of their own race, and how it positions them in society.

\section{Whiteness Studies}

Critical researchers in teacher education agree that Whiteness studies provide White students an opportunity to gain understandings about race and racism in the context of their own identity (Banks 2001; Howard, 2006; Ladson-Billings, 2000). Whiteness studies seek to take a deeper look at how White teachers address cultural difference and race, and what role their understandings of multiculturalism play in maintaining racist ideologies (Picower, 2009). The need for Whiteness studies is increasingly important as we see the colors and cultures of the national landscape shift in unique ways (Picower, 2009). This is even more pronounced when research asserts that White pre-service teachers exhibit behaviors that attempt to resist race discussions in teaching and learning. For example, Picower's (2009) work with pre-service teachers in a multicultural course, found that White students used "tools of Whiteness" to circumvent the weighty topic of race. Picower conceptualizes "tools of Whiteness" as mechanisms that are "designed to protect and maintain dominant and stereotypical understandings of race" (p. 1). Though these tools are usually narrowly defined as passive resistance, Picower suggests that these tools are used as armor to shield White students from alternative viewpoints that are different from their pre-existing concepts of race and culture.

The impetus of Whiteness studies provides avenues for exploring, talking, and analyzing White identity. Seidl's (2007) work supports the idea of fostering open, 
responsible discourse on race with pre-service teachers to become aware of, and challenge the politics of skin color while disrupting the hegemonic practices that sustain oppressive structures. Kincheloe and Steinberg (1998) posit that a healthy White identity is focused on "unlearning racism and encouraging insight into the nature of historical oppression and its contemporary manifestations, rather than simply eliciting feelings of guilt for White racism" (p. 19).

\section{Multicultural Frameworks}

Acknowledging the challenges explicated above, some TPPs have turned to incorporating multicultural frameworks in their courses, which seek to cultivate an awareness of culture and diversity that better prepare PSTs for teaching CLD students (Rose \& Potts, 2011). Given this, Gordon (2005) recommends offering multicultural courses, diverse field experiences, and curricula infused with tenets of multiculturalism to address the gap between white teachers and the students of color they serve. In support of Gordon's findings, Wiggins (2007) study of diverse field experiences for pre-service teachers found that immersion in schools with populations that do not share the same cultural, socioeconomic, or racial status, can lead to more culturally responsive teachers. However, in order to achieve this, multiple levels of support should be provided for preservice teachers as they are placed in settings with students who have different backgrounds.

Integration of cultural awareness into course syllabi is only a preliminary step (Bartolome', 2004). Teacher preparatory courses that boast a critical or multicultural framework fall flat if they "fail to provide the immersion experiences that allow (preservice teachers) to inquire about literacy as a socially and culturally situated practice" 
(Lazar, 2007, p. 412). This idea has prompted some researchers to dismiss the idea of a multicultural education altogether, with claims that teacher preparatory programs only provide superficial attempts at understanding diversity (Ullucci \& Battey, 2011). Tellez goes on to argue, that, "most programs are currently configured, attempts by novice instructors to "do diversity" and end up violating the integrity of the very students multicultural education intends to help" (Ullucci \& Battey, 2011, p. 91). Furthermore, the notion of a one-shot diversity or multicultural course in teacher education is no longer a viable solution in supporting TC knowledge base. Sleeter's (2001) critique of teacher education programs reflects that the most successful models occur when multicultural educational frameworks are nested within all required methods courses, rather than just one.

Though teacher education can provide a firm foundation, it is the work of conscious teacher educators who have the platform and power to make the biggest impact on PSTs cultural awareness. Ullucci and Battey (2011) assert that teacher educators need to forgo shallow versions of multicultural education that do not yield critical impact. Marx and Pennington (2003) argue that to provide the support and guidance necessary to open up discussion about multiculturalism, teacher educators must become familiar with the body of work on culturally relevant pedagogical practices, racism, and TC identity development.

To assist in the process of engaging PSTs in culturally relevant conversation, Milner's (2007) four-part framework provides a systematic approach. The framework consists of four parts: (a) examining one's own racial and cultural background and identity and how that might affect one's experiences and perspectives; (b) considering the 
racial and cultural backgrounds and identities of "the researched" (or of students for whom one is preparing teachers) and how one's own beliefs and convictions interact and may conflict with theirs; (c) engaging in reflection and representation in which teacher educators and community members think through together "what is happening in a particular research [or school] community, with race and culture placed at the core" (p. 396); and (d) shifting from self to system by learning to focus on how race structures community and school experiences and how racial barriers can be reduced or eliminated.

\section{Intersectional Positionality}

Initiating dialogue about power and privilege can be a challenging endeavor for PSTss (Hall, 2016). Blumenfeld and Jaekel (2012) note that novice educators may be hesitant to discuss issues related to social inequities, which include talking about how power and privilege impact the educational opportunities of some and not others (Hall, 2016). Based on the literature discussed above, social and cultural discussions are further challenged with candidates from White, middle class backgrounds. However, Blackburn and Smith (2010) assert that intersectional studies counter simplistic and static conceptions of race and culture, which position White students as oppressor. The authors state, "Intersectional discourse makes space for White people to perform alternate identities that include anti-racist or White ally attitudes and actions" (2010, p. 34). An intersectional approach to teaching about social inequities may avoid an over-emphasis of Whiteness, which may prompt White students to recede from class discussion and become silenced as a result (Ladson-Billings, 1996). 
Helping PSTs understand cultural perspectives outside of their own is weakened when explored through race alone. Researchers in critical studies justify the use of an intersectional framework to "fill the gaps, and address the limitations of existing disciplinary frameworks that use single-axis or additive approaches to explain social inequality and its effects on individuals, groups, communities, and societies" (Case, 2016, p. 29). Based on the lack of research exploring intersectional identities in teacher education, Grant and Sleeter argued, "A failure to consider the integration of race, social class, and gender leads at times to an oversimplification or inaccurate understanding of what occurs in schools, and therefore inappropriate or simplistic prescriptions for educational equity" (p. 197). Hence, broadening PSTs understanding of alternative social identities through intersectionality can act both as a mirror and a door. This mode of social analysis acts as a mirror from which PSTs can locate themselves as simultaneously privileged and oppressed, and provide a door to open conversations about how these divergent social locations position them as literate beings.

Williamson states, "by taking up the idea that literacy is socially constructed and that our identities as literate people are dependent on who we are and in what contexts, candidates begin to challenge their assumptions about what it means to be literate and how literacy develops" (2013, p. 140). This positional lens allows PSTs to challenge traditional conceptions of literacy, enabling them to understand and relate to CLD students by acknowledging the social categories which may influence their literacy development; Furthermore, helping to dismantle mythological notions of mediocrity and meritocracy based on stereotypes of CLD students (Sears, 2012). 


\section{Chapter 2 Summary}

This review of literature provided an array of voices that when unified speak to the need to "infuse teacher education curricula with critical pedagogical principles in order to prepare educators to aggressively name and interrogate potentially harmful ideologies and practices in the schools and classrooms where they work." (Bartolome', 2004, p. 98). Explicitly exploring critical perspectives through literacy helps PSTs to examine, and interrogate literacy texts, curricula and pedagogies that stand to deny students equitable educational outcomes. By first committing to honoring PSTs intersectional identities, teacher educators can begin to broach inequitable practices based on systemic racism, discrimination and marginalization. Approaching these kind of weighty educational issues are paramount if we want to prepare PSTs with the skills to successfully meet the needs of all children (Giroux, 2004). 


\section{CHAPTER III}

\section{METHODOLOGY}

\section{Study Overview}

In this chapter I will delineate the study's research design, research setting, participants, data collection, timeline, data analysis, researcher's positionality, and trustworthiness.

For this study, PST participants were enrolled in a literacy methods course, which met once a week for three hours, housed within a high-needs public elementary school. To conduct this work I received permission from the department chair and the instructor of record to work closely with this literacy methods course to influence curriculum development indicative of course objectives, and my research agenda. My specific research activities were implemented seven times throughout the semester, during 60 to 90 minute learning sessions that I facilitated within the 180 minute course day. In addition, I attended class weekly and acted as a co-teacher along with the instructor of record, as a means to develop meaningful relationships with the students. Weekly conversations with the instructor were integral to successful implementation of my research plan, which was why we remained in constant contact via e-mail, phone, and inperson conversation. 


\section{Research Questions}

1) What do reflective writings, reveal about the ways pre-service teachers construct meaning around critical perspectives in literacy education?

2) How do pre-service teachers use collaborative discussion to construct meaning around critical perspectives in literacy education?

\section{Research Design}

This exploratory study was conducted within the tradition of two different qualitative methodologies to provide a more robust understanding of how teacher candidates made sense of critical literacy when embedded into a literacy methods course. Specifically, this work borrows methods from ethnographic and case study traditions. The utility of these methods provided two lenses upon which to examine my data.

Exploratory case studies "are used to explore those situations in which the intervention being evaluated has no clear, single set of outcomes" (Yin, 2003, p. 35). Since exploratory case studies are often applied in a research context that is not clearly specified and still requires data for the formulation of valid hypotheses, theoretical propositions or assumptions are not created prior to the study. The broad themes, which emerge from an exploratory study, are positioned to open up the door for further examination of the phenomenon observed (McDonough \& McDonough, 1997; Yin, 1984). While the study design and data collection were not restricted by the confines of an established theory, the literature base relative to the conceptual frame provided a broad foundation from which study design, analysis, and findings were constructed. 


\section{Research Setting}

This research took place in a mid-sized research one institution, nested within an urban city of one million people, located in the southeastern region of the country. In an effort to increase the urban readiness of PSTs, The University established a unique partnership with the local school district, in which professional and methods courses would be taught within designated high-needs schools. This model aims to provide an authentic learning experience, reflective of the growing student population regionally as well as nationally. The PST participants for this study attended courses and conducted field experiences in an elementary school of high need in the local school district. This specific school is located within the heart of the downtown area of the metropolitan city. The students enrolled at this school derive from the surrounding neighborhood, which is characterized as an area of high poverty. The percentage of economically disadvantaged students in this school is $98.7 \%$ as of the $2015-2016$ school year, based on the free and reduced lunch index. The demographic breakdown of students is $84.2 \%$ African American, 6.3\% White, and 9.5\% Other Race.

\section{Participant Selection}

Three pre-service teachers were selected for this study. There were a total of eighteen students within this course: seventeen female and one male. All students enrolled maintained an elementary emphasis, while some also had a special education focus. The PSTs were purposively selected (Chein, 1981) based on the Cultural Diversity Awareness Inventory (CDAI), their initial intersectional reflective writing activity, and their racial identification. 
My goal in purposive sampling had three major purposes. First, I used the CDAI to identify PSTs who scored a higher level of cultural diversity awareness. I proposed that a high cultural diversity orientation would yield openness to the emancipatory principles (Freire, 1970) of a critical approach to literacy learning. Also, selecting PSTs with similar dispositions (literal replication) may predict similar results, strengthening the generalizability and transferability of this exploratory study (Yin, 1999). An outlier was also selected as one of the cases. The outlier was selected based on a limited awareness of cultural diversity as indicated by the CDAI score. A limited awareness may show a lack of willingness to acknowledge alternative perspectives that challenge stagnated stereotypes of students from non-traditional backgrounds. The outlier perspective may provide a more comprehensive view of how PSTs understand critical literacy perspectives, with results that contrast from the two other PST participants of similar critical dispositions. Yin (1999) states, "The decision to undertake multiple-case studies cannot be taken lightly. Every case should serve a specific purpose within the overall scope of inquiry" (p. 54). Each case must be carefully selected so that it either (a) predicts similar results or (b) produces contrasting results, but for predictable reasons.

Secondly I examined each student's Intersectional Positionality assignment, which was administered on the first and last day of class. For this assignment PST participants used the Intersectional Positionality graphic organizer to identify six of their most pronounced identities, and then provided a reflection, which revealed the challenges they experienced as multiple privileged and oppressed individuals. This assignment provided a deeper look at students as individuals, in that they shared how they identify as 
people in society and what these identifications have denied or afforded them in their k12 experience.

Lastly, considering critical literacy centers on challenging power, position, and privilege, I selected PSTs who identified as White, to better understand the role their dominant positions in society played in how they considered, engaged, and practiced critical ideologies. Additionally, considering the majority of PSTs entering the teaching profession are White, it is important that we examine how their social positions affect the ways in which they enact critical literacy practices.

Based on the criteria noted above, I selected three PSTs who will be called Hailey, Josh, and Allison. Both Hailey and Allison self-identified as White females, while Josh identified as a White male. The two White female PSTs were purposively selected based on their homogenous CDAI scores (63\%), which were some of the highest in the class, representing a higher level of cultural awareness. The White male scored seven points lower (56\%) than the two White female PST participants on the CDAI. Due to his lower score, and his gender I selected him as the outlier for the study. Each participant revealed a personally relevant portion of their intersected identities through their intersectional reflective writing assignment. The salient nature of their writings as compared to others in the course also contributed to my selection decision. I felt that their transparency in this first activity spoke to their level of openness and willingness to be honest in future written and verbal commentaries.

\section{Data Collection, Instruments and Procedures}

Burton and Bartlett (2009) suggest that qualitative artifacts offer an opportunity 
to concretely compare and contrast different institutions, present the potential to reveal data not known by PST participants, generate further questioning, and stimulate further discussion. Data collection for this study will consist of five sources including: a) Collaborative Inquiry Engagement learning sessions, b) critical writing reflections, c) small group discussion transcripts d) CDAI, and e) researcher logs. In the following paragraphs I will explain the data collection procedure and use of each data source. To organize each of these data sets in preparation for analysis, I created a virtual log using the on-line program Evernote. The table below shows the link between each piece of data and the research question it addresses.

Table 2. Data Collection table

\begin{tabular}{llllc}
\hline RQ's & $\begin{array}{l}\text { CIE } \\
\text { Learning } \\
\text { Sessions }\end{array}$ & $\begin{array}{l}\text { Small Group } \\
\text { Discussion } \\
\text { Transcripts }\end{array}$ & $\begin{array}{l}\text { Critical Written } \\
\text { Reflection \& Researcher } \\
\text { Log }\end{array}$ & CDAI \\
$\begin{array}{l}\text { 1) What do reflective writing, } \\
\text { reveal about the ways pre-service } \\
\text { teachers construct meaning } \\
\begin{array}{l}\text { around critical perspectives in } \\
\text { literacy education? }\end{array}\end{array}$ & $\mathrm{X}$ & & $\mathrm{X}$ \\
& & & \\
$\begin{array}{l}\text { 2) How do pre-service teachers } \\
\text { use collaborative discussion to } \\
\text { construct meaning around critical } \\
\text { perspectives in literacy } \\
\text { education? }\end{array}$ & $\mathrm{X}$ & $\mathrm{X}$ & $\mathrm{X}$ \\
\hline
\end{tabular}

\section{Collaborative Inquiry Engagements Curricular Structure}

During the semester I taught seven learning sessions, which I titled, "Collaborative Inquiry Engagements" (CIEs). The purpose of these instructional engagements was to provide inquiry-based experiences where PSTs engaged with critical literacy practices that provide practical and theoretical avenues of exploration. Leaning 
on the emancipatory practices of critical literacy as conceptualized by Freire (1970),

Janks (2010), and Rogers, (2013), the CIEs adhered to one critical literacy focus,

including, critiquing, resisting, or re-designing an educational practice from a critical

perspective. Table 2 shows each CIE focus, and the accompanying critical literacy

activity that took place during the CIEs.

Table 3. Collaborative Inquiry Overview

\begin{tabular}{|c|c|c|c|c|}
\hline CIE & Foci & Activity & Guiding Questions & Learning Purpose \\
\hline $\begin{array}{l}\text { CIE } \\
1\end{array}$ & $\begin{array}{l}\text { Critique } \\
\text { (Freire, } \\
1970)\end{array}$ & $\begin{array}{l}\text { Problem- } \\
\text { Posing by } \\
\text { Questioning } \\
\text { the Text }\end{array}$ & $\begin{array}{l}\text { Who or what is the focus in the text } \\
\text { and whose viewpoint is expressed? } \\
\text { Whose voices are missing, silenced, or } \\
\text { discounted? } \\
\text { What does the author want readers to } \\
\text { believe? }\end{array}$ & $\begin{array}{l}\text { Problem-Posing helps students } \\
\text { access a critical understanding to } \\
\text { literacy that helps them see that } \\
\text { every text, places value on certain } \\
\text { types of perspectives, and } \\
\text { activities, while discounting or de- } \\
\text { privileging others. (McLaughlin \& } \\
\text { DeVoogd, 2004) }\end{array}$ \\
\hline $\begin{array}{l}\text { CIE } \\
2\end{array}$ & $\begin{array}{l}\text { Resist } \\
\text { (Rogers, } \\
2013 \text { ) }\end{array}$ & $\begin{array}{l}\text { Resisting } \\
\text { Traditional } \\
\text { Literacy by } \\
\text { Exploring } \\
\text { Linguistic } \\
\text { Diversity }\end{array}$ & $\begin{array}{l}\text { Should linguistic variation be counted } \\
\text { as an error in a running record? } \\
\text { How can we honor students' home } \\
\text { language, when it may be divergent } \\
\text { from our own? } \\
\text { What biases do we bring to the } \\
\text { classroom, based on our intersectional } \\
\text { identities, and how can we resist } \\
\text { stereotyped ideations of reality? }\end{array}$ & $\begin{array}{l}\text { Literacy teachers need to } \\
\text { understand the difference between } \\
\text { reading difficulties and linguistic } \\
\text { differences. Too often linguistic } \\
\text { differences are translated into } \\
\text { deficits. PSTs need to } \\
\text { acknowledge and respect students' } \\
\text { home language, by validating their } \\
\text { language as a part of their rich } \\
\text { culture, which adds dynamism to } \\
\text { the classroom. (Artiles, Rueda, } \\
\text { Salazar, \& Higardeda, 2005, } \\
\text { Rogers, 2013). }\end{array}$ \\
\hline $\begin{array}{l}\text { CIE } \\
3\end{array}$ & 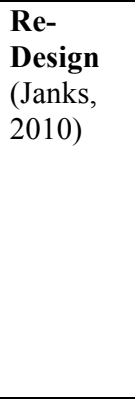 & $\begin{array}{l}\text { Counter } \\
\text { Narrative by } \\
\text { Talking Back } \\
\text { to Multi- } \\
\text { Media Text }\end{array}$ & $\begin{array}{l}\text { How can we use multi-media to } \\
\text { initiate complex conversations around } \\
\text { controversial social issues in the } \\
\text { elementary classroom? } \\
\text { How can counter narrative writing } \\
\text { activities provide power and agency } \\
\text { for marginalized students? } \\
\text { Why is it important to teach students } \\
\text { about multiple perspectives? }\end{array}$ & $\begin{array}{l}\text { A powerful aspect of critical } \\
\text { literacy is the readers' ability to } \\
\text { speak back to the text through } \\
\text { critical text production (Janks, } \\
\text { 2010). This process is done by } \\
\text { allowing students to re-design the } \\
\text { original textual narrative to create } \\
\text { a new narrative which counters } \\
\text { hegemony, and promotes equality } \\
\text { which gives voice to silenced } \\
\text { perspectives. (Janks, 2010). }\end{array}$ \\
\hline
\end{tabular}




\section{Collaborative Inquiry Engagement Instructional Structure}

The construction of each CIE is framed by Mezirow's transformative learning theory (2000), each engagement aimed to "transform taken-for-granted frames of reference to make them more inclusive, discriminating, open, and reflective" (Ukpokodu, 2009, p. 1). An example of the CIEs construction can be found in Appendix C. Mezirow (1991) characterizes transformative learning as “altering a person’s meaning making perspective structure" (p. 25). Transformative learning practices seek to restructure the ways in which a person does something, understands something, and more importantly understands oneself (Mezirow, 1991). Mezirow posits two forms of transformation, Epochal, which happens over minutes or days, and Incremental, which happens in small shifts in meaning that occurs over time. Hence the structure of the CIE is predicated on the latter of the two forms in that each engagement will occur incrementally over the course of the semester to help foster gradual shifts in students' understanding of critical literacy.

Mezirow provides three instrumental domains which aid the facilitation of perspective transformation. These three domains are defined below:

1. Disorienting Dilemma- This is a type of significant stimulus that leads many people to undergo a meaning perspective transformation. One result of the dilemma leads people to examine and reflect on why they are doing what they're doing in their lives. (Mezirow, 1995)

2. Rational Discourse- It is within the arena of rational discourse that experience and critical reflections are played out. Discourse becomes the medium for critical reflection to be put into action, where experience is reflected upon and 
assumptions and beliefs are questioned, and where meaning making schemes and meaning structures are ultimately transformed. (Mezirow, 1995)

3. Critical Reflection- Considered the distinguishing characteristic of adult learning, critical reflection refers to questioning the integrity of assumptions and beliefs on prior experience. It often occurs in response to an awareness of a contradiction among our thoughts, feelings, and actions. These contradictions are generally the result of distorted epistemic, psychological, and sociolinguistic assumptions. (Mezirow, 1995)

These three domains comprised the linear structure of the CIEs, which took place in a sequenced pattern. Each CIE consisted of three parts: (a) disorienting critical literacy experience, (b) disorienting experience rational discourse, and (c) critical reflection writing. The classroom structure of CIEs required a whole group lesson, facilitated by the researcher, followed by small group discussions that were independent of the researcher, and then finally a Blackboard-based reflective writing assignment, that PSTs completed independently.

\section{Disorienting Dilemma}

During the first phase of the CIE, the disorienting dilemma experience took place. During this stage, students experienced an activity or lesson that examined a specific critical literacy issue. The purpose of disorienting dilemma activity was to present an alternative perspective that disorients (Mezirow, 2000) or disrupts (Lewison et al., 2002) PSTs traditionalized conceptions of literacy education (Giroux, 1996). During this experience, I provided an objective overview of the topic, along with a research-based rationale for its importance in literacy education. 


\section{Collaborative Discussion}

The second stage of the CIE, called the rational discourse, was a time when students were presented with a question which presented a problem or challenge relative to part (a) of the CIE. To answer the question, PSTs had to collaboratively discuss how to best solve the problem. Each question contained a practical component, which linked the problem to a real-world issue they may face in their future classroom. During this phase, recording devices were placed in the middle of each group to capture unfiltered discussion. The transcripts from the rational discourse were used to better understand research question 2, "How do pre-service teachers use collaborative discussion to make meaning of critical perspectives in literacy education?"

\section{Critical Reflection}

The final stage of the CIE is critical reflective writing, which was a Blackboard assignment that students completed independently within one week of the CIE. Critical reflection is an integral component to critical literacy (Freire, 1970) and transformative learning (Mezirow, 2000), and is purposed to help students negotiate the dissonance between preconceived ideologies and new ways of receiving, reflecting, and responding to the world (Freire, 1970; Giroux, 1996; Hooks, 2001; Janks, 2009). For this assignment, PSTs were asked to respond to specific questions relative to their engagement with the CIE. All Blackboard questions can be found in Appendix O

\section{Collaborative Inquiry Engagement Integrated Curriculum}

To provide a more salient understanding of the seven learning sessions implemented through the study, I have provided a detailed account of each session which can be found in Appendix K, The CIE curriculum includes 5 parts which include: (a) CIE 
focus (critique, resist, re-design), (b) instructional goals, (c) curriculum used, (d) learning activities, and (e) real-classroom connection.

\section{Cultural Diversity Awareness Inventory}

The Cultural Diversity Awareness Inventory (CDAI), originally created in 1986 by Henry, is a measure which seeks to assess cultural diversity awareness. The profile contains 32 items and allows respondents to represent their answers using a 5-point Likert scale (score of $1=$ strongly disagree, score of $5=$ strongly agree). This quantitative tool was administered at the beginning of the course. This measure served one purpose for this study, which was to help identify individual with higher and lower cultural diversity awareness scores. Though this inventory was used, all EDTP 320 PST scores were within a 7-point range of each other, which place all students in the lower range for their cultural diversity awareness. Thus, this measure was not as beneficial for purposive sampling, as originally conjectured in the proposal of my study. PSTs completed the entire CDAI on the first day of class. Based on the scores provided, I found an average score for the entire class to be $57 \%$ out of $100 \%$. The case study PSTs I chose for the study had CDAI results that ranged from 63\%-56\%. The complete CDAI is located in Appendix D.

The CDAI originated in 1986, but was revised in 1995 by a panel of researchers to enhance its content validity. The instrument uses a 5-point Likert-type scale (e.g.; 1 = strongly disagree, $2=$ disagree, $0=$ neutral, $3=$ agree, $4=$ strongly agree) and reverse

order intermittently. The items that used the order as represented above are one, two, six, seven, nine, ten, and twenty-three through twenty-seven The items that used the reverse 
order are three, four, five, eight, eleven through twenty-two, and twenty- eight. The CDAI is composed of five different categories to assess participant cultural diversity sensitivity; these include: 1) Cultural Awareness, 2) Culturally Diverse Family, 3) CrossCultural Communication, 4) Assessment, and 5) Creating a Multicultural Learning Environment Using Multicultural Methods. I have selected this specific instrument because its psychometric properties have been tested and validated by several researchers over its twenty-year life span. The Cronbach's test of internal consistency showed an alpha coefficient of .90 , while the test-retest for reliability was established at .66 .

Though the CDAI was originally created for in-service teachers, it has been successfully used in various studies to examine the cultural diversity sensitivities of preservice teachers. The instrument was utilized by Davis (1993) to investigate the cultural sensitivity of elementary pre-service teachers. The inventory has also been used by Deering (1997) to explore the influence of a 10-week field experience on the diversity sensitivity of middle school teacher education students. In addition, Milner et al. (2003) used the instrument to investigate the extent to which teacher education programs were helping future teachers to become more multi-culturally aware. While in 2006, WalkerDalhouse and Dalhouse used the assessment to investigate elementary teachers' awareness of cultural diversity.

\section{Researcher Log}

Each week of the study I recorded the major events, ideas, and activities that take place for each class session. I recorded my class reflections on a template that I created where I shared my thoughts, feelings, observations, and theoretical conjectures, based on the classroom events. Pivotal conversations with the instructor, which help guide my 
research agenda, or that, reveal an extra layer of understanding about the four PSTs was also recorded in the researcher log. Instructor feedback and correspondence provided another perspective that added to my interpretation of the data practices. The researcher log was used to provide another layer of data, which helped me interpret findings and conclusions.

\section{Study Timeline}

January 2017- Administered CDAI and Intersectional writing reflection. Taught CIE learning session $1 \& 2$.

February 2017- Selected three PSTs of focus for deeper analysis. Taught CIE learning session 3.

* March 2017- Taught CIE learning session 4, 5, \& 6. Compiled all Blackboard critical reflections into Evernote program. Began initial coding of Researcher Log, and Blackboard reflections.

* April 2017- Taught CIE learning session 7. Administered critical intersectional reflection survey. Began initial coding analysis of written artifacts.

* April-July 2017- compiled all data onto Evernote program. Data Analysis and Findings.

* July-September 2017- Conclusions and Recommendations.

September-October 2017- Present Dissertation

\section{Data Analysis}

Aligned with qualitative inquiry, I approached all data inductively to allow relevant themes and patterns to emerge naturally, opposed to a pre-conceived frame. My 
initial coding analysis remained unbiased, and open to interpretation consistent with the methodological stance of grounded theory (Charmaz, 2014). Since examining PSTs meaning making structures was the major goal of this work, second round analysis was conceptualized through a Vygotskian framework that considered knowledge construction through a sociocultural lens.

\section{Reflective Writing Content Analysis}

The purpose of the critical reflective writing analysis sought to answer research question 1) What do reflective writings, reveal about the ways pre-service teachers construct meaning around critical perspectives in literacy education? Therefore analysis began by investigating each participant separately. First, I examined each of their Blackboard critical reflections to identify critical literacy oriented messages or questions based on their responses. From here, I looked for similar themes in their small group classroom assignments. I found that all four PST participants were providing similar feedback through their written reflections and thus the second phase of analysis took a more holistic approach to data analysis where I looked for common themes across all PSTs.

The second phase of analysis was conducted using content analysis to better identify major themes found in PSTs critical reflective writings. Content analysis is a versatile analytic method that is accepted in both quantitative and qualitative research for inductive and deductive purposes. Typical content analysis consists of three main faces: preparation, organization, reporting (Elo \& Kyngas, 2008). For qualitative study, the communication of meaning is the measure or focus of the analysis (Merriam, 2009). Ultimately, content analysis " looks for insights in which 'situations, settings, styles, 
images, meanings and nuances are key topics' (Altheide, 1987, p. 68). The process involves the simultaneous coding of raw data and the construction of categories that capture relevant characteristics of the documents content" (Merriam, 2009, p. 205), an example of my initial coding can be found in (Appendix K).

Being cognizant of the multiple variables which contextualized the ways in which I approached data analysis. I interpreted data by acknowledging the intersections of critically based curriculum, participants' motivations, and researcher Positionality. Adapted from Mayring's (2014) Content-Analytic Communication Mode, the figure below represents the intermingling of contextual considerations that influenced my overall analysis. 


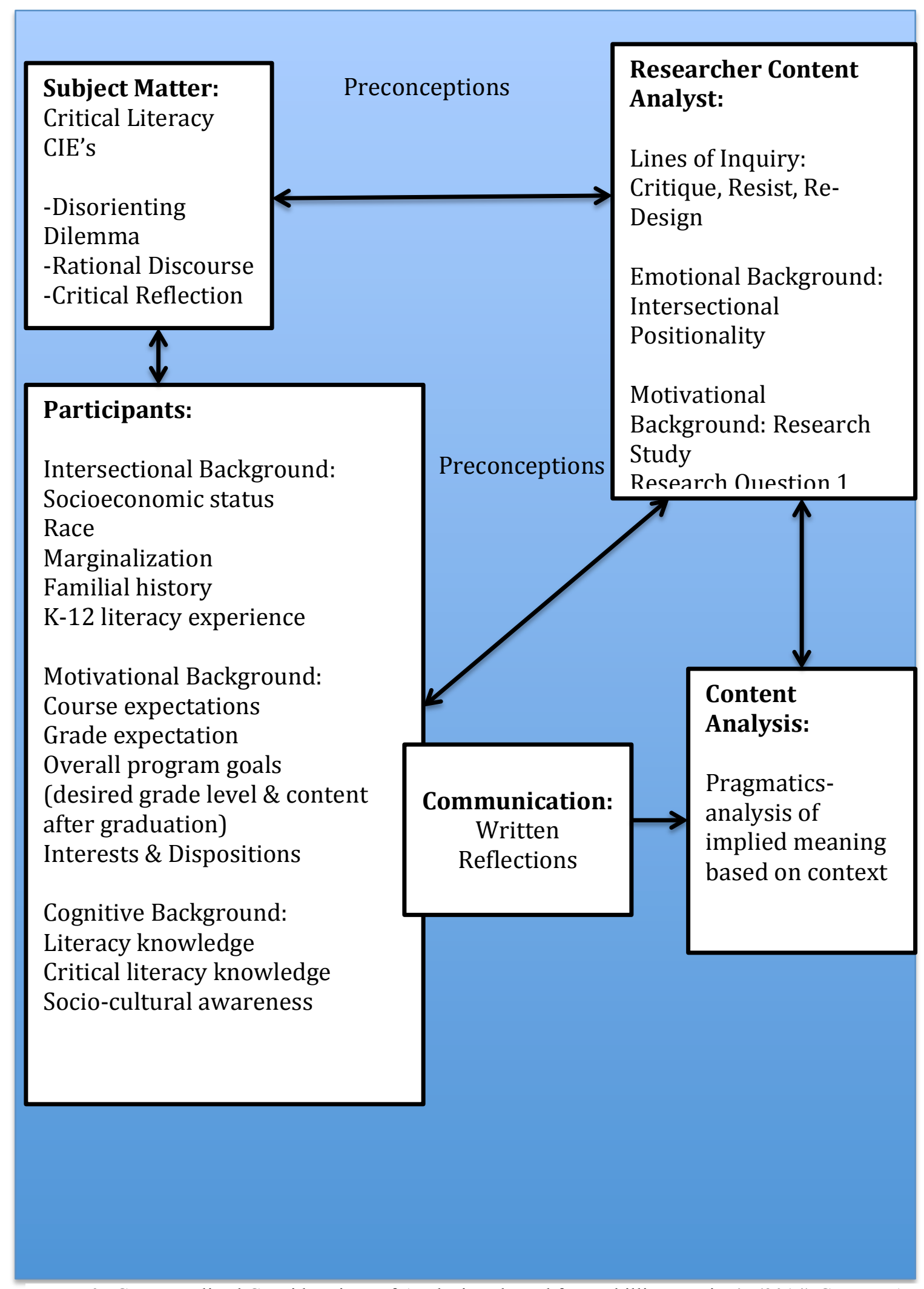

Figure 2. Contextualized Considerations of Analysis, adapted from Phillip Mayring's (2014) Content-Analytic Communication Mode 
Content analysis was approached using the above model as a lens for data analysis. The content analysis of small group data was conducted in two steps, which are delineated below.

Step one: Preparation- Preparation of data analysis began by deciding what to analyze and in what detail. I decided to use two pieces of data for content analysis: a. PSTs critical reflections (Appendix B), b. PSTs critical intersectional reflections (Appendix I). After this, I identified the unit of analysis which Elo and Kyngas state (2008) can consist of a word or theme, and contain several meanings. Further, in deductive content analysis units of analysis may be viewed through pre-existing models that may include testing categories, models, concepts, or a categorized matrix (Elo \& Kyngas, 2008). Considering this, I decided that the unit of analysis would be larger themes found in participant texts which reflected elements of the critique, resist, redesign framework of the CIE's. Understanding that critical literacy is outside of traditional modes of curriculum and instruction, I also looked for areas of tension where PSTs challenged or rejected critical concepts introduced through the CIEs learning sessions. To familiarize myself with the data, I read each set multiple times to better understanding what was happening. With each reading I asked myself the following questions: a. are there elements of the CRR framework present? b. how are PSTs making sense of the CIEs?, c. what are PSTs trying to convey through their response?

Step Two: Organizing- In this step I created a critique, resist, re-design (CRR) categorization matrix that served as the framework for the coding process. To do this I used a coding process, where I identified words or phrases that represented the CRR focuses. For example, for the Critique focus, I parsed PSTs reflections to find where they 
questioned themselves, or a specific practice. For the Resist focus, I parsed their words to look for ways they challenged traditional outlooks on literacy or education. For the ReDesign focus, I looked for words and phrases that expressed a re-thinking or reconceptualization of literacy practices. Using this matrix made coding more systematic because the CRR framework served as a guide for my coding decisions. An example of my coding matrix can be found in Appendix J. Initial coding attempts were completed manually, where I used different color highlighters to identify themes relative to the CRR matrix. Second round coding was completed using NVivo 11 software. The NVivo 11 analysis tool assisted in storing, organizing, and retrieving data to help illuminate codes across each data. Each code within NVivo was defined and categorized into a codebook. When coding the data I choose themes, which fit the CRR matrix, and also coded themes that did not fit within the matrix (rejecting/challenging critical literacy), which became new codes.

From here, codes turned into broader categories based on the frequency of times a certain phrase or CRR concept was used. I then used the CRR codes to employ a constant comparative method to sort units of data into natural categories that yielded commonality (Merriam, 1998). Initial constant comparative analysis yielded 25 different categories. From here I omitted categories that were not relevant to research question 1, and combined major categories. Once major categories were defined, and smaller clusters of sub-categories were refined, major themes emerged from the data, which resulted in 7 major themes, which are explained thoroughly in Chapter 4. 


\section{Discourse Analysis}

I conducted discourse analysis, to answer research question 2) how do pre-service teachers use language to construct meaning around critical perspectives in literacy education? Using small group collaborative discussion, two different analysis models were used to best answer research question 2 which will be described in the paragraphs that follow.

\section{Verbal Exchange Analysis}

Discourse analysis was conducted on seven transcripts, which captured three episodes of small group discourse relative to the CIE learning sessions that I facilitated throughout the spring 2017 semester. For discourse analysis I wanted to gain a deeper understanding of how different levels of verbal interaction supported or suppressed PST participants' understanding of critical perspectives in a literacy context. Therefore I applied a distinctive framework to analyze the small-group communication by using verbal exchange coding (Goodall, 2000). I resonated with this ethnographic approach because it provided markers for how often the small group dialogue hovered in a safe zone of ordinary conversation or verbal exchange and, when it reached higher levels of discussion, which moved beyond superficiality. This deeper level of discussion lent itself to illuminating how PSTs were using language to make sense of critical ideas introduced in class.

Verbal exchange coding consists of verbatim transcript analysis through interpretation of the types of conversation and key moments in verbal exchanges. This approach is systematic and holistic in nature, and attempts to capture different levels of 
communicative intensity. Though it mirrors other discourse analysis techniques, Saldana (2016) states, "Goodall's introductory approach to the analysis of talk and text is just one of many extensive and systematic approaches to conversation and discourse analysis. However, unlike several of these methods, which include detailed notation systems for microanalyses, Goodall advocates a more holistic and truly interpretive approach to the data by novices."'(p. 36).

Specifically, this method categorizes 5 different levels of verbal exchange, which will be used in chapter 4 . A brief synopsis of each level is listed below:

1. Phatic or Ritual Communication- A class of routine social interactions that are basic in nature.

2. Ordinary Conversation- Patterns of questions and responses that provide personal, relational, and informational issues, and concerns.

3. Skilled Conversation- A higher level of information exchange, including debates, conflict management, and negotiations.

4. Personal Narratives- Consisting of individual or mutual self-disclosure.

5. Dialogue- In which conversation "transcends" information exchange and the boundaries of self and moves into higher levels of spontaneous ecastic mutuality.

For verbal exchange coding I used descriptors created by Goodall which provided detailed markers that characterized and defined each of the five levels of verbal exchange. This framework was instrumental to my coding analysis coding because it served as a guide for my coding scheme. In addition to this I used the three questions from my content analysis to focus in on important phenomenon that were taking place 
during the exchanges. Specifically I parsed the discourse to uncover: a. are there elements of the CRR framework present? b. how are PSTs making sense of the CIEs?, c. what are PSTs are trying to convey through their response? Using these guiding questions supported my interpretation of discourse, which influenced study findings and conclusions. An example of initial discourse coding can be found in Appendix L.

Using Goodall's framework (abbreviated example of descriptions noted above) as a reference, I read each PST participant transcripts individually and used NVivo 11 to categorize and organize participant responses into one of the five categories (ordinary, phatic, skilled, personal, or dialogue) of verbal exchange. After this, I looked at all of the verbal exchanges as a whole to quantify the number of times participant discussion fell into one of the five categories of verbal exchange. This quantifying measure helped me to understand how PSTs relied on collaboration to help navigate and understand critical ideas introduced during the CIEs.

\section{Context of Dialogue Analysis}

Goodall characterizes dialogue exchanges as "conversation which transcends information exchange and the boundaries of self into higher levels of spontaneous ecastic $^{3}$ mutuality" (2000, p. 41). Therefore I chose to exploit one pivotal dialogic exchange from the data to show how PSTs engaged in naturalized discourse that retreated from the safe boundaries of polite conversation which is indicative of surface level or introductory levels of verbal exchange (phatic, ordinary). This dialogue exchange was important to analyze because it was the only exchange where PSTs engaged in a disagreement.

${ }^{3}$ Ecastic- involving an experience of mystic self-transcendence 
To better understand how PSTs participants used language to express divergent viewpoints, I utilized a framework created by Keefer, Zeitz \& Resnick, (2000) entitled the Context of Dialogue. The authors developed this tool to analyze student led discussion to identify diverse dialogue forms and functions. Keefer et al. state that different dialogue types have "different starting points, have different rules regarding the Table 4. Context of Dialogue admission, and management of dialogue commitments" (p. 57). I used this framework to help categorize how small group participants used language as a semiotic device to manage, negotiate, and navigate conflict and consensus (Keefer et al., 2000). The table below created by Keefer et, al. gives a brief overview of the contexts of the dialogue types. Each dialogue has an initial starting point, a main goal, the PSTs aims, and the characteristic method or means of moving from the starting point to the goal.

\begin{tabular}{|c|c|c|c|c|}
\hline Dialogue Type & Initial Situation & Dialogue Goal & Method & $\begin{array}{l}\text { Participant } \\
\text { Goal }\end{array}$ \\
\hline Critical discussion & $\begin{array}{l}\text { Difference in } \\
\text { opinion leading to } \\
\text { an issue }\end{array}$ & $\begin{array}{l}\text { Accommodate } \\
\text { divergent } \\
\text { viewpoints, } \\
\text { understanding }\end{array}$ & $\begin{array}{l}\text { Balance of } \\
\text { considerations }\end{array}$ & $\begin{array}{l}\text { Persuade others, } \\
\text { share opinions }\end{array}$ \\
\hline $\begin{array}{l}\text { Explanatory } \\
\text { inquiry }\end{array}$ & Lack of knowledge & Correct knowledge & Cumulative steps & $\begin{array}{l}\text { Estimate proof, } \\
\text { make } \\
\text { hypothesis }\end{array}$ \\
\hline Eristic discussion & $\begin{array}{l}\text { Conflict and } \\
\text { antagonism }\end{array}$ & $\begin{array}{l}\text { Provisional } \\
\text { accommodation }\end{array}$ & $\begin{array}{l}\text { Defense of } \\
\text { position, tricky } \\
\text { arguments }\end{array}$ & $\begin{array}{l}\text { Personal } \\
\text { attacks, defend } \\
\text { position }\end{array}$ \\
\hline $\begin{array}{l}\text { Consensus } \\
\text { dialogue }\end{array}$ & $\begin{array}{l}\text { Agreement in } \\
\text { opinion }\end{array}$ & & & \\
\hline
\end{tabular}


The dialogic exchange that was analyzed using the context of dialogue was defined as critical discussion. Keefer et al. suggest the essential goal of critical discussion hinges on divergent viewpoints, which allow PSTs the space to present their opinion in relation to others. For analysis of this verbal exchange, I created a visual coding system to illustrate the flow of the critical discussion as PSTs made arguments,

Figure 3. Visual Coding Key counter arguments and or concessions, which revealed their underlying positionalities, and intentions for communication. I used this visual coding system to ascertain if the arguments PSTs were presenting helped to deepen their understanding of critical perspectives based on how often they allowed their discussion to exist in argument or counter argumentative zones. I considered when participants' conceded their argument by making a concession that this form of exchange was not conducive to leveraging their understanding of criticality. The visual coding key that I created to represent this critical discussion is shown below.

\begin{tabular}{|c|c|c|}
\hline Argument & Counter Argument & Concession \\
\hline & & サत \\
\hline
\end{tabular}

Coding of critical discussion was conducted by identifying when PSTs presented an argument, a counter argument or concession. A thorough account of how the visual coding system was used and the analysis of data can be found in Chapter 4 . 


\section{Researcher Intersectional Positionality}

Imperative to this study is how my social, racial, cultural, familial and gender-based experiences situate me within this work. Only acknowledging my researcher positionality within racial and gender contexts neglects the rich experiences that have helped sculpt my epistemological perspectives and ontological word view. Therefore, I honor my various intersectional positions by making them paramount in my research outlook and praxis.

Intersectionality is a framework that provides a lens to study the various strands of an individual's identities, and the multi-faceted nature in which these identities intertwine. Rooted within Black Feminist Studies (Collins, 1990; Crenshaw, 1989) Intersectionality argues against narrow binaries of identity that stem from a reductionist stance which only acknowledge one's race and gender. What draws me to this outlook is that it acknowledges the complexities of intersecting social identities and how they can position us in dominant or subordinate groups (Case, 2016). My conceptual approach to intersectionality predicates within Collins' Matrix of Oppression (1989). This visual representation (See Figure 4) illustrates how a person's multiple identities can situate them within privileged or oppressed social standings. Collins view of intersectionality attends to the historical, cultural, racial, and societal identities, which converge to create our social locations within society (Case, 2016; Collins, 2000). 


\begin{tabular}{|c|c|c|c|c|}
\hline \multicolumn{7}{|c|}{ Matrix Of Oppression } \\
\hline $\begin{array}{c}\text { Social Identity } \\
\text { Categories }\end{array}$ & $\begin{array}{c}\text { Privileged } \\
\text { Social Groups }\end{array}$ & $\begin{array}{c}\text { Border } \\
\text { Social Groups }\end{array}$ & $\begin{array}{c}\text { Targeted } \\
\text { Social Groups }\end{array}$ & Ism \\
\hline Race & White People & $\begin{array}{c}\text { Biracial People } \\
\text { (White/Latino, Black, } \\
\text { Asian) }\end{array}$ & $\begin{array}{c}\text { Asian, Black, Latino, } \\
\text { Native People }\end{array}$ & Racism \\
\hline Sex & Bio Men & $\begin{array}{c}\text { Transsexual, } \\
\text { Intersex People }\end{array}$ & Bio Women & Sexism \\
\hline Gender & $\begin{array}{c}\text { Gender Conforming } \\
\text { Bio Men } \\
\text { And Women }\end{array}$ & $\begin{array}{c}\text { Gender Ambiguous } \\
\text { Bio Men and Women }\end{array}$ & $\begin{array}{c}\text { Transgender, } \\
\text { Genderqueer, } \\
\text { Intersex People }\end{array}$ & Transgender \\
Oppression
\end{tabular}

(C) Teaching for Diversity and Social Justice, Second Edition, Routledge, 2007

Table 5. Matrix of Oppression

Grounding my positionality within an intersectional frame represents how my multiple identities are used to view this research study, and how this posture guides the way in which I view the world. Figure 5 demonstrates the nested concentric graphic, which situates my identities in multiple social groups that speak to the complex and fluctuating axis's that create my critical outlook on educational research and literacy education. 


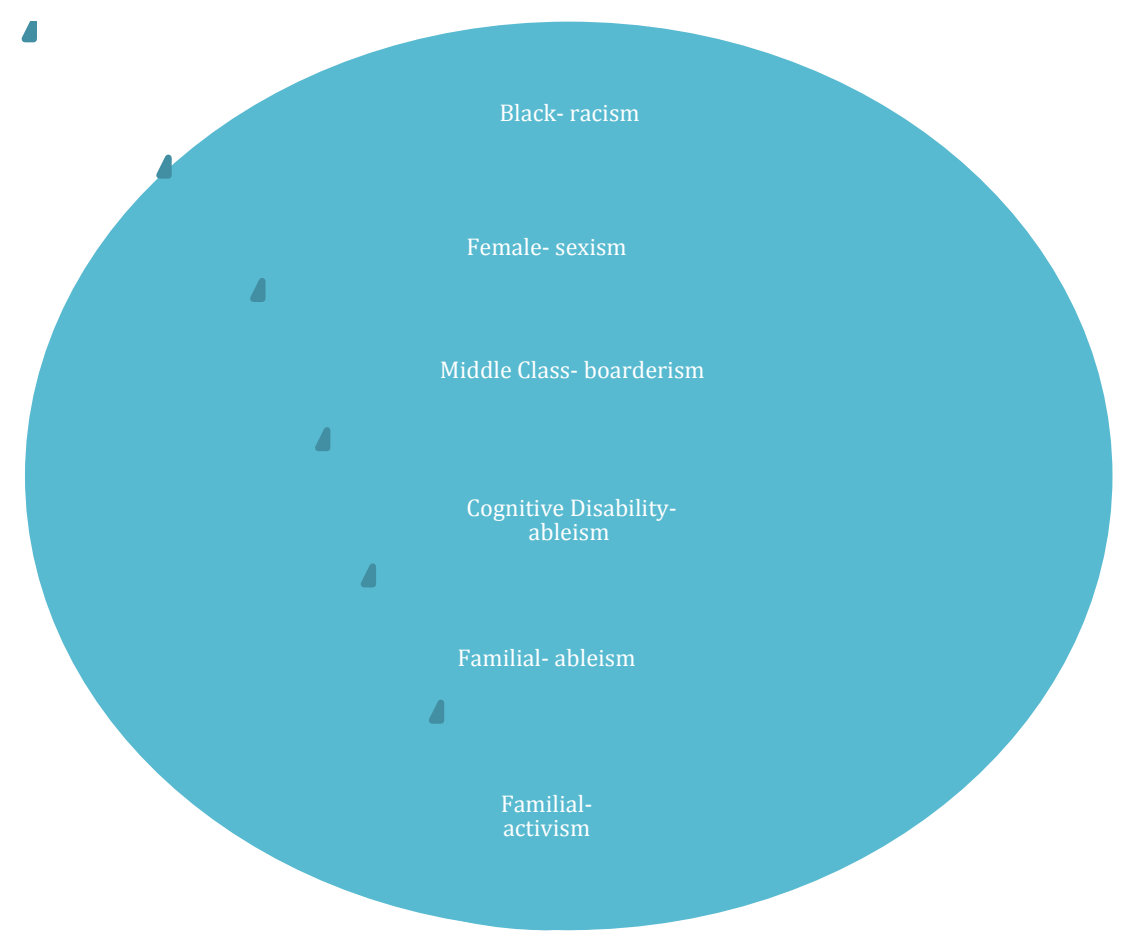

Figure 4. Researcher Intersectional Positionality

Approaching figure 5 from looking at the larger or surface level circles first, to the smaller inside circles, represent the diverse spectrum of my positionalities, starting with surface level identities of race and gender, and ending with my familial positionality. Based on the matrix of oppression, I am multi oppressed and privileged, which means my experience in the world is influenced by complex interactions that may help and/or hinder me based on my social location. Existing within the boarders of both positionalities is beneficial because it offers me a greater perspective from which to view the world, which would be narrowed if I only identified as privileged or oppressed. I used this multivariate outlook to help me critique, resist, and re-design hegemonic practices that threaten the goals of emancipatory education (Freire, 1970). 


\section{Trustworthiness}

To fortify the reliability of this study, a rigorous investigation of study components was enacted to substantiate credibility, transferability, dependability, and confirmability (Lincoln \& Guba, 1985). Credibility and confirmability were protected by the use of pattern matching and explanation building during the final phases of data analysis (Yin, 1989) along with triangulation of multiple sources of evidence. In addition, I employed member checking with the instructor of record during the course and cyclical rounds of independent coding and collaborative coding based on expert feedback and discussion from my chair and co-chair. Thick description (Geertz, 1973) addressed transferability, and will entails a rich account of each participant and the context in which they participated in this study. Utilizing multiple sources of data, and having my chair and co-chair review a draft of the coding analysis measures in the form of an external audit, addressed dependability. External validity was more difficult to address based on small participant size, which weakened petite generalizability (Stake, 1995) of external populations. However, the homogeneity of cases seeks to promote a literal replication, in that it predicts similar results (Yin, 2005). For study reliability, I maintained a study database using the on-line tool Evernote. Within this database, I compiled and organized all data relative to the study for systematic retrieval and added confidentiality of records.

\section{Summary}

This chapter presented the procedures and methods of research that were used for this study. The methods described in this chapter included Collaborative Inquiry Engagements, participant critical reflections and the CDAI, aimed to better understand 
how PSTs construct meaning centered on critical literacy practice in the classroom. The multi-layered analysis techniques described in this chapter also sought to provide a comprehensive structure that is instrumental in answering both of my research questions. 


\section{CHAPTER IV}

\section{FINDINGS}

In this chapter, I will present findings related to the research questions : 1) What do reflective writings, reveal about the ways pre-service teachers construct meaning around critical perspectives in literacy education, 2) How do pre-service teachers use collaborative discussion to construct meaning around critical perspectives in literacy education? Within the first section of the chapter, I will provide introduce the small group participants, and provide brief character sketches of their positionalities. Next I will share

findings pertinent to Research Question 1 by describing the themes that emerged from the Blackboard reflections and intersectional reflections of the small group participants. In the second section of the chapter, I will present results relating to Research Question 2 that will focus on small group discourse analysis using verbal exchange, and context of dialogue analysis.

\section{Small Group Participants}

Four small group PST participants', Hailey Allison, Morgan and Josh, worked together seven times in a small group setting to analyze and discuss the critical literacy strategies introduced through the CIEs. The paragraphs below introduce each participant through personal sketches that provide background information based on their written reflections, demographic data, and personal information shared during small group discussion. Specifically, I aimed to glean a better understanding of participants' k-12 
experience. Understanding the communities, social setting, and educational contexts of the participants helped me better understand their positionality within the classroom and how it contributed to their meaning making of critical literacy throughout the study. Though there were four participants, data based on Morgan is limited due to her lack of attendance in class. Though she was absent for the majority of the data collection the data compiled on Morgan was integral to the discourse analysis of the study.

\section{Hailey}

Hailey is a White female student from a middle class family. She was raised in a large urban area; in a mid-sized state in the Southeastern part of the country. She does not speak any languages outside of English, but wishes she learned another language. Her educational context was unique in that she spent half of her k-12 experience in an urban public school environment and the other half in a suburban environment. Hailey attended elementary and middle school with a predominately African-American population where White students were the minority. Hailey reported that she was bullied a lot for being White in middle school, though she did have some Black friends.

In high school, Hailey's parents "sacrificed a lot” (Intersectional Writing Reflection 1, April 2017) to send her to a very prestigious private school. Being that her new high school was 90\% White, Hailey said that she experienced a "culture shock" (Intersectional Writing Reflection 1). Sadly, Hailey stated that many of her previous friends from middle school ostracized her once she moved to her private school setting. Many of her former friends characterized her as "stuck up" (Intersectional Writing Reflection 1). However, Hailey reports that her parents worked hard to support her to 
attend private school. She also worked hard in high school and received scholarships to attend her private school. Hailey felt like she was judged based on her private school status, but her former friends were unaware of how much she and her family struggled for this. Based on Hailey's intersectional positionality matrix and reflective writing, she viewed race (Whiteness) and socioeconomic status as forms of oppression for her, which is contrary to the traditional view of White middle class women in society. Hailey's perceived "minority status" may account for the many equity-based stances that she takes in her reflections as well as her discussions with other small group members.

\section{Morgan}

Morgan was raised in a two-parent household, and attended an affluent public high-school in a diverse city. She identified her scholastic ability as a privilege that she experienced during her k-12 schooling. Specifically she was identified as gifted and talented, which allowed her access to "high level" classes throughout education. Morgan shared that her "small size" was an oppressed identity for her in that people "assumed a lot of things" about her maturity level based on her physical appearance. After Morgan engaged with CIE 3 (linguistic diversity) she shared with me that her parents strategically moved Morgan to different school systems to ensure that she spoke "correct" English, because they understood how important it was. Now as an adult, Morgan also believes that speaking "correct" English is important, and contributes to the achievement gap between high and low socioeconomic students. Though Morgan held tightly to somewhat conservative and traditional viewpoints, her rhetoric throughout the class was very liberal. In her final intersectional survey she stated that she tries to live her life 
acknowledging her privileged lens. Though Morgan purported to be more aware of social inequities and misconceptions, some her statements countered this viewpoint. This idea is clearly articulated in the Critical Discussion discourse analysis between Morgan and Hailey, which can be found later in chapter four.

\section{Josh}

Josh is a White male, who was raised in a small community 50 miles outside of a large urban city in the Southeastern portion of the country. Josh does not speak any languages outside of English. Self-reportedly, Josh spent the majority of his k-12 experience within a small rural community which was comprised of predominately middle class, White individuals who shared similar religious and social outlooks. Josh stated that his high school was culturally monolithic in nature, but due to his outside affiliation with sports and volunteering, he had multiple experiences that took him outside of his city limits where he was exposed to "different races and cultures" (Intersectional Writing Reflection 1).

Josh said that after being exposed to different individuals outside of his community, he began recognizing bias and racist comments when he would talk with his high school friends. Though Josh began seeing racism within his peer group, he said that he didn't address any of the comments made by his friends, due to peer pressure.

Currently, Josh attributes much of his cultural awareness to his college experience where his understanding and exposure to multiple cultures was amplified. Josh acknowledges his socioeconomic privilege, but does not identify Whiteness as a privilege. Josh was 
strategic in avoiding words or phrases which named race in any way related to unearned privileges in all interactions during this study.

\begin{abstract}
Allison
Allison identifies as a middle class White female who was raised in a suburban community situated in a mid-sized city located in the Southeastern portion of the country. Allison admits that her k-12 experience, which was within a small private and Christian school, "profoundly impacted [her] personal development" (Intersectional Writing Reflection 1). Allison expounds upon this idea by stating that all of her fellow peers and students were White and middle class just like her. Allison reports that since all of her peers were similar to her, she never had the opportunity to think about biases, privileges, and cultural differences. Allison quickly names her privileges as she identifies her religious and socioeconomic position in the world. Though Allison does acknowledge her Whiteness, she does not specifically name this construct as a privilege. Allison pays homage to her current collegiate experience as an eye-opening one that has pushed her to consider bias and privilege, which she had never done in previous educational settings.
\end{abstract}

\title{
Research Question 1 Findings
}

Research Question 1: What do reflective writings, reveal about the ways pre-service teachers construct meaning around critical perspectives in literacy education?

The findings below report on the major themes found from conducting deductive content analysis where data was coded against the CCR framework. A detailed account of my coding structure can be found in Chapter 3. Final themes were identified based on the 
Blackboard critical writing reflections that small group participants completed after three CIE learning sessions and two critical-intersectional reflective writings. For each Blackboard reflection, participants had to respond to a question provided by the researcher relative to their learning. I used participants' answers to these questions to develop the themes delineated below. A list of all Blackboard Critical Reflection questions can be found in Appendix O.

\section{Seven Major Themes}

Seven major themes emerged as the data were reviewed and coded. For some themes, data points were found more readily in certain sources than others; however, each source provided valuable information for Research Question 1. The seven themes derived from this data analysis include:

1. Curriculum as Catalyst

2. Considering Equity

3. Challenging Traditionalism

4. Questioning Practicality of Critical Literacy

5. Re-Conceptualizing Literacy within Critical Contexts

6. Collaboration as Catalyst

7. Stepping out of Comfort Zones

\section{Curriculum as Catalyst}

An overarching challenge in teacher education, is cultivating curriculum that provides foundational theoretical understanding along side practical knowledge. Hence, a 
primary goal of this research examined the impact of the CIE curricular alterations which sought to deliver practical applications alongside critical ideas about literacy learning and instruction.

The curriculum as catalyst theme was identified consistently in all small group written data, in that each participant named a key curricular event that facilitated their knowledge of critical literacy. The curriculum as catalyst theme represents how participants' understandings were elevated through working with the CIEs. Participants expressed the influence of curriculum on their learning in the following ways:

I really liked looking at the magazine cover and reading the book and doing the activity where we had to look for 'who or what was in the text?' and 'who or what is missing from the text?' and so on. It was an interesting way to break down pieces of literature in a way that a lot of people don't think about. It made me think critically and question my own biases and things I originally thought about the text. (Hanna, CIE Reflection 1)

This activity helped me to understand critical literacy a little bit more because I always felt like critical literacy was maybe a bit too hard on literature and was almost looking for something wrong. This activity helped me to see how looking at something in a critical way can be helpful because you're not attacking the piece when you're being critical; you are just considering what is missing from it or some microaggressions that you might not have recognized or understood had you not analyzed the piece. (Allison, CIE 1 Reflection)

The structure of the 3Hats activity was easy to follow. I do think I will use it my future classroom for many reasons. One of those reasons is the easiness of the activity and the extensive topics that can be talked about in it. (Josh, CIE 2 Reflection)

As evident from the bolded sections above, all four participants shared how a particular CIE activity leveraged their understanding of critical literacy.

For Hailey CIE 1 was helpful in supporting her understanding of deconstructing text to analyze its parts. During CIE 1, we viewed two magazine covers that focused on 
the millennial generation from negative and positive perspectives. Using Freire's problem posing strategy (critique) we asked questions to reveal hidden biases and messages on both covers. Specifically Hailey shared two key takeaways from CIE 1 . First, this activity helped her understand how to "break down" literature from an instructional standpoint, and secondly, this engagement pushed her to "think critically" to question her own biases.

Like Hailey, CIE 1 was instrumental for Allison in providing a more concrete understanding of what critical literacy was. Until CIE 1, Allison admits that for her, the notion of being "critical" meant being harsh by looking for elements that were wrong in the piece. However after experiencing CIE 1, Allison shares that her outlook shifted to consider critical literacy as a method to analyze text to find "what is missing" to uncover messages that you may not have recognized without critical analysis.

For Josh, CIE 3 was helpful in facilitating his understanding of critical literacy. The 3 Hats debate centered on looking at multiple perspectives, using a multi-media format where students were asked to respond to media clips that showed Malala and Donald Trump discussing the Muslim religion. In the quote listed above, as well as other responses, Josh found that the 3 Hats structure was easy to follow which made it a worthwhile strategy that he will use in his future classroom.

The quotes above speak to the multiple ways participants made sense of critical literacy. Each reported on different aspects of the CIE curriculum that deepened their understanding from a curricular and instructional perspective. Since critical literacy is not static in nature, it can take on various forms and functions. Through exposing participants 
to these various modes of critical literacy curriculum, they are hopefully better prepared to understand and use critical orientations to curriculum development in their future classrooms.

\section{Considering Equity}

Though research speaks to the sluggish nature in which teacher preparatory programs have responded to the need for equity education, critical pedagogical practices are predicated on challenging inequity. Thus, the data showed that participants were internalizing equitable ideologies in a myriad of different ways.

For example Hailey's quote below is intriguing in that the concept of Funds of Knowledge (Moll, 1992) was introduced in a previous class (Building Learning Communities). However, by leaning on her background knowledge of Funds of Knowledge, she is able to make sense of why honoring language difference is important in the classroom. In addition, I find the impact of this reflection powerful in that Hailey used the term "school language". Being that the idea of school language was just introduced through the CIE 3, I conjecture that this concept was helpful in supporting her understanding the difference between home languages and school language in the classroom.

I have learned that we, as teachers need to value differences in language because it helps us understand individual students' Funds of Knowledge. Moving forward in school, and specifically with language, means understanding differences and meeting the students half way. You want them to hold on to their culture and language differences, but to succeed in the mainstream classroom they will need to learn "school language". (Hailey, CIE 3

Reflection) 
Likewise, Allison, and Josh reveal emerging equity stances by reiterating the importance of accepting varying "language patterns" in the classroom. Though not explicitly stated by the participants, this viewpoint resists hegemonic notions of education predicated on monolingual classrooms which only value standard forms of English.

Josh's admission of valuing language patterns that counter what is expected in the classroom reflects his way of pushing against traditionalism to encompass a broader understanding and an appreciation of different forms of language.

The first thought I have when reading this quote is that is important that the language patterns of students are valued even if they may be significantly different that what is typically expected. (Josh, CIE 3 Reflection)

Allison's quote below illustrates her equity outlook through acknowledging that teachers need to make shifts in their thinking to ensure that culturally and linguistically diverse student "vernaculars" are not challenged in the classroom.

I think linguistic variation just requires a shift in the teacher's perspective. We should not be 'challenged' to rid students of their varying vernaculars as their language is a part of who they are. (Allison, CIE 3 Reflection)

All of the equity-based perspectives above came from CIE 3. This is not to say that equity stances were not identified in other CIE reflections; however, CIE 3 offered the most prominent representations of equity based attitudes. Perhaps this is because CIE 3 focused on linguistic variation, running records, and African-American Language. This engagement required participants to think about the role of language in reading assessment and achievement. This activity also encouraged participants to question if a students' home language should be held against them when conducting a running record 
and the negative implications of this deficit perspective on the literacy achievement of students.

\section{Challenging Traditionalism}

$21^{\text {st }}$ Century teachers are challenged by standardized ideologies and teacher-proof curricula which promote status quo interpretations of society (Apple, 2005; Bartolome, 2000; Finn, 2009). I argue that with the "multi-dimensionality of the teacher's task in contemporary schooling" (Kirk, 2015, p. 1), teacher education programs must arm PSTs with the critical capacities needed to resist hegemonic practices in education. Though each of the participants in the study have similar cultural backgrounds, which nest comfortably in the culture of Whiteness, each began platforming criticality as an instrument of resistance to dominant forms of classroom conformity.

The structure of the 3 Hats activity was easy to follow. I do think I will use it my future classroom for many reasons. One of those reasons is the easiness of the activity and the extensive topics that can be talked about in it. Yes, some of the topics are uncomfortable but it is important to see what our students are thinking during events that are trying. We cannot just say "it's adult stuff"; that does not instantly wipe the questions out of the kids head nor does it stop the scenes from appearing on television. (Josh, CIE 2 Reflection)

In comparing all of Josh's contributions, this quote was one of the longest and most self-revealing. Typically, I found Josh's word usage to speak in generalities and collective responses which seemed to distance him from taking a stand on any one issue. However, this quote made salient his stance to push the envelope of uncomfortability, by challenging teachers to explore controversial issues within the classroom. Josh shows an understanding of the harsh images and messages that students are exposed to through 
multimedia outlets at a young age and the vital role of teachers in helping students

unpack heavy social issues.

I do think that highlighting these issues are important in the elementary literacy classroom. Often teachers shy away from these topics because of how we were raised or we think we are going to offend someone by discussing the topic. No matter how we feel about a topic, it is our duty as educators to educate the next generation so they won't shy away from the topic like we do. The more we get children to think deeply and critically the more we can teach them to have thoughts of their own and opinions they have created for themselves. (Hailey, CIE 2 Reflection)

I think that these issues are very important to highlight in an elementary classroom because students are exposed to these issues everyday regardless of our desire to protect them. While ignoring such issues may come with the best of intentions, it means that the students go out into the world to face these issues without the background knowledge to address it. Often when people are uninformed or misinformed they make poor, rash decisions that fall in line with whatever the social norm of the time is and perpetuate these issues. (Allison, CIE 2 Reflection)

Though both Hailey and Allison are willing to push the boundaries of the classroom through critical questioning, I found it interesting that both made excuses as to why some teachers may not engage in such radical practices. For example, Hailey states, "Often teachers shy away from these topics because of how we were raised or we think we are going to offend someone by discussing the topic." While Allison states, "I think that these issues are very important to highlight in an elementary classroom because students are exposed to these issues everyday regardless of our desire to protect them. While ignoring such issues may come with the best of intentions..." From a critical race theory lens, these covert forms of negation or "false empathy" (Delgado, 1996) could be a manifestation of their conflicting identities in enacting critical literacy in the classroom. They may be grappling with realistically situating themselves as novice educators attempting to push boundaries that were rarely pushed in their own schooling. For 
example, Riley and Crawford-Garret share this sentiment in their research centered on working with PSTs to acknowledge privilege, they state, "When students in our classes applied critical lenses to their past experiences in k-12 classrooms, many of them expressed dismay and anger at the limits of their own education, which tended to exclude critical content, privilege, and favor discourses of certainty" (2016, p. 98). Thus the importance of this kind of critical reflection is key in helping PSTs build their critical stance as future educators.

\section{Questioning Practicality of Critical Literacy}

Though the bulk of participant responses were positive in adopting critical ways of thinking, a continuum in which participants vacillated existed. This continuum symbolized their shifting positionalities where they resonated with the idea of critical literacy, but questioned the functionality of the practice with elementary students. All of the examples provided below derive from the first CIE reflection. These responses were based on participants' first introduction to critical literacy in which I provided an abstract understanding of the construct using a comparison of magazine covers and the strategy of problem posing (critique).

This activity might be challenging for elementary students because it really requires you to think further than the surface level, to think critically, and in a complex way. I think elementary age students would look at stories like "The Three Little Pigs" and see it for something cute and funny; I don't think it would be their first thought to try and analyze and find details like older students would right off the bat. Hailey, CIE 1 Reflection)

I think this activity might be challenging because students, especially those of younger ages, are often very egocentric and may find it difficult to grasp this concept. Its also something that is fairly abstract and can be difficult to represent in a concrete manner which may also be another road block for students' understanding. (AllisonCIE 1 Reflection) 
I think the questions may be difficult for K-3 classrooms however, it would help in the development of perspective. (Josh CIE 1 Reflection)

In all three excerpts above, participants felt that critical literacy was "too challenging" for elementary-aged students. Capturing participants' first reactions to critical literacy instruction was helpful in gauging how they viewed and understood the practice. I view this theme from two different perspectives.

From a teacher educator standpoint I was glad that they questioned the practicality of this activity because it showed they were considering the developmental needs of students. From a reflective standpoint, it was obvious that my initial critical literacy activity did not provide students with an appropriate model upon which to fully grasp how to use this strategy with elementary-aged students. In the future I would bypass this initial lesson, which focused on analyzing magazine covers, and opt for a more elementary appropriate text to set the foundation for critical questioning/problem posing. Thus the subsequent learning session used the text "The Three Little Pigs \& The Somewhat Bad Wolf" along with the same problem-posing questions to connect criticality to elementary appropriate literacy practice.

\section{Re-Conceptualizing Literacy within Critical Contexts}

The theme, "Re-Conceptualizing Literacy Within Critical Contexts", reflects the ways participants began to merge their linear understandings of literacy (phonics, fluency, comprehension, etc.) with new critical conceptions of the practice. This shift in meaning is reflected in the responses below. 
Prior to this lesson I had honestly only thought of diversity in respect to where the children in the story were from, what their family structure looked like, different language spoken, etc., rather than different types of languages within one language. It was interesting to think about if from a different perspective that is so relevant to so many students. (Allison CIE 3 Reflection)

Analysis of Allison's quote shows that interaction with CIE 3, helped to broaden her understanding of the term "diversity". For example, the terms social justice and diversity get used so frequently in education that novice educators, may need a clear definition of the different modes of diversity and what these mean from a literacy perspective. Allison admits that considering linguistic diversity was "interesting to think about from a different perspective" which connotes that this activity helped her to conceptualize language difference in a new way.

The language variation lesson resonated with me personally. Much of what we discussed in class was in question for me and it was nice to hear others perspective on this subject. I now believe that you have to take every student into account, and that every students' running record can't be done in the same way. I loved the videos usage of the word "translation"! (Josh, Intersectional Reflection)

For Josh, engaging in CIE 3 was helpful in that it clarified misconceptions about language differences in the classroom. The video that accompanied CIE 3 showed a male teacher using the game of Jeopardy to teach the difference in linguistic (syntactic) features between African-American Language and Mainstream American English. Josh noted twice in two different reflections how this video was instrumental to his understanding of how to teach language difference in the classroom.

This activity helped me think about critical literacy in a new and good way. Sometimes I think we as teachers think of literacy as analyzing writing and reading the text when it is so much more than that. This had me look at literacy in a way that incorporated perspectives, writing, analyzing and so much more. It pushed me to step outside of myself and try stepping into others 
shoes which is often hard for kids to do. Especially for little kids, I think they struggle with seeing any other perspective but their own; this activity MAKES them do it. (Hailey, CIE 2 Reflection)

Though Allison and Josh reported a shift in thinking through their CIE 3 engagement, I feel Hailey's quote epitomized the notion of "reconceptualizing" in that she shared how the CIE 2 activity reframed her thinking on multiple levels. Hailey notes that some teachers only view literacy as "reading the text" and fail to see literacy "in a way that incorporates, perspectives, writing, analysis, and so much more". Hailey is transparent in her response and admits that CIE 2 helped her conceptualize critical literacy "in a new and good way". Hailey's response suggests that teachers, who have a linear or narrow definition of literacy may miss opportunities to expand the parameters of literacy by not practicing critical literacy strategies like CIE 2 (3 Hats).

\section{Collaboration as Catalyst}

Grounded in the theoretical tenants of sociocultural theory, this theme speaks to the ways in which participants mechanized collaborative discussion as a semiotic tool for greater meaning construction. Wells' (1995) approach to knowledge creation accepts the transactional nature of the learning process. He emphasizes "what we learn depends crucially on the company we keep, on what activities we engaged in together, and on how we do and talk about these activities" (p. 238). The quotes below speak to how each participant used discussion to further their understanding.

I liked this activity because it challenged me to think in a new way. I appreciated how each area of critical literacy was broken down so we could focus specifically on each area and get a more intensive understanding of the concept. I also liked that the activity was done in groups because it allowed me to hear other's perspectives. (Allison, CIE 1 Reflection) 
This activity challenged me in many ways: primarily, it challenged me because I had to look at a viewpoint that is completely different from mine. I had to come up with a way to sound genuine in an opinion when my opinion is the polar opposite. It challenged me to think critically and sort of infer what other people in my group were thinking. (Hailey, CIE 2 Reflection)

I really liked how we were given different perspective questions in our groups. It really helped to show how differently people look at things based on their own perspective. I think it helps to discuss these types of topics with peer to help broaden your own point of view. (Josh CIE 3 Reflection)

Based on the participant comments above, each leaned upon the small group as a form of support and guidance in navigating each CIE experience. Listening and sharing ideas within the small group seemed to assist Hailey, Allison, and Josh to make sense of new ideas. For these participants, their interpretation of small group discussion translated into a negotiation of meanings through interactional contexts. Specifically, participants commented on the power of collaboration as an integral part of their meaning making process.

\section{Stepping out of Comfort Zones}

In thinking about the dispositions of pre-service teachers, research suggests that many enter programs with beliefs about teaching and learning based on their previous schooling experiences (Wall, 2016). For many, k-12 experiences encapsulated mainstream narratives of status quo realities which rarely provided opportunities to challenge hegemony. Considering the emancipatory and empowering utility of critical pedagogy, its not surprising that participants noted a "stepping out" of comfortability with 'trying-on" this new theoretical perspective. I interpret participants' expression of "stepping out" as an initializing phase in self-awareness as they recognize the disharmony between their prescribed k-12 educational beliefs and critical literacy practices. 
The video clip did challenge my thinking a little bit because I have always felt like pointing out differences in language because of race or culture was kind of "rude". After watching how effective the lesson was and how well the students understood the differences in language made me feel like it could be a possible activity in my classroom one day. With saying how I have always viewed it as "rude", I now understand how being a teacher means confronting differences and being open to talking about them. (Hailey CIE 3 Reflection)

I think with teaching you constantly have to check yourself and be sure you are not projecting your own life experiences and preferences on your students. I feel the same way about students' language diversity. I know I will want to correct students to speak the way that I grew up believing is "correct" (standard English). However, I will have to remind myself that there is no "right way" to speak. I would say the video/discussion challenged me to think about language in a new and better way. (Allison, CIE 3 Reflection)

As a teacher yes, I think the 3 Hats format may be difficult to figure out how to highlight some arenas, but it is important that they are addressed as soon as possible. I think this is because many of my misconceptions come from when I was in elementary school. I can vaguely remember the day of $9 / 11$ and the fear in my class;an event like that is more than enough to affect peoples ideas of things. (Josh, CIE 2 Reflection)

Hailey, Allison, and Josh's displayed their "stepping out" of comfort zones, by boldly resisting comfortability through various forms of self-accountability. Worldrenowned poet and orator Maya Angelou in her 1969 autobiography, I know Why the Caged Bird Sings stated, "I did then what I knew how to do. Now that I know better I do better; which reflects that when a new lesson is learned we use our new knowledge to improve upon our practice by "doing better". I feel this notion of "doing better" is represented by self-accountability statements that connote a higher standard of responsibility upon reconceptualizing literacy through a critical lens. Hailey exerts her accountability by announcing that her role as an educator predicates on a commitment to "confronting difference, and being open to talking about them." Allison checks her bias at the door and believes that it is important to fight the urge to correct language difference in the classroom because "there is no 'right way' to speak". While Josh raises 
responsibility in the classroom as he challenges the tendency to shy away from controversial topics in the classroom because as he asserts, " it is important that [controversial topics] are addressed as soon as possible."

Overall, the tension that lies between what we $d o$ and when we do it better is the crux of interrogation for this study. This kind of cognitive dissonance is important for teacher educators to identify as it could symbolize a reconciliation of antiquated beliefs with new practices which may result in new modes of thinking for teacher candidates. However the data collected for this study is not substantial enough to make such a large claim.

\section{Critique, Resist, \& Re-Design Continuums}

A foundational element of the CIE learning sessions were linked to the Critique, Resist and Re-Design (CRR) critical literacy focus topics (chapter 3). As stated thoroughly in chapter 3 , each focus was grounded by a critical theorists' interpretation of critical literacy: Critique- Paulo Freire, Resist-Rebecca Rogers, Re-Design- Hilary Janks. Each CIE embodied one of the three focus topics, as an anchor, which linked critical theory to an instructional practice. Though none of the participants explicitly refer to the CRR focuses in their reflections, I specifically analyzed their responses to uncover words which typified the critical foundations of the CRR focuses.

Through this coding process, I created individual continuums, which provide a holistic picture of Hailey Allison, and Josh's understanding of critical literacy through the lens of the CRR focuses. Though I analyzed four different writing reflection spanning from 1/31$3 / 27$, most of the CRR elements did not start to emerge until the later part of the semester between 3/6-3/27. The following continuums illustrate how each participant moved 
through their understanding of critical literacy to reflect the CRR focuses in their critical

reflections.

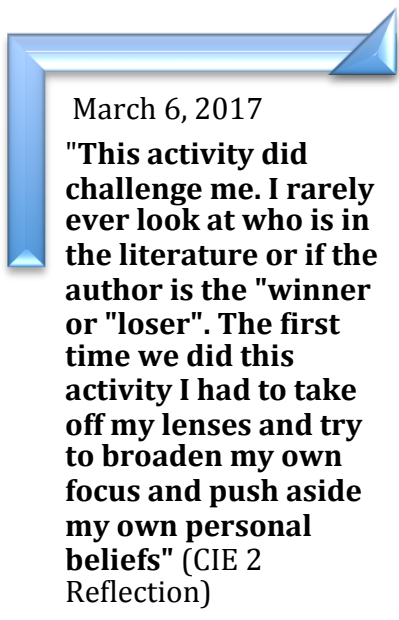

\section{Critique}

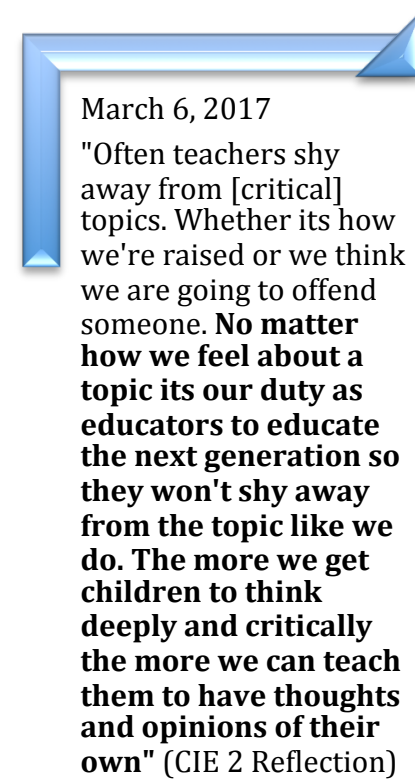

\section{Resist}

March 27, 2017

"The video clip did challenge my thinking because I have always felt like pointing out differences in language because of dialectic difference was kind of 'rude'. After watching how effective the lesson was and how well the students understood the differences in language made me feel like it could be a possible activity in my classroom one day. Though I've always viewed it as rude, I also understand how being a teacher means confronting differences and being open to talking about them" (CIE 3 Reflection)

\section{Re-Design}

Table 6 Hailey's CRR Summary

\begin{tabular}{|l|l|l|}
\hline $\begin{array}{l}\text { CRR } \\
\text { Domain }\end{array}$ & CIE Lesson & Overall Analysis \\
\hline Critique & $\begin{array}{l}\text { 3 Hats Multiple } \\
\text { Perspectives }\end{array}$ & $\begin{array}{l}\text { This response reflects how the 3 Hats CIE challenged her to "take off" her lens to look at } \\
\text { a topic from a different viewpoint outside of her comfort zone. Through this activity } \\
\text { Hailey was pushed to question or Critique her own biases. }\end{array}$ \\
\hline Resist & $\begin{array}{l}\text { 3 Hats Multiple } \\
\text { Perspectives }\end{array}$ & $\begin{array}{l}\text { This response represents the Resist domain because Hailey is articulating a firm stance } \\
\text { on the role and obligations of educators by saying that regardless of personal beliefs it is } \\
\text { the "duty of teachers to "get children to think deeply and critically" to prepare them for } \\
\text { the next generation. The 3 Hats CIE provided the space for Hailey reflect on critical } \\
\text { literacy and its importance in the classroom. Further helping to refine her positionality as } \\
\text { a future educator. }\end{array}$ \\
\hline $\begin{array}{l}\text { Re- } \\
\text { Design }\end{array}$ & $\begin{array}{l}\text { Linguistic } \\
\text { Variation, AAL, } \\
\text { \& Running } \\
\text { Records }\end{array}$ & $\begin{array}{l}\text { The Re-Design domain is reflected in this statement because Hailey s interaction with } \\
\text { the linguistic variation CIE broadened her understanding of language difference, which } \\
\text { allowed her to reconceptualize how to approach linguistic variations in the classroom. }\end{array}$ \\
\hline
\end{tabular}




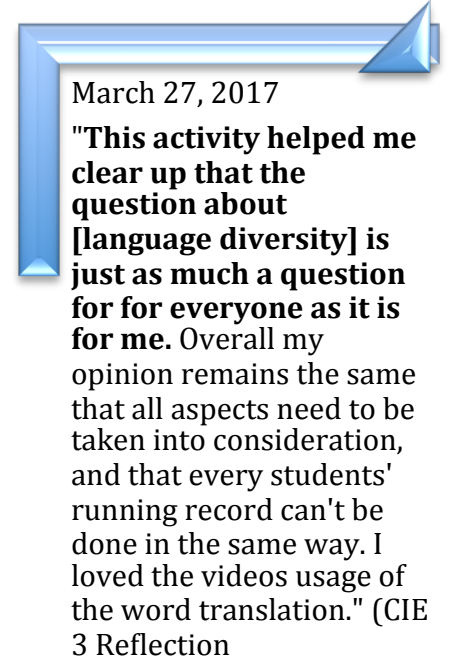

\section{Critique}

Figure 6. Josh's CRR Continuum

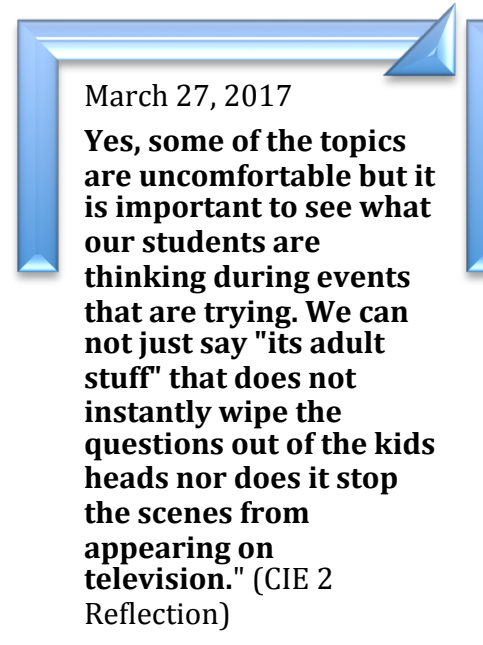
$\overline{\operatorname{March} 6,2017}$
March 6, 2017
"The structure of the 3
Hats activity was easy to
follow. I do think I will
use it in my future
classroom for many
reasons. One is the
easiness of the activity
and the extensive topics
that can be talk about in
it. (CIE 2) Reflection

\section{Re-Design}

\section{Resist}

\begin{tabular}{|l|l|l|}
\hline $\begin{array}{l}\text { CRR } \\
\text { Focus }\end{array}$ & CIE Lesson & Overall Analysis \\
\hline $\begin{array}{l}\text { Critique } \\
\text { (Freire) }\end{array}$ & $\begin{array}{l}\text { Linguistic } \\
\text { Variation, } \\
\text { AAL, \& } \\
\text { Running } \\
\text { Records }\end{array}$ & $\begin{array}{l}\text { This response reflect the Critique domain because Josh is using the Linguistic Variation } \\
\text { CIE to help him make sense of how to handle language differences and running records } \\
\text { in the classroom. After engaging in whole group discussion Josh realized that addressing } \\
\text { language difference is a question that many PSTs have which made him helped him } \\
\text { solidify his position on the issue. }\end{array}$ \\
\hline $\begin{array}{l}\text { Resist } \\
\text { Rogers) }\end{array}$ & $\begin{array}{l}\text { Linguistic } \\
\text { Variation, } \\
\text { AAL, \& } \\
\text { Running } \\
\text { Records }\end{array}$ & $\begin{array}{l}\text { The Resist domain is reflected in Josh's comment above in that he is rejecting excuses, } \\
\text { which dismiss teachers from their responsibility to examine controversial issues in the } \\
\text { classroom. Josh honors that today's students are inundated with various media messages } \\
\text { that teachers need to be aware of. }\end{array}$ \\
\hline $\begin{array}{l}\text { Re- } \\
\text { Design } \\
\text { (Janks) }\end{array}$ & $\begin{array}{l}\text { M Hats } \\
\text { Merspectives }\end{array}$ & $\begin{array}{l}\text { Josh's comment reflects the Re-Design domain because he shares that the 3 Hats CIE } \\
\text { provides a new strategy that he will implement in his classroom due to its ease in } \\
\text { introducing extensive topics. }\end{array}$ \\
\hline
\end{tabular}

Table 7. Josh's CRR Summary 


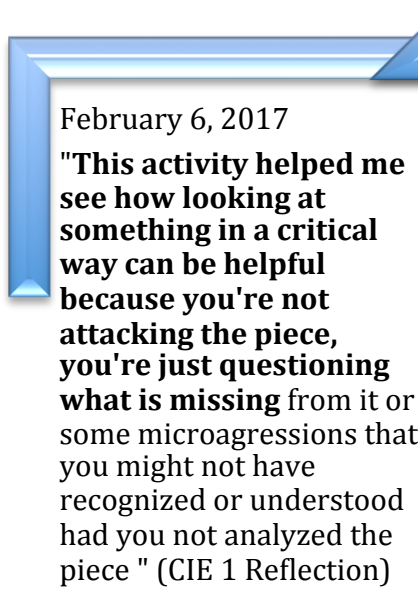

\section{Critique}

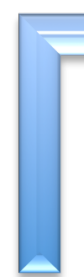

March 6, 2017

"I think these issues are very important to highlight in the elementary classroom becasue the students are exposed to these issues everyday. While ignoring such issues may come with the best of intentions, it means that the students go out into the world to face these issues without the background knowledge to address it. By informing our students about [critical] situations we give them a background with which they will approach the world through empathy" (CIE 2 Reflection)

\section{Resist}

March 27, 2017

"Prior to this lesson I had honestly only thought of diversity in respect to where the children in the story were from, what their family structure looked like, different langauges spoken etc. rather than differnt types of language in one language. It was interesting to tink about it from a different perspective that is so relevant to so many students" (CIE 3 Reflection)

\section{Re-Design}

Figure 7. Allison's's CRR Continuum

\begin{tabular}{|l|l|l|}
\hline $\begin{array}{l}\text { CRR } \\
\text { Domain }\end{array}$ & CIE Lesson & Overall Analysis \\
\hline Critique & $\begin{array}{l}\text { Problem- } \\
\text { Posing with } 3 \\
\text { Little Pigs }\end{array}$ & $\begin{array}{l}\text { Allison's response represents the Critique domain because she began to question } \\
\text { and alter her perception of the word "critical". Prior to this first experience Allison } \\
\text { thought being critical was about attacking or judging, but after engagement with the } \\
\text { CIE she broadened her understanding of the construct. }\end{array}$ \\
\hline Resist & $\begin{array}{l}\text { 3 Hats Multiple } \\
\text { Perspectives }\end{array}$ & $\begin{array}{l}\text { Like Hailey and Josh, Allison resists tradition and takes a controversial stand to } \\
\text { express the importance of supplying students with the "background" knowledge } \\
\text { necessary for them to approach the world with empathy. }\end{array}$ \\
\hline $\begin{array}{l}\text { Re- } \\
\text { Design }\end{array}$ & $\begin{array}{l}\text { Linguistic } \\
\text { Variation, } \\
\text { AAL, \& } \\
\text { Running } \\
\text { Records }\end{array}$ & $\begin{array}{l}\text { Experiencing the Linguistic Variation CIE helped Allison to re-define the idea of } \\
\text { diversity. She admits that her view of the word was relegated to ethnicity, race, and } \\
\text { national origin. However after learning about the differences between variations of } \\
\text { the English language her understanding of the concept was broadened. }\end{array}$ \\
\hline
\end{tabular}

Table 8. Allison's Summary of Findings 


\section{Research Question 1 Summary}

My interpretation of findings for Research Question 1 views participants' critical reflection (Mezirow) as a semiotic tool which supported them as they made sense of critical ideas introduced during the disorienting dilemma (Mezirow) portion of the CIEs. In semiotic mediation, the role of tool acts as a means of semiotic transmission, where knowledge is cultivated through systems of social meaning-making resources. Vygotsky differentiates tools into two separate categories: a) concrete and b) abstract. Concrete or technical tools are of a material nature while abstract tools are comprised of an individual or conscious other. Though different, both tools work to achieve the same goal of creating new knowledge.

Working under this assumption, I assert that curriculum (concrete) and collaboration (abstract) served as overarching meaning making tools which provided the platform from which all other outputs of meaning (themes) were constructed. Hence, the seven themes found in the data can be linked to interaction through curriculum, collaboration, or both. The figure below illustrates my interpretation of this dynamic. 


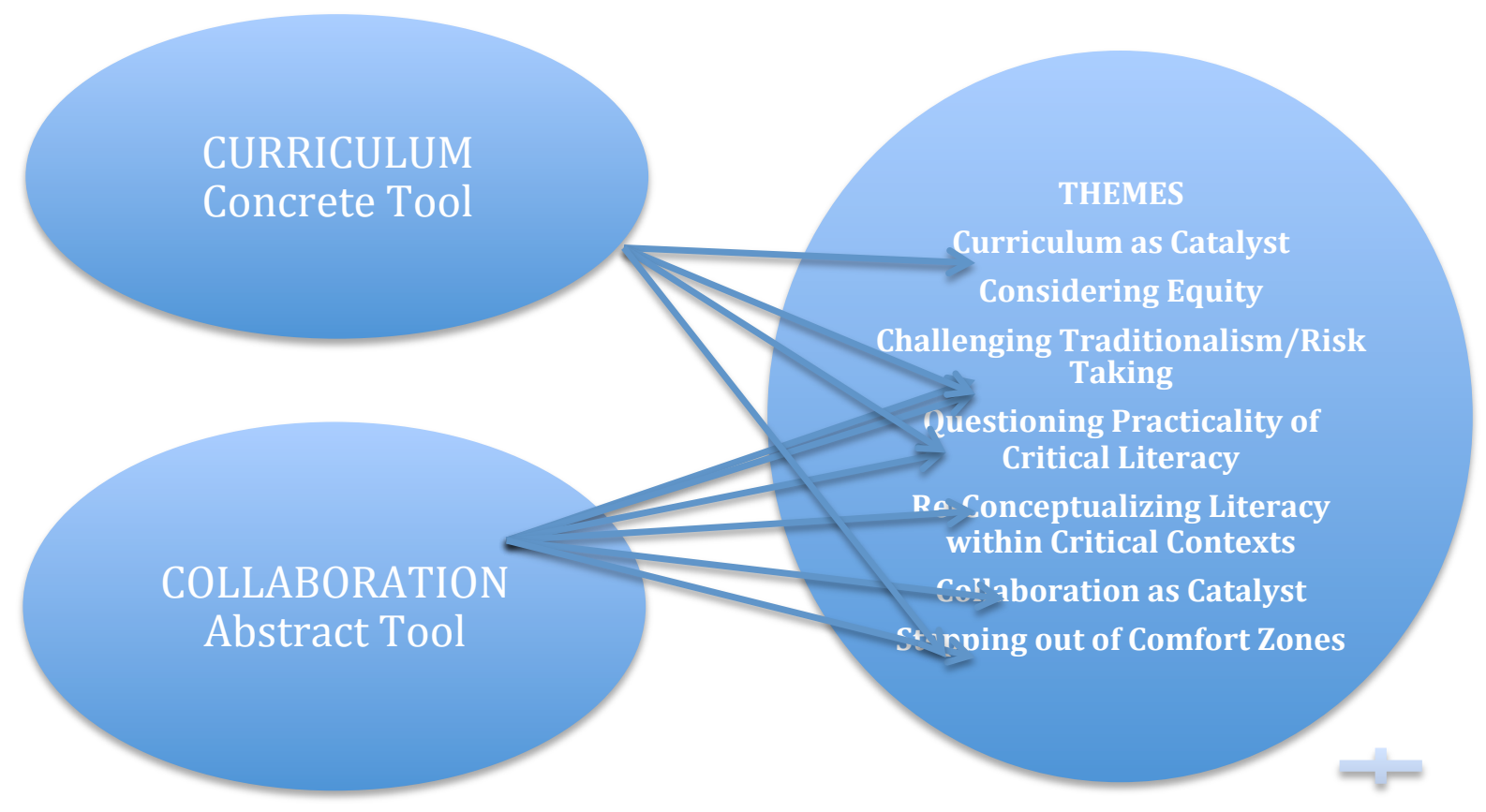

Figure 8. Semiotic Mediation Findings

Findings suggest that critical reflection paired with collaboration provided space for participants to wrestle between preconceived notions of literacy and critical literacy. Each participant pointed to a curricular event or collaborative event which helped them make sense of new ideas explored through the CIEs. The Blackboard critical reflection questions helped guide participants to think through and respond to their understanding of new concepts explored during the CIEs. Resoundingly, all participants reflected on the points and elements discussed during rational discourse (small group discussion) and how this collaborative space facilitated their thinking. To add to the findings of this study, I would like to extend my analysis to examine the role of instructor as both concrete and abstract semiotic tools to how my interactions, re-directions, and relationship to and with the classroom community supported or suppressed students meaning making process of critical literacy. 


\section{Research Question 2 Findings}

2) How do pre-service teachers use collaborative discussion to construct meaning around critical perspectives in literacy education?

In this section of the chapter, I provide the emerging themes from multiple iterations of discourse analysis based on the verbal exchange coding framework (Goodall), which sought to uncover how often small group participants allowed discussion to progress into more complex dimensions of verbal exchange. A detailed description of how I coded data based on verbal exchange can be found in Chapter 3: Discourse Analysis. Though seven total learning sessions commenced throughout the semester, small group discussion was only audiotaped three of those times. Therefore findings reflect three different speech events, which took place on February $6^{\text {th }}$ and March $27^{\text {th }}, 2017$. The tables below quantify the number of speech utterances that fell into one of the five categories of verbal exchange:

1. Phatic or Ritual Communication- A class of routine social interactions that are basic in nature.

2. Ordinary Conversation- Patterns of questions and responses that provide personal, relational, and informational issues, and concerns.

3. Skilled Conversation- A higher level of information exchange, including debates, conflict management, and negotiations.

4. Personal Narratives- Consisting of individual or mutual self-disclosure.

5. Dialogue- In which conversation "transcends" information exchange and the boundaries of self and moves into higher levels of spontaneous ecastic mutuality. 
Table 9. CIE 1 Verbal Exchange Table

\begin{tabular}{|c|c|c|c|c|c|}
\hline \multicolumn{7}{|c|}{ Total Speech Utterances- 97 } \\
\hline $\begin{array}{c}\text { Verbal } \\
\text { Exchange } \\
\text { Categories }\end{array}$ & $\begin{array}{c}\text { Phatic } \\
\text { Communicatio } \\
\text { n }\end{array}$ & $\begin{array}{c}\text { Ordinary } \\
\text { Conversation }\end{array}$ & $\begin{array}{c}\text { Skilled } \\
\text { Conversatio } \\
\text { n }\end{array}$ & $\begin{array}{c}\text { Personal } \\
\text { Narratives }\end{array}$ & Dialogue \\
\hline \# of Utterances & 0 & 35 & 49 & 6 & 7 \\
\hline $\begin{array}{c}\text { Percentage of } \\
\text { Conversation } \\
\text { focused on } \\
\text { specific } \\
\text { Verbal } \\
\text { Exchange } \\
\text { Codes }\end{array}$ & $0 \%$ & $36 \%$ & $50 \%$ & $6 \%$ & $7 \%$ \\
\hline
\end{tabular}

The table above reveals the most frequent type of exchange was skilled

conversation while the lowest frequency was within the phatic communication category.

The lack of phatic communication is a trend that was found throughout the data. This could be because phatic communication consists of routine social interactions that consist of salutations and greetings. Since small group participants knew each other from other classes, and were familiar with working on the CIEs together, general greetings were unnecessary which allowed participants to begin conversation at the ordinary and skilled level. For example, the following excerpt shows the beginning of the CIE 1 conversation.

Hailey: Okay, so the first question is, "What message does the text seem to convey?"(Ordinary)

Josh: Being different can be a good thing?(Ordinary)

Hailey: That could be a possibility.(Ordinary)

Allison: I think it means taking your time and working hard on something is better than doing it quickly to get it over with and then chilling with your sodie pop (laughs). (Skilled)

$50 \%$ of CIE 1 discourse was coded as skilled conversation while $36 \%$ of the conversation was coded as ordinary conversation. Interesting to note were the ways in which participants would drift in and out of skilled and ordinary conversation. When one student would attempt to make a critical or bold statement or conjecture, another 
participant would pull the conversation back to a safe place, perhaps to neutralize the conversation in an effort to gain comfort. Asking blanket questions and or agreeing with statements that failed to move the conversation forward created this form of neutrality.

Goodall distinguishes skilled engagement as "conversations that feature an exchange of conflicting views, charges or constructions of meaning" (p. 104). While ordinary communication is described as "responses that provide interactants with data through acquiring, describing, analyzing, evaluating, and acting on information in everyday life" (p. 103). The balancing act found between the skilled and ordinary conversation is represented in the discourse below.

Hailey: What do the images do to add to the message and values in the text? Yeah, because like, seeing ... you know like how she pointed out that the two pigs were riding on something and then the other one was ... Maybe because without seeing that it wasn't actually in the text.- Skilled Josh: Yeah - Ordinary Allison: Or like the fact that they do call the pig a girl but she has a blue bow onher head most of the time so it's even more like if the kid misses it (Skilled) Hailey: It's like hidden yeah (Skilled) Allison: Or not paying attention. Yeah.(Skilled) Josh: Didn't one of them have like dots or brown spots on them? (Skilled) Hailey: Brown spots on it yeah. (Ordinary)

Josh: What about the other ones? Or did all of them? (Ordinary)

Hailey: I thought I noticed that, but then the text said almost kind of like they were dirty too. (Ordinary)

Josh: Yeah- Ordinary Allison: Good talk guys. (Ordinary)

Hailey: I want to see what books they had over there. (Referring to books in the classroom library).(Ordinary)

Upon deeper inspection this speech event can be dissected into two distinct categories to garner a clearer picture of how language is functioning. Van Dijk explains that basic tenants of discourse analysis are informally divided into surface structures or underlying structures. Van Dijk (1993), states “surface structures are usually associated with the forms of language use one can see or hear. Underlying structures are usually 
associated with meaning or (inter)action and sometimes with cognitive phenomena, such as mental representations or strategies of understanding and production” (p. 105, 1993)

In this analysis I correlate skilled, narrative, and dialogic exchanges as underlying structures of language, and phatic and ordinary exchanges as surface structures. Though I identify the variations between skilled and ordinary exchanges as different levels of communicative meaning and intensity, I understand the importance of ordinary conversation in developing a comfortable environment that provide pathways for open and deep discussion. Van Dijk (1993) writes, "but it should be recalled that meaning structures require surface structure expressions or coding and these surface structures again are crucial in the comprehension of discourse" (p. 103). When participants use ordinary exchanges they may be grappling with how to respond to new knowledge based on the CIE lesson and collaborative inquiry.

Table 10. CIE 2 Verbal Exchange Table

\begin{tabular}{|c|c|c|c|c|c|}
\hline \multicolumn{5}{|c|}{ Total Speech Utterances- 20 } \\
\hline $\begin{array}{c}\text { Verbal } \\
\text { Exchange } \\
\text { Categories }\end{array}$ & $\begin{array}{c}\text { Phatic } \\
\text { Communication }\end{array}$ & $\begin{array}{c}\text { Ordinary } \\
\text { Conversation }\end{array}$ & $\begin{array}{c}\text { Skilled } \\
\text { Conversation }\end{array}$ & $\begin{array}{c}\text { Personal } \\
\text { Narratives }\end{array}$ & Dialogue \\
\hline $\begin{array}{c}\text { \# of } \\
\text { Utterances }\end{array}$ & 0 & 3 & 10 & 3 & 4 \\
\hline $\begin{array}{c}\text { Percentage } \\
\text { of } \\
\begin{array}{c}\text { Conversation } \\
\text { focused on } \\
\text { specific } \\
\text { Verbal } \\
\text { Exchange }\end{array}\end{array}$ & $0 \%$ & $15 \%$ & $50 \%$ & $15 \%$ & $20 \%$ \\
\hline
\end{tabular}

CIE 1 and CIE 2 shared similar findings in that $50 \%$ of all speech utterances were of a skilled nature. However, there was a considerable increase in the amount of personal narratives $(15 \%)$ and dialogue $(20 \%)$ with a decrease in ordinary exchanges. The 
fluctuation in communication could be indicative of several variables relative to the sociocultural elements of the small group and the curricular materials explored during the learning session. CIE 2 was focused on interrogating multiple perspectives. To enact this strategy we discussed palpable social issues that focused on President Trump, Malala, immigration and the controversial travel ban on Muslims in the United States.

Though this speech act only produced 20 utterances, the discourse quickly bypassed phatic and ordinary exchanges and initialized with skilled conversation. Furthermore, this learning session took place 7 weeks into the semester implicating that within this time frame, the small group had developed a comfort level of communication where ideas, thoughts, and conjectures were more spontaneous. An example of this form of higher-level discourse is noted below.

Allison: Things like that... Social issues like that? As much as it will be un comfortable for future teachers in two years, we're still going to be dealing with these same kinds of social issues that we're just touching on right now. How do you handle that with a fifth grader that asks you a question about some of these things because he read it on Facebook? Do you turn it into a teachable moment and talk about bias or without getting parents on your back, you don't want to... you don't want to be biased in a classroom but how do you teach these things without ruffling some feathers? - (Skilled)

Josh: And I think that's why teacher tend to avoid it, because they know how it should ... Because I mean, no matter what your political views are, you can look at our election this year and it was not one side compromising with the other, its completely two different sides, and if you take one side you don't understand the other side... (Skilled)

Allison: There's not the other side... (Skilled)

Josh: Yeah and that's because... it starts at an elementary level where teachers aren't teaching that to students. How to sit and listen to the other person's point of view. (Skilled)

Allison: It's a delicate balancing act, and with that the parents' sides are then communicated to the kids who you know. That's the natural way of things. (Skilled)

Hailey: Right, yeah. (Ordinary)

Allison: And then so I don't know if any of you guys have had any experiences in your placement during the election last year, different things were said... 
(Dialogue)

Hailey: Yessss. One of my Muslim students asked if she was going to be sent back to Africa! (Dialogue)

Allison: What? No! Yeah literally, and how do you handle that? (Dialogue) Hailey: Or asking the questions for our social studies class this semester.

Students they understand a lot more than what you think. (Dialogue) Josh: Yeah (Ordinary)

Hailey: I don't know if they actually know in depth information about it, but they've heard this stuff so they're starting to analyze. So they've got the first step. (Dialogue)

Table 11. CIE 3 Verbal Exchange Table

\begin{tabular}{|c|c|c|c|c|c|}
\hline \multicolumn{7}{|c|}{ CIE 3 } \\
\hline $\begin{array}{c}\text { Terbal } \\
\text { Exchange } \\
\text { Categories }\end{array}$ & $\begin{array}{c}\text { Phatic } \\
\text { Communication }\end{array}$ & $\begin{array}{c}\text { Ordinary } \\
\text { Conversation }\end{array}$ & $\begin{array}{c}\text { Skilled } \\
\text { Conversation }\end{array}$ & $\begin{array}{c}\text { Personal } \\
\text { Narratives }\end{array}$ & Dialogue \\
\hline $\begin{array}{c}\# \text { of } \\
\text { Utterances }\end{array}$ & 0 & 6 & 30 & 9 & 37 \\
\hline $\begin{array}{c}\text { Percentage } \\
\text { of } \\
\text { Conversation } \\
\text { focused on } \\
\text { specific } \\
\text { Verbal } \\
\text { Exchange }\end{array}$ & $0 \%$ & $7 \%$ & $36 \%$ & $10 \%$ & $45 \%$ \\
\hline
\end{tabular}

The CIE 3 analysis was unique in that it reflected the highest amount of Dialogue exchanges (45\%). The conversational climate of CIE 3 was intense, due to the delicate nature of the lesson which centered on miscue analysis, running records, and linguistic variation/language diversity. Within this learning session, students had to decide if specific words counted as errors as they listened to a running record, strategically read by the instructor, in African-American language. To make these decisions participants had to reconcile pre-conceived notions of "Standard English" while considering students with varying linguistic markers outside of mainstream English; thus, calling in to question, 
their personal outlooks on language, their identities, as well as their positionalities as future teachers. All of these factors were simultaneously at play which could indicate why this CIE had the highest amount of dialogic exchange.

\section{Verbal Exchange Summary}

Dewey in his recommendation for progressive education asserts that, " in order for students to engage with a topic it must be one that poses problems or raises doubts that will motivate the student to explore further" (1938, p. 77). Based on study findings, the critical orientation of the CIEs pushed small group participants to "explore further" as they leaned upon each other to disaggregate their understandings and negotiate positionalities through interacting with the CIEs. The CIE verbal exchange tables above along with the figure below illustrate this form of exploration, as we notice an increase in skilled, personal and dialogue exchanges as students grappled with more complex and controversial issues.

Participants' increased reliance on higher levels of verbal exchange represented their need for greater semiotic resources in making sense of new learning. Thus verbal exchange was pushed beyond phatic and ordinary levels when conversation necessitated participants to reveal personal attitudes, values, and perspectives. Verbal exchange findings support the importance of providing openings for students to wrestle with critical content through collaborative dialogue, to increase student engagement and overall understanding in the methods classroom.

The table below illustrates a cumulative view of the verbal exchanges made by small-group participants across all CIEs, which also reflects the synthesis of findings for 
Research Question 2.

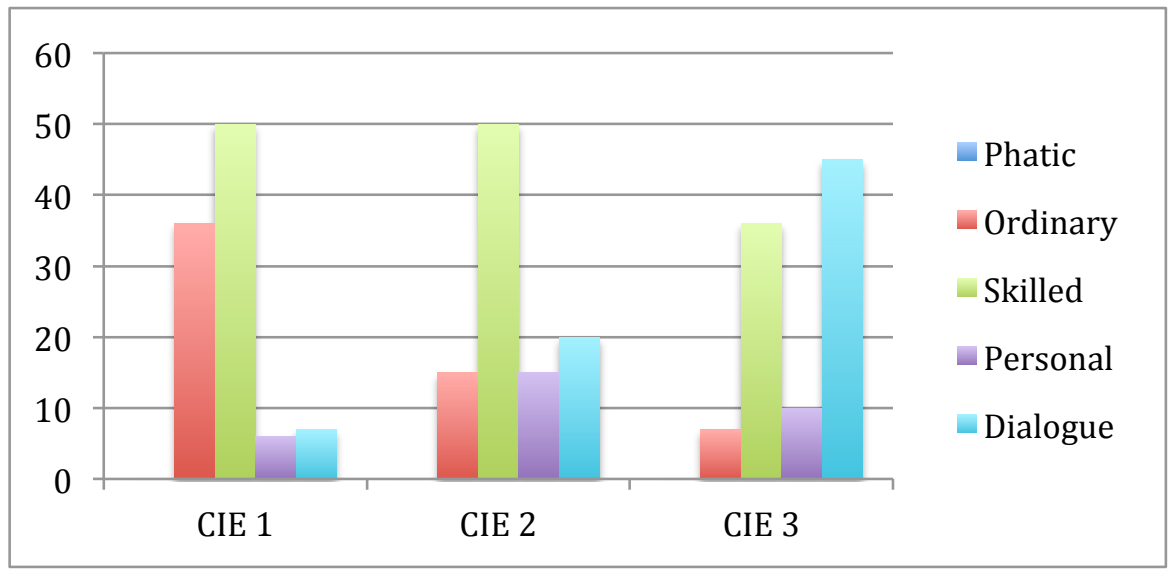

Figure 9. Verbal Exchange Summary

Figure 10 suggests that as participants progressed through the course, their level of ordinary conversation decreased. Their level of skilled conversation remained almost the same until the final CIE 3, while personal and dialogue conversation increased throughout the semester. There was an evident spike in dialogue conversation in the last CIE which is reflective of the argumentative nature of the conversations around linguistic diversity. Since there were only three incidences of discussion recorded, there is not enough data to make generalizations about why participants began to dive into deeper levels of conversation. However, I would hypothesize that the influx in conversation complexity was influenced by the growing familiarity and comfortability that participants had with each other as well as the structure of the CIE.

\section{Context of Dialogue Findings}

Goodall characterizes dialogue exchanges as "conversation which transcends information exchange and the boundaries of self into higher levels of spontaneous ecastic mutuality" (2000, p. 41). Therefore I chose to exploit one pivotal dialogic exchange from 
the data to show how participants engaged in naturalized discourse that retreated from the safe boundaries of polite conversation found in introductory levels of verbal exchange (phatic, ordinary, skilled). This analysis is further supported by Halliday who maintains that "theory should be based on natural data rather than experimental data: that is on language that is unconscious; not self-monitored; in context, not in a vacuum; observed not elicited" (p. 19)

\section{Critical Discussion \& Rational Discourse}

The dialogue exchange for this investigation was categorized as critical discussion based on the context of dialogue framework. Keefer et al. suggest the essential goal of critical discussion hinges on divergent viewpoints which allow participants the space to present their opinion in relation to others. Two participants, Morgan (only participated in one small group session and thus is not included as one of the small group participants) and Hailey, engaged in critical discussion during CIE 3. This interaction was important to note since argument-based discourse never surfaced from any other small group data. Along with the discourse data, I created a visual coding system that illustrates the flow of the critical discussion as participants engaged in

dialogic markers (argument, counter argument, concession). Each response is identified by a number which represents the sequence in which the response was uttered during the verbal exchange. The table below represents the visual coding key and the dialogic exchange examined. 


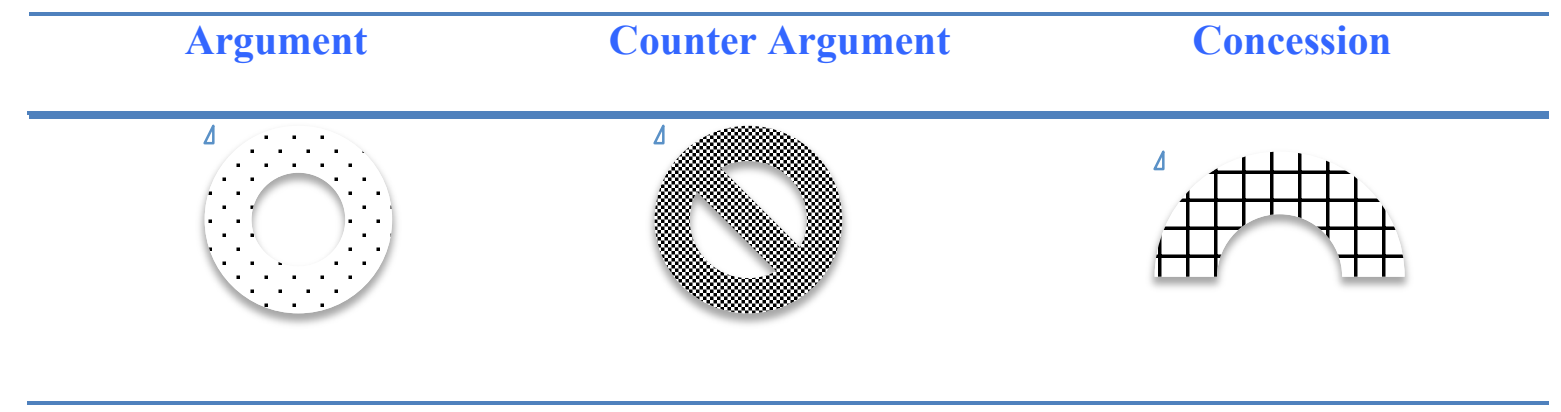

Table 12. Visual Coding Key

Instructor: Oh yeah. All right, so number two. "It is easy to misinterpret or fail to appreciate the complex processing that diverse language speakers apply when reading. Knowledge of the language systems that children bring to the classroom is necessary so we can interpret children's attempts at text correctly and respond to them in ways that support the child as a language learner without demeaning the language that he speaks."

Morgan: 1

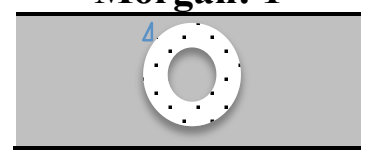

The thing that immediately ran into mind with this is in Hawaii the children, the Hawaiian language pronounces their vowels differently than they do in the English language, so if you know that maybe in Hawaii if like you're in a classroom and if the diversity maybe is a little different than the African-American AAL language, but you do have children sounding things out, what if they, they're first language is Hawaiian and they're pronouncing their "i"s as "e" cause that's how you pronounce it, it literally makes an "e" sound. Yeah, and so like taking that for really early readers, right, those kinds of experiences and understanding that they are actually sounding it out, they just need to be more familiar with American vowel sounds. Same with maybe Spanish, I don't

Hailey: 2 really know.

But like, if you're a teacher like if one of us moved to Hawaii then I feel like we would be the ones who need to learn the correct dialect. 


\section{Morgan: 3}

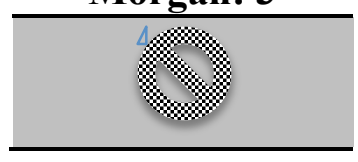

Hailey: 4

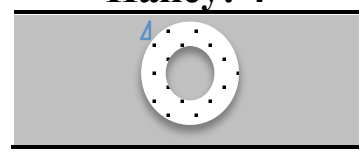

Morgan: 5

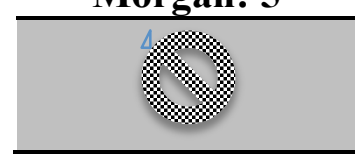

Hailey: 6

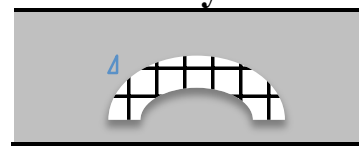

Morgan: 7
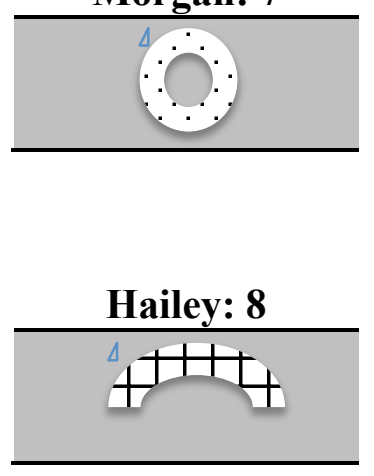

Morgan: 9

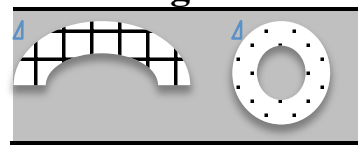

That happens a lot.

So the students shouldn't change because I don't feel like you can come into a completely different culture -a Hawaiian culturewhich is probably completely different. You can't come into their culture and tell them, "You're pronouncing this wrong.

But at the same time, you have to learn American vowel sounds. You know, unless you're specifically in a Hawaiian language class.

I guess I'm thinking they're gonna live in Hawaii their whole life.

But you're not gonna go to the southern region of America and try to be like, "Speak English. The reason why that came up is cause that's a problem I grappled with personally. It is a cultural thing, right, so I try to bring it up at teacher conferences and a mom got pissed off at me and I was like ... What?

Yeah, right. I don't know.

I don't know, yeah. But I guess that kind of, maybe taking it away from Hawaii and back to here, that could happen with like, maybe the words, like how they think they're pronounced, like "wouldn't", "wasn't" like they're trying to make those letters make the sounds that they're familiar with. 
Hailey: 10

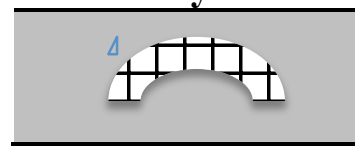

Yeah.

Morgan: 11

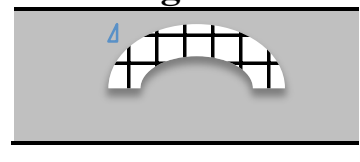

Hailey: 12

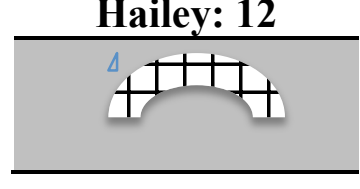

I think that's how I'm reading this. I don't know that I'm right either.

\section{Context of Dialogue Overview}

The dialogue exchange presented above revealed how both participants relied on personal-experiential knowledge to stake their claim about language diversity in the classroom. Indicative of rational discourse, the participants used personal beliefs, counter arguments, and concessions to help them achieve the ultimate goal of critical discussion; where there is a balance of considerations and affordance to see divergent viewpoints. The engagement of argumentation or oppositional perspectives is important because

From a dialogic perspective students must present arguments, ideally based on their own beliefs or values that lead to a divergence of opinion. Divergence of opinion is necessary because it allows students to form and take ownership of their ideas as they are challenged by the other participants with different beliefs (Keefer et al., 2000, p. 61) 


\section{Visual Coding Findings}

Marked by the visual coding system created above, the start of the conversation reflected critical discussion where arguments and counter arguments were presented on both sides as a means to greater understanding (Keefer, 2000). But as Morgan started to rely on experiential counter arguments in verbal exchanges three, five and seven , Hailey relinquished her critical stance as evidenced by her terms of consensus ("yeah", "right"), found in verbal exchanges, six, eight, ten and twelve which shifted the discourse into ordinary conversation,. Perhaps Hailey's lack of experiential or factual knowledge relative to linguistic variation prevented her confronting Morgan's argument further. Nonetheless, the conversation came to an anti-climactic close where both participants ended with polite statements found in exchanges, 8-12 of "I don't know", to ease the tension of the exchange; which weakened the fortitude of each argument, resulting in a lack of clarity on both sides.

\section{Tiptoeing on Criticality}

The heading, "Tiptoeing on Criticality" reflects the swaying negotiations that Morgan and Hailey endorsed as their positionalities wavered between the safe space of college student, and critical challenger. To parse out this idea of critical challenger, I look to Bell hooks' notion of "Radical Openness" which she describes as an "openness to ideas and ability to engage in challenging, probing, and penetrating dialogue as a site of resistance" (p. 43, 2004). Similar to hooks, I define critical challenger as a disposition which exhibits a willingness to critique, or resist oppressive ideologies. From this perspective, Hailey exhibited a disposition of critical challenger when she critiqued 
Morgan's narrow representation of linguistic diversity as evidenced by exchanges two and four of the visual coding system.

Though Allison and Josh were present during this exchange, it was Hailey who made a conscious choice to challenge Morgan's statements. Hailey's outward objection to Morgan's responses is important to note in reference to study aims and purposes. Specifically, engaging in oppositional verbal exchange is uncommon and uncomfortable for most PSTs. This is especially true when you consider PSTs conversational experiences have been predicated on politeness, correctness, and conformity (Bissonnette, 2016). In her research on "niceness" and culturally responsive teacher preparation, Bissonnette states:

Perhaps the greatest obstruction to preparing literacy practitioners to teach in culturally responsive ways lies in the challenge of disrupting the culture of niceness that imperceptibly osmoses many teacher education programs. This construct allows PSTs to offer "nice", liberal-oriented insights without truly engaging in the complex, and arduous, self-reflection processes culturally responsive teaching requires. $(2016$, p.10)

I assert that Hailey's first challenge to Morgan's statement positioned her critical posture which forced Morgan to justify her stance therein shattering the safety of "niceness". Hailey's initial challenge to Morgan's comment served as a catalyst to the dialogic exchange. However limitations of this work were also identified within this exchange. Though Hailey was critical of Morgan's comment, in verbal exchanges, six, eight, ten, and twelve, we saw Hailey rescind her position, and concede to Morgan's weak justification, also noted in the paragraph above.

\section{Context of Dialogue Summary}


On a broader level, this dialogic examination sheds light on the power of sculpting critical spaces, which push PSTs to question, challenge, and explore ideological conundrums that make salient their own attitudes towards education. Providing this foundation helps novice educators to cultivate their professional identities prior to entering the classroom. By combatting and/or consenting with divergent perspectives, Morgan and Hailey were forced to take stances that helped to fortify their positionalities.

\section{Research Question 2 Summary}

For Research Question 2, my interpretation of the findings is based upon the percentages of verbal exchanges, and the context of dialogue analysis. Findings reflect that participants understanding of critical content was leveraged further when discussion entered into higher levels of verbal exchange. When conversations lingered within ordinary verbal exchanges, students were able to stay in a conversational safe zone, where opportunity for critical engagement was lacking. However, when conversations entered into skilled, personal narrative, or dialogue exchanges, the opportunity to wrestle with critical notions was amplified. The strategic nature of each CIE aimed to provide a disorienting dilemma coupled with a time for rational discourse. It is within rational discourse that experience and critical reflections are played out. Discourse became the medium for critical reflection where experience is reflected upon and assumptions and beliefs are questioned to therein make new connections and meaning (Mezirow, 1995). 


\section{CHAPTER V}

\section{DISCUSSIONS \& CONCLUSIONS}

To provide PSTs with the skills to meet the needs of CLD students they must have opportunities to interrogate how social issues affect the learning outcomes of diverse students, and what this means as they attempt to teach within a multicultural society (Douglas \& Nganga, 2015; Palmer \& Larey, 2016). This level of critical analysis requires PSTs to acknowledge systemic inequities that may challenge mainstream understandings of teaching and learning. According to Comber (2001), "Critical literacies involve people using language to exercise power to enhance everyday life in schools and communities, and to question practices of privilege and injustice" (p. 1) This study was

designed to examine the tools PSTs used to create new knowledge around critical literacy in a literacy methods course. Four pre-service teachers were presented in this work to uncover how they made sense of literacy methods curriculum that embedded elements of criticality which pushed them to critique, resist, and re-design traditional literacy practices.

Drawing on four bodies of interrelated research, critical literacy, teacher education, PST disposition, and intersectionality, this study considered how PSTs mediated their understanding of critical literacy through interaction with critical curriculum, and collaboration. Describing the influence that critical curriculum and 
collaboration had on PSTs understanding of critical literacy provides insight into how PSTs begin to think about criticality in a methods classroom. 
To better understand how PSTs made sense of critical pedagogy, I created the following research questions:

1: What do reflective writings, reveal about the ways pre-service teachers construct meaning around critical perspectives in literacy education?

2: How do pre-service teachers use collaborative discussion to construct meaning around critical perspectives in literacy education?

The paragraphs that follow will discuss the major elements of this study in three parts: first a summary of methodology and study findings; second, a discussion of implications based on findings; and third recommendations for educational researchers, teacher educators, and teacher preparatory programs.

\section{Summary of Methodological Details}

During the spring semester of 2017, I facilitated seven learning sessions called Collaborative Inquiry Engagements (CIEs) within the EDTP 320 literacy methods course, where I acted as a co-teacher in conjunction with the instructor. I attended 12 out of 14 classes; to build rapport with students and ensure my learning sessions aligned with the instructors' lesson focus of the week. Each learning session was inquiry-based and allowed students to engage with critical literacy exercises that merged theory and practice. To better understand how PSTs made sense of the learning sessions, I collected three forms of data from four focal students- Hailey, Allison \& Josh which included: a) audio recordings of small group conversation, b) PST participants' critical reflective writings, c) PST participants intersectional pre/post survey. 


\section{Overview of Research Findings and Insights}

In this exploratory study, I analyzed the written reflections and small group discussions of Hailey, Allison, and Josh to better understand how they made meaning of critical literacy practices in a literacy methods course. This analysis revealed how PSTs engaged, and grappled with thinking about literacy in non-traditional ways. The following section revisits the research questions, which guided my study, and a summary of findings for each.

\section{Research Question 1 Summary of Findings}

Research Question 1: What do reflective writings, reveal about the ways pre-service teachers construct meaning around critical perspectives in literacy education?

For research question 1, analysis of findings was based on four critical reflections produced by PSTs. In this study, critical reflection was a part of the CIE curricular framework, which sought to open space for Hailey, Allison, and Josh to wrestle between preconceived notions of literacy and new understandings of critical literacy. PSTs critical reflections revealed that a curricular event, collaborative event, or both facilitated their sense making of critical literacy, represented by 7 themes listed below:

1. Curriculum as Catalyst

2. Equitable Perspectives

3. Challenging Traditionalism

4. Questioning Practicality of Critical Literacy

5. Re-Conceptualizing Literacy within Critical Contexts

6. Collaboration as Catalyst 


\section{Stepping out of Comfort Zones}

A thorough explanation of each theme is explicated further in chapter 4 . However, each theme is integral to the summary of findings in that elements of each are represented throughout this section.

An overall summary of findings suggests that for novice educators, "taking on" critical literacy can be a complex process. First, this orientation to literacy reaches beyond typical linear models that only focus on phonics, fluency, and comprehension. In addition, enacting critical literacy in the classroom requires multiple considerations which could include: critically geared curriculum selection, critically oriented instructional decisions, and the appropriateness of critical content based on student development. These multiple considerations were evident for Hailey, Allison and Josh as they struggled with how to mechanize critical literacy in real world settings. The theme, Questioning the Practicality of Critical Literacy, reflects their hesitation in using critical literacy with young students:

I think elementary age students would look at stories like The Three Little Pigs and see it for something cute and funny, I don't think it would be their first thought to try and analyze and find details like older students would right off the bat. (Hailey, CIE 1 Reflection)

I think this activity might be challenging because students, especially those of younger ages, are often very egocentric and may find it difficult to grasp this concept. It's also something that is fairly abstract and can be difficult to represent in a concrete manner that may also be another road block for students' understanding. (Allison CIE 1 Reflection)

I think the questions may be difficult for K-3 classrooms, however it would help in the development of perspective. (Josh CIE 1 Reflection)

The tension between what critical literacy is as a theoretical orientation, and how

to practice it, is a normal challenge for even experienced teachers (Lewison et al., 2008). 
I was not surprised when the data revealed that Hailey Allison and Josh approached critical pedagogy cautiously. Their positions seemed to vacillate between the tension of adopting a critical stance, and the practicality of making space for these stances within an elementary classroom.

Though each participant encountered challenges in conceptualizing the practicality of critical literacy, they also identified a CIE lesson, which further facilitated their understanding. In the final intersectional survey of the course Hailey, Allison, and Josh shared which CIE served as the most influential in their understanding of critical literacy. To select the most meaningful CIE I asked students to rank each activity based on what they gained from the lesson. Hailey's number one ranking was the 3 Hats Multiple Perspectives lesson, which focused on immigration, the ban on Muslims in the United States and featured video clips from Malala Youfsafzai, and Donald Trump. Hailey states, "I liked the activity where we had to write from completely different perspectives. It really helped me TRY to understand other people's view on a topic, even if their opinion was completely different".

Allison's rank mirrored Hailey's, in that the 3 Hats activity was the most meaningful for her. Allison states, "This resonated with me because writing from multiple perspectives forced me to see things from the other side, which was very challenging but beneficial and necessary when critically analyzing something." For Josh, he felt the most beneficial lesson was the Linguistic Variation lesson centered on running records and African American Language. Josh states, "This section resonated with me personally. Much of what we discussed was in question for me and it was nice to see that 
neither side was wrong." It is interesting to note that none of the PSTs chose CIE 1

which focused on traditional literature (3 Little Pigs) and was the most concrete and least controversial of all of the learning sessions. This could point to PSTs elevating comfortability with critical concepts in the classroom, and their interest in exploring nontraditional literacy topics.

Based on Hailey, Allison, and Josh's intersectional end of course survey, they believed that learning about critical literacy was meaningful for them. This perspective was most pronounced in their response to question 5, which asked them to share major takeaways from their experience with critical literacy. In response to this question Hailey stated, "Going into teaching, I think I will be more comfortable talking about thinking critically and pushing my students to do the same.'(Hailey Final Reflection). Allison stated, "While it may be difficult from the teachers' perspective, it's eye opening and meaningful to students!" (Allison Final Reflection). Josh shared that, "Overall my perspective has been broadened if not exactly changed. It was largely beneficial” (Josh Final Reflection). Though each participant formed individualized understandings of critical literacy, their reflections revealed a shift in thinking which stemmed from reading, discussing and practicing critical literacy.

\section{Research Question 1 Findings Summary}

The critical reflections of Hailey, Allison and Josh, speak to the ways in which they embarked upon altering their pre-existing understanding of literacy pedagogy and practice. Using critical reflection to understand how PSTs internalized critical literacy was helpful in identifying how their meaning making schemas shifted by interacting with 
the CIE curricular framework. Mezirow asserts "for learners to change their meaning schemes, they must engage in critical reflection of their experiences, which in turn leads to a perspective transformation (1991, p. 167). The power of employing critical reflection for Hailey, Allison, and Josh, made room in the methods classroom for thoughtful analysis of new modes of thinking, being, and acting critically.

The process of critical reflection promotes a type of self-examination that forces one to question pre-conceived assumptions, values, and belief systems (Brown, 2004). Critical reflection according to Mezirow (1991) supports adult learners to become "aware of oppressive structures and practices, develop tactical awareness of how they might change these, and build the confidence and ability to work for collective change" (Brown, p. 85, 2004). For Hailey, Allison, and Josh, the act of critical reflection illustrated their questions, assumptions, and new thinking centered on critical literacy. I assert, when PSTs are provided the space to critique, resist and re-design their own assumptions about what it means to be literate they have the latitude to explore literacy in a broader context (Williamson, 2013).

\section{Research Question 2 Summary of Findings}

Research Question 2: How do pre-service teachers use collaborative discussion to construct meaning around critical perspectives in literacy education?

Research question 2 findings reflect analysis based on three learning sessions, which analyzed small group discourse that took place three times throughout the course. The summary below will provide a collective examination of findings based on the two different modes of discourse analysis, which included: a) Verbal Exchange Coding framework (Goodall, 2000) b) Context of Dialogue framework (Keefer, 2000) 
The utility of using two discourse analysis strategies, offered me the benefit of analyzing participant discussion from macro and micro levels. My aim for research question 2 sought to uncover how Hailey, Allison, and Josh used rational discourse to better make meaning of critical literacy. Mezirow views rational discourse as a platform for "testing the validity of one's construction of meaning" (1991, p. 35). Therefore, findings were used to uncover how often PSTs language reflected elements of Dialogue defined by Goodall (2000) as the place "in which conversation transcends information exchange and the boundaries of self and moves into higher levels of spontaneous ecastic mutuality" (p. 238); and Critical Discussion where the goal of discussion "hinges on divergent viewpoints, which allow PSTs the space to present their opinion in relation to others" (Keefer, 2000, p. 42). Analysis of these two dialogic structures was important to understanding how PSTs used language because it was within these structures that their voices began to gain volume, where they veered away from politeness and social formality and revealed personal attitudes which were alternative or controversial to the group.

\section{Verbal Exchange}

I used Verbal Exchange Coding, to examine how often Hailey, Allison, and Josh engaged in various forms of conversation based on the Verbal Exchange hierarchy. Each rung on the ladder of Verbal Exchange provided a support in elevating conversation to higher levels, which heightened the potentiality for critical engagement. Findings revealed that small group conversation entered into Dialogue as defined by Goodall, when students began to feel comfortable sharing personal and cultural attitudes. As PSTs engaged in conversation to unpack controversial elements of the CIE's they were pushed 
to reveal personal aspects of themselves that sometimes took on critical stances. While at least $40 \%$ of all verbal exchange for this study stayed within an area of skilled conversation, an example of when PSTs shared social critique which is represented by the example below from CIE 3 learning lesson.

Allison: Things like that... Social issues like that? As much as it will be un comfortable for future teachers in two years, we're still going to be dealing with these same kinds of social issues that we're just touching on right now. How do you handle that with a fifth grader that asks you a question about some of these things because he read it on Facebook? Do you turn it into a teachable moment and talk about bias or without getting parents on your back, you don't want to... you don't want to be biased in a classroom but how do you teach these things without ruffling some feathers? - Personal/Dialogue

Josh: And I think that's why teachers tend to avoid it, because they know how it should ... Because I mean, no matter what your political views are, you can look at our election this year and it was not one side compromising with the other, its completely two different sides, and if you take one side you don't understand the other side...- Dialogue

Allison: There's not the other side...- Skilled

Josh: Yeah and that's because... it starts at an elementary level where teachers aren't teaching that to students. How to sit and listen to the other person's point of view.- Dialogue

Allison: It's a delicate balancing act, and with that the parents' sides are then communicated to the kids who you know. That's the natural way of things. - Skilled

Hailey: Right, yeah. - Ordinary

Allison: And then so I don't know if any of you guys have had any experiences in your placement during the election last year, different things were said...Dialogue

Hailey: Yessss. One of my Muslim students asked if she was going to be sent back to Africa! - Dialogue

Allison: What? No! Yeah literally, and how do you handle that? - Dialogue Hailey: Or asking the questions for our social studies class this semester. Students they understand a lot more than what you think. - Dialogue

Josh: Yeah- Ordinary

Hailey: I don't know if they actually know in depth information about it, but they've heard this stuff so they're starting to analyze. So they've got the first step. - Dialogue

Based on the categorization of verbal exchange, Hailey, Allison, and Josh,, used the 3

Hats multiple perspectives lesson as a vehicle to share their personal opinions about 
addressing critical social issues in the elementary classroom. The elements represented through PSTs exchange reflected that of a critical stance as identified by Lewison et al. (2008). Lewison provides four dimensions that help identify the attitudes and dispositions that learners adopt as they begin to develop their critical awareness (Scherff, 2012). Through their honest discussion Hailey, Allison, and Josh began to reveal dispositions that embodied Lewison's definition of conscious engagement, where they moved beyond simple responses into thoughtful engagement to name and reframe controversial social issues. This mode of renaming was most pronounced in Josh's critique teachers, and their lack of teaching students how to handle alternative perspectives in the elementary grades. What was interesting about this exchange was the bold risk that Josh took through his discussion to challenge the status quo.

Teacher preparation that arms PSTs with the skills to think independently and interrogate critical issues, may look to rational discourse as an effective method to further

cultivate their critical stance. However, many PSTs are confined by their adherence to traditional school-based ideologies, which define the role of student as passive and polite (Bissonette, 2016). The role of politeness can hinder rational discourse for PSTs, because this orientation to discussion promotes a preoccupation with niceness that prevents students from taking on new discourses that take risks.

\section{Context of Dialogue}

To better understand how PSTs used language during Dialogic exchanges I used Keefer et al. (2000) framework entitled, The Context of Dialogue to help me identify how PSTs use language as a semiotic device to manage, negotiate, and navigate conflict and 
consensus (Keefer et al., 2000). A more thorough definition of each level of Context of Dialogue framework and its definitions is provided in Chapter 4 (Findings). The dialogue examined through the Context of Dialogue framework was categorized as critical discussion. Keefer et al. suggest the essential goal of critical discussion hinges on divergent viewpoints, which allow PSTs the space to present their opinion in relation to others.

Findings from the Critical Discussion highlighted a short exchange between Morgan and Hailey, where they engaged in a verbal disagreement. To better understand how Morgan and Hailey used critical discussion to navigate their different opinions, I developed a visual coding system (chapter 4) that helped me make sense of their interaction. The visual coding system revealed that Hailey used her critical stance to question and confront Morgan's comment about linguistic variation, which reflected a hegemonic stance. However, as Morgan relied on personal experience to substantiate her claim, Hailey's relinquished her position as challenger by becoming reluctant to Morgan's attempts to defend her comment.

What is interesting to note from this exchange are the ways in which both were projecting a specific stance. During this interaction, Hailey and Morgan left the comfortability of polite student and made a conscious decision to interrogate and investigate each other's claim. This kind of disposition represents conscious engagement (Lewison, 2008), through actively responding to divergent viewpoints. Further, Hailey's willingness to confront Morgan's hegemonic comment represents what Lewison defines as taking responsibility to inquire, which signifies any action that confronts ideologies which threaten the tenets of critical pedagogy. 
In chapter 4 of my dissertation, I qualify Hailey's bold objection as taking up a critical challenger disposition because she exhibited a willingness to critique and resist Morgan's hegemonic rhetoric. From this perspective, teacher education needs to conduct more research on when and why PSTs enact critical dispositions in whole or small group interactions. Research in this area could provide greater insight into effective models of critically engaged curriculum that provide the support for students to engage in critically responsible dialogue with peers.

\section{Research Question 2 Findings Summary}

Affording Hailey, Allison and Josh opportunities to engage in interactive discussion that interrogated and challenged traditional viewpoints was critical in helping them develop their critical literacy awareness. Teacher educators can provide support and encouragement to PSTs as they attempt to leverage new ideas and begin to view education through a critical lens. In my study, I used various forms of discussion (whole, small, one-on-one, virtual) to help students rehearse actions, and recognize conflicting ideas between traditional literacy and critical literacy. Teacher educators can use reflective discussion as a place to have PSTs analyze, and respond to varying notions of literacy in the university classroom, engage in critical examination of practices, and construct personal stances. 


\section{Discussion \& Implications}

The following sections discuss implications gathered from study findings, observations, and research log notes. Here I provide implications that link the strategies I used to create a classroom environment that supported PSTs in exploring critical literacy concepts.

\section{Critically Cultivated Curriculum}

One implication from study findings suggests that critically infused curriculum has the potential to push students to think about literacy in new ways. If the goal is to create opportunities for critical reflection on systemic social issues that may affect CLD students, then PSTs need explicit models of how to adopt and enact critical lessons that interrogate those concepts through interaction with critically based lessons. For this study, critically based curriculum was mechanized through the Collaborative Inquiry Engagements (CIEs), which provided a consistent curricular structure that guided the seven learning sessions. Because the construction of the CIEs were grounded by Mezirow's (1991) Transformative Learning Theory, they aimed to make small shifts in PSTs meaning structures through interaction with the disorienting dilemma, rational discourse, and critical reflection. Mezirow asserts that these three elements are what lead to perspective and meaning transformation (1991).

Specifically, the CIE instructional framework uses the disorienting dilemma, rational discourse, and critical reflection as scaffolds to support new knowledge construction by providing a balance of explicit modeling, small and whole group discourse, and written reflection. Though the CIE's relied heavily on the three domains of 


\section{Transformative Learning Theory (Mezirow, 1991) the mechanizing of each directly}

reflected the research questions that guided the study, relative to study outcomes. The

figure below shows how I utilized each transformative domain from an instructional

standpoint, and its purpose for my study.

\section{Transformative Learning Domains}

\begin{tabular}{|c|c|c|c|}
\hline & Disorienting Dilemma Domain & $\begin{array}{c}\text { Collaborative Discussion } \\
\text { Domain } \\
\end{array}$ & Critical Reflection Domain \\
\hline \multirow{3}{*}{ 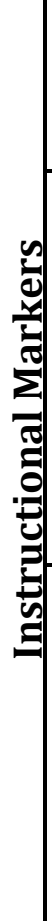 } & $\begin{array}{l}\text { a). Instructor introduces Critical } \\
\text { Literacy concept (critique, resist, } \\
\text { re-design) through engaging } \\
\text { format. }\end{array}$ & $\begin{array}{l}\text { a). Small groups dissect } \\
\text { instructor's modeled lesson } \\
\text { to understand it's parts, and } \\
\text { ask further questions relying } \\
\text { on peers for support. }\end{array}$ & $\begin{array}{l}\text { a) Students respond to critical reflections } \\
\text { questions independent of small or whole } \\
\text { group influence, outside of the classroom } \\
\text { setting. }\end{array}$ \\
\hline & $\begin{array}{l}\text { b). Instructor uses inquiry to } \\
\text { explore different points of view } \\
\text { through whole group question } \\
\text { and answer. }\end{array}$ & $\begin{array}{l}\text { b). Small groups "try-on" } \\
\text { strategy through role-play or } \\
\text { active engagement with } \\
\text { strategy. }\end{array}$ & 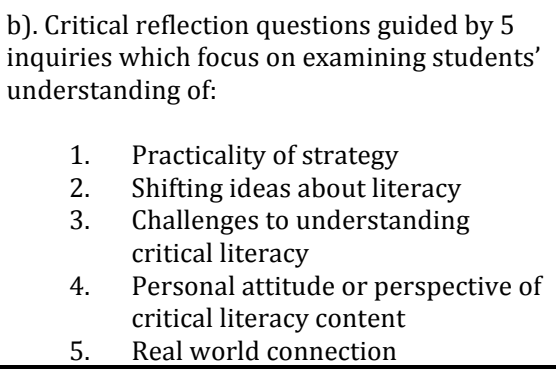 \\
\hline & $\begin{array}{l}\text { c). Instructor teaches critical } \\
\text { literacy strategy through explicit } \\
\text { modeling of practice to show } \\
\text { classroom application. }\end{array}$ & $\begin{array}{l}\text { c). Small groups discuss } \\
\text { convergent or divergent } \\
\text { viewpoints about critical } \\
\text { literacy concept and its' } \\
\text { application in the classroom. } \\
\text { Small groups ask further } \\
\text { questions that need } \\
\text { clarification from instructor. }\end{array}$ & $\begin{array}{l}\text { c). Instructor uses critical feedback to develop } \\
\text { future lessons based on student attitude, } \\
\text { lingering questions, and understanding of } \\
\text { critical literacy concepts based on student } \\
\text { reflection responses. }\end{array}$ \\
\hline \multicolumn{4}{|c|}{ Intended Purpose } \\
\hline & $\begin{array}{l}\text { Exposure to sociopolitical issue, } \\
\text { and how to teach it through } \\
\text { literacy. }\end{array}$ & $\begin{array}{l}\text { Collaborative time without } \\
\text { the guidance of the } \\
\text { instruction to make sense of } \\
\text { new learning obtained from } \\
\text { disorienting dilemma. }\end{array}$ & $\begin{array}{l}\text { Independent time to work through new ideas } \\
\text { acquired from the disorienting dilemma and } \\
\text { collaborative discussion. }\end{array}$ \\
\hline
\end{tabular}

Table 13. Critical Instructional Framework

\section{Open Learning Environment}

Initiating dialogue about oppression and privilege can be a challenging endeavor

in the university classroom. This notion is compounded when PSTs are White and middle

class. Blumenfeld and Jaekel note, that White novice educators may be hesitant to discuss 
issues related to social inequities, which include talking about how power and privilege impact the educational opportunities of some and not others. Further, socially and politically charged conversations often become even more complex when facilitated by female faculty of color (Haddix, 2015; Ladson-Billings, 1996; Stanley, 2006).

Consequently, a major component of this study predicated on discussing and analyzing controversial topics in whole group and small group settings. Considering the challenges of being an African-American female instructor broaching the concept of privilege, and equity with predominately White and middle-class students, I created a critical-intersectional framework, which served three main purposes in discussing privilege and oppression with PSTs, these include:

1) Support PSTs to amplify their critical self-awareness, and social location.

2) Introduce PSTs to critical habits of mind, which challenge status quo interpretations of society through literary analysis, dialogue and reflection.

3) Honor PSTs multiple identities beyond just race to help them acknowledge social inequities based on race, gender, socioeconomic status, sexual orientation, national origin, language proficiency, and body shape and size.

The first tenant of the critical-intersectional framework is critical self-awareness. Researchers steeped in critical multicultural education, deem self-awareness as one of the most important aspects in acknowledging and accepting multicultural outlooks (Banks, 1994; Brown, Panham, \& Yonker, 1996). Hence the first instructional step of the criticalintersectional framework heightens students' intersectional social location, to help them develop a realistic sense of their social status in the world. To do this, I share with them 
the Matrix of Oppression (Collins, 1991), which explicitly illustrates how various intersectional identities position us as oppressed or privileged beings, based on socially accepted definitions of dominant norms.

Upon sharing my own intersectional positionality, as multi-oppressed and multiprivileged, students begin to examine their own intersectional identities to reveal how multiple identities (race, gender, class, sexual orientation etc.) have shaped their outlook on education and their experience in the world. This form of self-discovery is indicative of what Freire (1994) calls "critical consciousness". Through the process of identifying and naming how various identities have positioned them in society, students begin to interrogate and question how these intersecting realities have supported or sustained their educational experiences. Through open conversation facilitated by me, we begin to unpack how students from diverse cultural, social, linguistic, and economic backgrounds are positioned in society to succeed or fail based on their social location. Specifically, I used active engagement and real-world scenarios to help PSTs think about how race, culture, class, and gender impact the literacy achievement outcomes of themselves as well as CLD students.

Considering research which suggest that some White PSTs resist multicultural frameworks due to White shame, cultural misunderstanding, and ethnocentrism, the critical-intersectional framework works to broaden PSTs cultural lens to better understand social inequities that affect CLD students, and how adopting a critical approach to teaching and learning can support them in creating equitable classrooms.

Since this was the first time the critical-intersectional framework was used to support PSTs discussion of controversial topics in the methods classroom, the present 
study is exploratory and does not provide definitive analysis. However, based on student feedback, reflection, and small group discourse, I believe this non-traditional approach to curriculum and instruction allowed PSTs to enact alternative identities outside of raceto cultivate open dialogue about privilege power and oppression.

The critical-intersectional framework needs to be further tested in various settings and contexts to better understand the role it plays in supporting PSTs social awareness. Addressing inequities within educational practices that center on race, privilege, and institutionalized oppression are weighty topics that may cause PSTs to withdraw from classroom conversation, or disengage from instruction. A critical-intersectional approach could provide teacher educators with pedagogical avenues to address these hesitations preemptively, offering space to counter and circumvent PST resistance of non-dominant discourse around educational equity.

In conjunction with the critical-intersectional framework, I employed a coconstructed learning approach. Freire states, "that to teach is not to transfer knowledge but to create the possibilities for production or construction of knowledge" (1998, p. 30). From this perspective, I recognize that the function of "teacher" is "more as a facilitator who coaches, mediates, and helps students develop and assess their understanding, and thereby their learning." (Lipez, 2006, p.89). Throughout this study I approached teaching and learning as a reciprocal process where students and I acted as agents of change through collaborative knowledge construction. During critical discussion I was intentional about not holding the absolute truth about every controversial subject. Though students would appeal to me for direct answers to critical questions, I answered many of their inquiries with further questions which facilitated independent thought. The 
strategies I employed were supportive in allowing knowledge to be constructed through a process of interactive collaboration and mutual respect. This kind of open and humanizing classroom environment is necessary as teacher educators interrogate critical conundrums that highlight educational hegemony, oppression, and systemic inequities.

\section{Critical Practitioner}

Efforts to enact criticality into any course will falter if teacher educators are not willing to take critical stances in their classroom practice. Teacher educators have opportunities to engage PSTs in activities specifically designed to increase cultural awareness of inequitable educational practices and recognize opportunities to promote criticality. One way I employed this strategy in my study was through dialogic discussion of modeled teaching practices. This strategy required me to be transparent about my instructional purposes and outcomes, and support students as I pushed them to explore controversial topics through discussion. Teacher educators who are committed to promoting a critical stance must "simultaneously be critically thinking about and inquiring into their own practices" (Scherff, 2012). To enact this I had to be able to accept and encourage critical analysis of my own teaching practices. I did this by journaling in my research log after each learning session, and having extensive debriefing conversations with the teacher of record. This notion reflects Cochran-Smith and Lytle's (2009) idea of inquiry as stance:

Working from and with an inquiry stance, then involves a continual process of making current arrangements problematic; questioning the ways knowledge and practice are constructed, evaluated, and used; and assuming that part of the work of practitioners individually and collectively is to participate in educational and social change. (p. 121) 
The critical practitioner stance, means maintaining a high level of inquiry, reflectivity and reflexivity to continuously raise new questions about ourselves, and about our pedagogy.

Though the ideologies which undergird critical pedagogy predicate on fighting injustice and challenging oppression, translation of these abstract concepts unearths a unique tension as teacher educators look to transform theory into practice for PSTs. Since being a critical practitioner boasts reflexivity and reflectiveness (Darder, Baltodano, \& Torres, 2003; Dewey, 1933), it is important that as we approach the subject of criticality in teacher education we hold a critical awareness about the varying positionalities of our students, and how their life experiences influence their societal outlooks.

For example, we cannot presume to know all of the experiences of White, pre-service teachers by simply acknowledging their race alone. This form of overgeneralization is dangerous because it fails to capture the dynamic identities that comprise their experiences. Freire, in 1970 articulates this point by stating, "Many educational plans have failed because their authors designed them according to their own personal views of reality, never once taking into account to whom the program was ostensibly directed (p.75). Appreciating, acknowledging and understanding how PSTs intersectional identities have shaped their lived experiences can help teacher educators understand how to reach and teach PSTs about critical topics in teacher education.

\section{Critical Literacy Framework}

The three implications noted above were not necessarily tied to my research questions, but were elements that were successful during the study, evidenced from informal observation, my research log, and conversations with the teacher of record. The framework below represents how I make sense of these implications and their 
relationship to one another. At the heart of the framework is the teacher educator whose commitment to criticality is paramount in supporting the other three elements. Without the teacher educator, no other part of the framework can be fully realized. Thus even if TPPs develop critically cultivated curriculum, it is dependent on the teacher educator to build a safe and open classroom environment upon which critical discussions and reflections can occur.

\section{Cultivating Critical Curriculum}

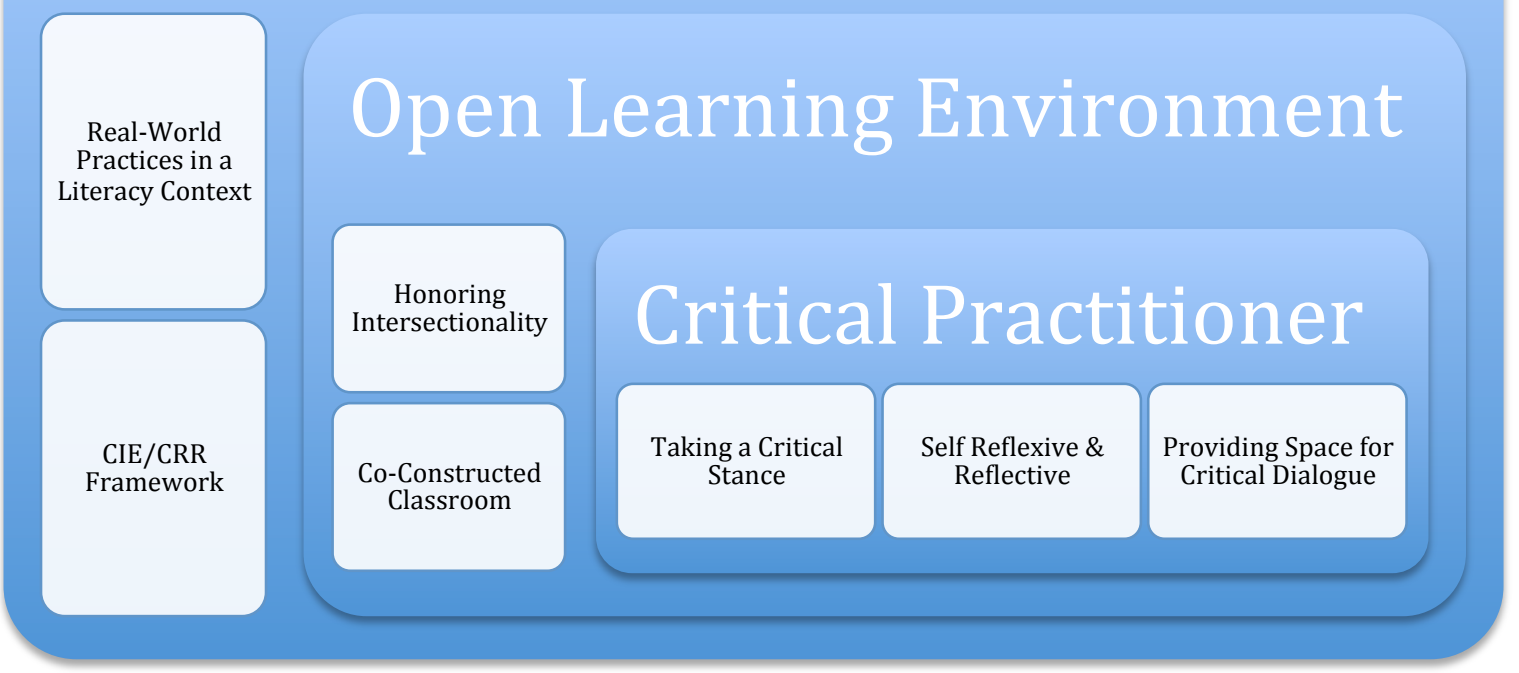

Figure 10. Critical Literacy Framework

\section{Recommendations}

\section{Study Modifications \& Limitations}

In reflecting on the process, design, and findings of my study, I have three modifications for future studies with similar lines of inquiry (critical literacy, pre-service 
teachers, and teacher education). If a study of this nature were replicated some recommendations to acquire more comprehensive findings are listed below.

1. Include focus group interviews

2. Develop a Critical Literacy Awareness survey Pre/Post

3. Add a component that examines practice (observation)

The three modifications above are elements that I wish I had included in my dissertation study. I consider the absence of these three elements to be limitations to study findings. The paragraphs that follow will describe how these elements could have provided a more robust understanding of how PSTs made sense of critical approaches to literacy instruction.

First, I feel that adding at least one pre/post semi-structured focus group interview would have provided a deeper understanding of Hailey, Allison and Josh's underlying and surface level thoughts and feelings about critical literacy. Not having this information forced me to make broad assertions in Chapter 4 (findings) about PSTS motivations and learning relative to the CIE experiences. The information garnered from interviews would have filled in some of the gaps that I still have about PSTs perspectives.

Secondly, I wish I had included a critical literacy pre/post survey. Though I did administer the critical-intersectional survey at the beginning and end of the course, this tool focused mainly on intersectional identities rather than critical literacy. Having an assessment tool that focused solely on critical literacy would provide even more context into PSTs background knowledge and experience with the construct. Further, comparing 
pre/post survey results would given me an better understanding of what students actually learned through the semester long interaction with the CIEs.

The last modification I would have added to my study would be classroom observation. Building on the theoretical tenets of critical theory, true transformation cannot be realized until it is attached to social action or what Freire calls praxis. Since the creation of the CIEs predicated on infusing theory and practice, observing PSTs in their field placements, or with our reading buddies would have provided me another lens of analysis to uncover if PSTs were adopting or abandoning critical instructional strategies in their practice. This addition would have allowed me to evaluate if what I was teaching in the methods classroom was being actualized in a real-world context. Having students practice critical literacy in a classroom setting would have only increased their understanding of the construct, which may have fostered a more solidified critical stance. Though introducing PSTs to critical modes of thinking is important, the ways in which they apply this learning in the classroom with actual students is the true test of their knowledge and understanding.

Explicating the successes and limitations of this qualitative work could inform the much larger conversation around curricular design elements relative to shifts in PSTs perspectives on critical pedagogy. Studies like this one, which seek to investigate how PSTs take up critical approaches to teaching, could be useful in developing syllabi that provide the structures needed to promote this approach. Though I am unable to substantiate that PSTs will utilize critical literacy in their future practice, an extension of this study could re-visit Allison, Josh, and Hailey in their first years as teachers to identify 
if lessons or ideas shared during our 320 course were evident in their planning and practice. However, I would conjecture that PSTs limited exposure to explicit critical literacy instruction might not have been enough to expect it to be seen in their practice.

\section{Methods Classroom as Critical Catalyst}

Though I believe that critically engaged curriculum and instruction are necessary, this complex paradigm cannot be isolated to one course if we seek to provide PSTs with a firm foundation of critical understanding and practice. If we, as higher educational professionals, believe in education that fights against injustice, inequity, and oppression, then our efforts should match our rhetoric. As the terrain of teacher education turns toward social justice, course and program design must be reconceptualized to reflect these goals. Therefore I recommend a united critical curriculum that supports students in their efforts to critique, resist, and re-design inequitable practices that deny the "rich cultural and linguistic legacies of diverse student populations" (Kinloch, 2013, p. 15). My interpretation of a united critical curriculum is one that is committed to criticality in all methods based courses. Considering the criticism of critical theory lies in the lack of practical models which operationalize this strategy, I propose a framework that provides a balanced approach concentrated on embedding one to three critical concepts in each methods course to ensure that the seed of critical literacy is planted and nurtured as PSTs move throughout their teacher preparatory program.

A critically infused united curriculum brings together all professional courses to ensure PSTs are receiving comprehensive exposure to content specific methods within a critical context. Using the University of Louisville's professional program for initial 
teacher certification as an example, the united curriculum could be based on the four dimensions of critical literacy as posited by Lewison, Flint and Van Sluys (2002):

1. Disrupting the Commonplace

2. Interrogating Multiple Viewpoints

3. Focusing on Sociopolitical Issues

4. Taking Action and Promoting Social Justice

Starting with the first literacy course, EDTP 311, and ending with student teaching, students have the opportunity to engage in critical perspectives in each course they encounter based on the four dimensions the figure below represents a tentative model of the scope and sequence of a united critical curriculum.

\section{United Critical Curriculum}

Semester 1

Courses:

1. Writing Methods

2Building Learning

Communities

Critical Focus:

Disrupting the

Commonplace
Semester 2

Courses:

1. Reading Methods

2. Social Studies

Methods

Critical Focus:

Interrogating

Multiple

Viewnoints
Semester 3

Courses:

1. Science Methods

2. Math Methods

Critical Focus:

Focusing on

Sociopolitical

Issues
Student Teaching

Course:

1. Field Placement

2. Critical Literacy

Observation Rubric

Critical Focus:

Taking Action \&

Promoting Social Justice

Figure 11. United Critical Curriculum 
Due to the collaborative nature of the united critical curriculum, such an endeavor would need to be mobilized with support from faculty, staff, and students. To enact this, a critical curriculum committee could be created that included the voices of all methods based faculty (full-time and seasoned adjunct), department chairs, as well as former PSTs. Infusing critical focuses into methods based curriculum would be a large undertaking that would need to be appreciated by the majority of the department in order for it to be conceptualized, created, and implemented. Though the idea of a united curriculum is grandiose, I believe ambitious ideas are needed to develop radically-based curriculum that push PSTs to dismantle systems of educational inequity to meet the needs of $21^{\text {st }}$ century CLD students.

\section{Moving Critical Pedagogy Forward}

As a critical researcher I define critical pedagogy as a framework that examines knowledge and questions the socio-historical constructs of oppression through curriculum (Freire, 2000). Upholding this critical stance prompts me to think about ways of expanding contemporary critical pedagogy to reflect the intersecting cultural, racial, linguistic, and economic realities in which we currently exist. This approach to criticality challenges singular notions of oppression to encompass a broader understanding of how overlapping marginalities situate individuals in the world, and how these societal positions can result in inequitable treatment, outcomes and opportunities. Viewing pedagogy through this lens requires a critical interrogation of how various social positions interact to deny individual access to power, privilege, and resources (Hankivsky \& Cormier, 2011) and the underlying sources of inequality that promulgate these social injustices (Mendieta, 2012, p. 459). 
Though analysis of singular positionalities (race, gender, class, language) are necessary to examine the human condition, many critical pedagogues fall into a pattern of overgeneralizing one or not emphasizing any, which creates an imbalanced portrayal of how social positions affect people differently. Further, single axis conceptions of social positionality relegate individuals to finite and fixed understandings of themselves and their juxtaposition to the world. For example, as a Black female I am traditionally viewed as an oppressed being. Though these two facets (race and gender) of my identity are oppressed, I have multiple identities that are privileged. Acknowledging myself as both oppressed and privileged grants me the power to re-conceptualize my value within society from an asset perspective rather than a marginalized one.

Though an intersectional appreciation does not aim to discount the multiple marginalities of the Black female experience, it does aim to provide a more realistic portrait of lived experiences, which in turn allows historically privileged and marginalized identities to re-name their lived realities through a new lens. Freire (1970) connects the power of "naming" as a necessary component in transforming the world to become more fully human. He states,

Human existence cannot be silent, nor can it be nourished by false words, but only by true words, with which men and women transform the world. To exist humanly, is to name the world, to change it. Once named, the world in its turn reappears to the namers as a problem and requires of them a new naming. Human beings are not built in silence, but in word, in work, in action-reflection. P.69

Based on Freire's conception of critical consciousness (Freire, 1970), I argue that a more 
enlightened understanding of identity would account for the diverse tapestry of our lived realities, which honors our privileges and oppressions to represent a more holistic interpretation of our lives.

As critical pedagogy continues to grow and evolve, what is needed now is a shift that resembles the multifaceted colors, cultures, and challenges of $21^{\text {st }}$ century people. This begins with a greater understanding of how to critique, resist, and re-design intersected positions of societal oppression "to empower the powerless and transform existing social inequalities and injustices" (McLaren, 2003, p.160). This mode of critical awareness retreats from overgeneralized notions of identity to encompass a more inclusive critique of the complexities of our identities as multi privileged and oppressed beings. This critical analysis provides a new naming that allows the privileged to support the oppressed and the oppressed to support the privilege as we work as a collective to become more fully human and humane. 


\section{Conclusion}

This activity helped me think about critical literacy in a new and good way. Sometimes I think we as teachers think of literacy as analyzing writing and reading the text, when it is so much more than that. This had me look at literacy in a way that incorporated

perspectives, writing, analyzing, and so much more. It pushed me to step outside of myself and try stepping into others shoes which is often hard for kids to do. Especially for little kids, I think they struggle with seeing any other perspective but their own; this activity MAKES them do it. (Hailey, CIE 2 Reflection)

Hailey's quote above resonated with me because it shares her excitement in learning about literacy "in a new and good way"; which was the overall purpose of this study. Acknowledging that literacy achievement is heavily connected to the racial, cultural, and socioeconomic backgrounds of k-12 students, the overarching purpose of this work aimed to raise the critical awareness of four PSTs to help them understand the socially constructed nature of literacy through critical literacy practices. Understanding how PSTs access and think about critical ideologies is important, because it provides a snapshot of the ways in which they approach issues of justice, equity, and oppression. Having a firm grasp on the ways PSTs interrogate critical ideas provides a foundation to develop lessons, syllabi, and programs that provide the multiple dimensions to support their critical outlook.

Throughout this study Hailey, Allison, and Josh revealed parts of themselves through their writing and discussion, which granted insight as to how they were affected by critical literacy. I share this work to continue the conversation around enacting critical pedagogies in higher education in hopes of opening new modes of thought for curricular development and application. To honor Hailey, Allison, and Josh's words the word cloud 
below captures the essence of their shared experience around critical literacy based on the Research Question 1 theme entitled, "Challenging Tradition/Taking Risks".

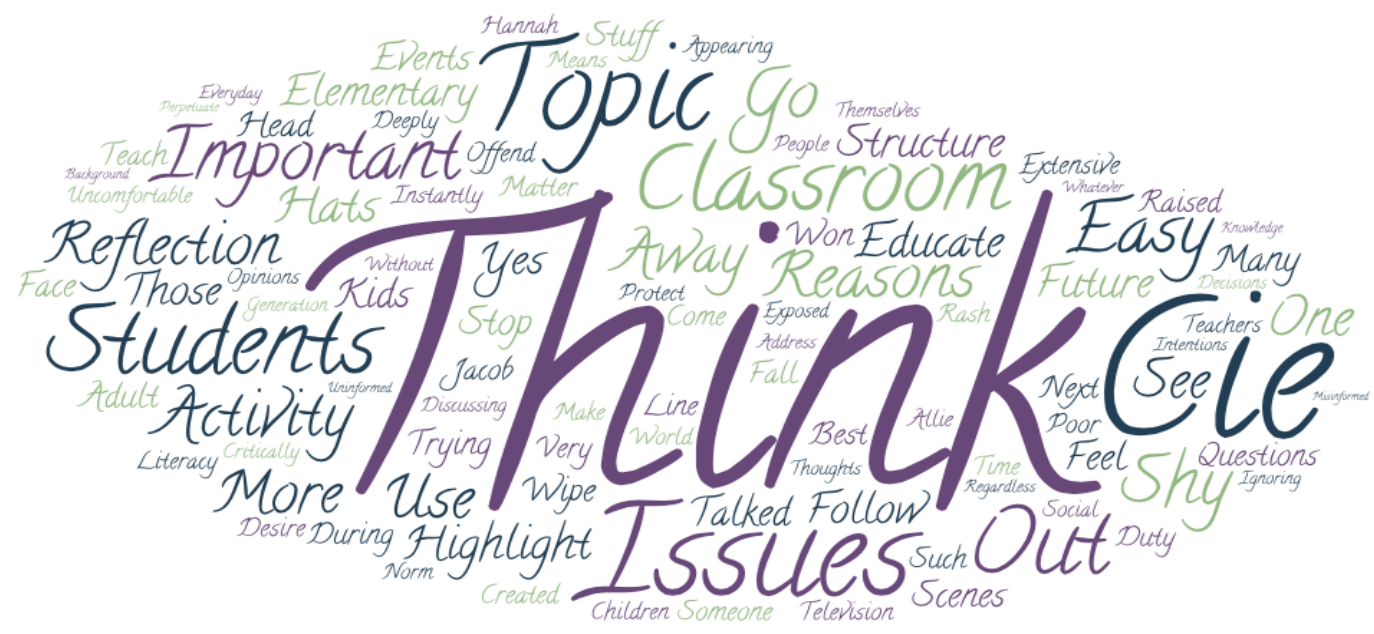

Figure 12. Hailey Allison, \& Josh Word Cloud 


\section{REFERENCES}

Abednia, A., \& Izadinia, M. (2013). Critical pedagogy in ELT classroom: Exploring contributions of critical literacy to learners' critical consciousness. Language Awareness, 22(4), 338-352.

Allen, R. L., \& Rossatto, C. A. (2009). Does critical pedagogy work with privileged students? Teacher Education Quarterly, 36(1), 163-180.

Altheide, D. L. (1987). Reflections: Ethnographic content analysis. Qualitative sociology, 10(1), 65-77.

Anderson, G. L., \& Irvine, P. (1993). Informing critical literacy with ethnography. In. C. Lankshear \& PL McLaren,(Eds.) Critical literacy: Politics, praxis, and the postmodern (pp. 81-104).

Apple, M. W. (2005). Education, markets, and an audit culture. Critical Quarterly, $47(1-$

2), 11-29.

Ball, A. F., \& Ellis, P. (2008). Identity and the writing of culturally and linguistically diverse students. Handbook of research on writing: History, society, school, individual, text, 499-513.

Ball, D. L., \& Forzani, F. M. (2009). The work of teaching and the challenge for teacher education. Journal of Teacher Education, 60(5), 497-511.

Banks, J. A. (2001). Citizenship education and diversity: Implications for teacher education. Journal of teacher education, 52(1), 5-16. 
Banks, J. A., \& Banks, C. A. M. (2009). Multicultural education: Issues and perspectives. John Wiley \& Sons.

Banks, J. A. (1994). An introduction to multicultural education. Allyn and Bacon Inc., 160 Gould St., Needham Heights, MA 02194.

Bartolomé, L. I., \& Trueba, E. T. (2000). Beyond the politics of schools and the rhetoric of fashionable pedagogies: The significance of teacher ideology. Immigrant voices: In search of educational equity, 277-292.

Bartolome, L. I. (2004). Critical pedagogy and teacher education: Radicalizing prospective teachers. Teacher Education Quarterly, 31(1), 97-122.

Bassey, M. O. (1999). Western education and political domination in Africa: A study in critical and dialogical pedagogy. Greenwood Publishing Group.

Bissonette, G. B., \& Roesch, M. R. (2016). Development and function of the midbrain dopamine system: what we know and what we need to. Genes, Brain and Behavior, 15(1), 62-73.

Blackburn, M. V., \& Smith, J. M. (2010). Moving beyond the inclusion of LGBT themed literature in English language arts classrooms: Interrogating heteronormativity and exploring intersectionality. Journal of Adolescent \& Adult Literacy, 53(8), 625-634.

Blumenfeld, W. J., \& Jaekel, K. (2012). Exploring levels of Christian privilege awareness among preservice teachers. Journal of Social Issues, 68(1), 128-144.

Bonilla-Silva, E. (2006). Racism without racists: Color-blind racism and the persistence of racial inequality in the United States. Rowman \& Littlefield Publishers. 
Taylor, S., Brock, C. H., Case, R., \& Taylor, S. S. (2013). Dilemmas in guiding preservice teachers to explore literacy instruction and diversity. Teacher Education Quarterly, 40(1), 81-100.

Burton, D., \& Bartlett, S. (2009). Key issues for education researchers. Sage Publishing. Case, K. (2013). Deconstructing privilege: Teaching and learning as allies in the classroom. Routledge.

Case, K. (Ed.). (2013). Deconstructing privilege: Teaching and learning as allies in the classroom. Routledge.

Cervetti, G., Pardales, M. J., \& Damico, J. S. (2001). A tale of differences: Comparing the traditions, perspectives, and educational goals of critical reading and critical literacy. Reading online, 4(9), n9.

Charmaz, K. (2014). Constructing grounded theory. Sage.

Christensen, L. (2000). Reading, writing, and rising up. Milwaukee, WI: Rethinking Schools.

Chubbuck, S. M. (2010). Individual and structural orientations in socially just teaching: Conceptualization, implementation, and collaborative effort. Journal of teacher education, 61(3), 197-210.

Hill Collins, P. (2010). The new politics of community. American Sociological Review, 75(1), 7-30.

Collins, P. H. (2003). Some group matters: Intersectionality, situated standpoints, and black feminist thought.

Collins, P. H., \& Bilge, S. (2016). Intersectionality. John Wiley \& Sons. 
Crenshaw, K. (1989). Demarginalizing the intersection of race and sex: A black feminist critique of antidiscrimination doctrine, feminist theory and antiracist politics. $U$. Chi. Legal F., 139.

Crenshaw, K. (1991). Mapping the margins: Intersectionality, identity politics, and violence against women of color. Stanford law review, 1241-1299.

Crenshaw, K. (1991). Mapping the margins: Intersectionality, identity politics, and violence against women of color. Stanford Law Review, 1241-1299.

Cochran-Smith, M. (2001). The outcomes question in teacher education. Teaching and teacher education, 17(5), 527-546.

Cochran-Smith, M. (2004). Walking the road: Race, diversity, and social justice in teacher education. Teachers College Press.

Cochran-Smith, M., \& Lytle, S. L. (2009). Inquiry as stance: Practitioner research for the next generation. Teachers College Press.

Comber, B., \& Simpson, A. (Eds.). (2001). Negotiating critical literacies in classrooms. Routledge.

Compton-Lilly, C. (2002). Confronting racism, poverty, and power. Children, 39(4).

Counts, G. S. (1932). Dare progressive education be progressive. Progressive Education, 9(4), 257-263.

Counts, G. S. (1978). Dare the school build a new social order? (Vol. 143). SIU Press.

Cross, B. E. (2005). New racism, reformed teacher education, and the same ole' oppression. Educational Studies, 38(3), 263-274.

Darder, A., Baltodano, M., \& Torres, R. D. (Eds.). (2003). The critical pedagogy reader. Psychology Press. 
Delgado, R., \& Stefancic, J. (2012). Critical race theory: An introduction. NYU Press.

Delpit, L. D. (2006). Other people's children: Cultural conflict in the classroom. The New Press.

Dewey, J. (1986). Experience and education. In The Educational Forum (Vol. 50, No. 3, pp. 241-252). Taylor \& Francis Group.

Douglas, T. R., \& Nganga, C. (2015). What's radical love got to do with it?: Navigating Identity, Pedagogy, and Positionality in Pre-Service Education. International Journal of Critical Pedagogy, 6(1)

Elo, S., \& Kyngäs, H. (2008). The qualitative content analysis process. Journal of advanced nursing, 62(1), 107-115.

Fairclough, N. (2013). Critical discourse analysis: The critical study of language. Routledge.

Fecho, B. (2011). Teaching for the students: Habits of heart, mind, and practice in the engaged classroom. Teachers College Press.

Finn, P. J. (2010). Literacy with an attitude: Educating working-class children in their own self-interest. Suny Press.

Freire, P. (1970). Pedagogy of the oppressed. Bloomsbury Publishing.

Freire, P., \& Macedo, D. (1987). Reading the word and the world. Westport, CT: Bergin \& Garvey.

Galman, S., Pica-Smith, C., \& Rosenberger, C. (2010). Aggressive and tender navigations: Teacher educators confront whiteness in their practice. Journal of Teacher Education, 61(3), 225-236. 
Gay, G. (2010). Culturally responsive teaching: Theory, research, and practice. Teachers College Press.

Geertz, C. (1973). The interpretation of cultures: Selected essays (Vol. 5019). Basic books.

Giroux, H. A. (1985). Teachers as transformative intellectuals. Social Education, 49(5), 376-79.

Giroux, H. A. (1988a). Literacy and the pedagogy of voice and political empowerment. Educational theory, 38(1), 61-75.

Giroux, H. A. (1988b). Teachers as intellectuals: Toward a critical pedagogy of learning. Greenwood Publishing Group.

Giroux, H. A. (2012). Disposable youth: Racialized memories, and the culture of cruelty. Routledge.

Gomez, M. L. (1994). Teacher education reform and prospective teachers' perspectives on teaching "Other people's" children. Teaching and Teacher Education, 10(3), 319-334.

Gordon, R. G. (2005). Ethnologue: Languages of the world . Dallas, TX: Summer Institute of Linguistics.

Grant, C. A., \& Sleeter, C. E. (2011). Doing multicultural education for achievement and equity. Routledge.

Grant, C. A., \& Zwier, E. (2011). Intersectionality and student outcomes: Sharpening the struggle against racism, sexism, classism, ableism, heterosexism, nationalism, and linguistic, religious, and geographical discrimination in teaching and learning. Multicultural perspectives, 13(4), 181-188. 
Grant, C. A., \& Sleeter, C. E. (2011). Doing multicultural education for achievement and equity. Routledge.

Grossman, P., \& McDonald, M. (2008). Back to the future: Directions for research in teaching and teacher education. American Educational Research Journal, 45(1), 184-205.

Haddix, M. M. (2015). Cultivating racial and linguistic diversity in literacy teacher education: Teachers like me. Routledge.

Hall, J. M., \& Carlson, K. (2016). Marginalization: A revisitation with integration of scholarship on globalization, intersectionality, privilege, microaggressions, and implicit biases. Advances in Nursing Science, 39(3), 200-215.

Halliday, M. A. K. (1973). Explorations in the functions of language.

Hooks, B. (1994). Teaching to transgress education as the practice of freedom.

Hooks, B. (1995). Teaching to Transgress: Education as the Practice of Freedom. Journal of Leisure Research, 28(4), 316.

Howard, G. R. (2006). We can't teach what we don't know: White teachers, multiracial schools. Teachers College Press.

Irizarry, J. (2007). Ethnic and urban intersections in the classroom: Latino students, hybrid identities, and culturally responsive pedagogy. Multicultural Perspectives, $9(3), 21-28$.

Irwin, J. (2012). Paulo Freire's philosophy of education: origins, developments, impacts and legacies. Bloomsbury Publishing.

Janks, H. (2000). Domination, access, diversity and design: A synthesis for critical literacy education. Educational review, 52(2), 175-186. 
Janks, H. (2009). Literacy and power. Routledge.

Janks, H. (2010). Language, power and pedagogies. Sociolinguistics and language education, 40-61.

Janks, H. (2015). The social justice project of critical literacy revisited. In Keynote address at the Conference on English Education, New York, NY.

Jones, C., \& Shorter-Gooden, K. (2003). Shifting: Based on the African American Women's Voices Project.

Kamler, B. (2001). Relocating the personal: A critical writing pedagogy. SUNY Press.

Keefer, M. W., Zeitz, C. M., \& Resnick, L. B. (2000). Judging the quality of peer-led student dialogues. Cognition and instruction, 18(1), 53-81.

Kinloch, V. (2013). Difficult dialogues in literacy (urban) teacher education. Literacy Teacher Educators (pp. 107-120). Sense Publishers.

Kincheloe, J. L., \& Steinberg, S. R. (1998). Unauthorized methods: Strategies for critical teaching. Psychology Press.

Ladson-Billings, G. (1995a). But that's just good teaching! The case for culturally relevant pedagogy. Theory Into Practice, 34(3), 159-165.

Ladson-Billings, G. (1995b). Toward a theory of culturally relevant pedagogy. American Educational Research Journal, 32(3), 465-491.

Ladson-Billings, G. (2001). Crossing over to Canaan: The Journey of New Teachers in Diverse Classrooms. The Jossey-Bass Education Series. Jossey-Bass, Inc., 350 Sansome Street, San Francisco, CA 94104.

Ladson-Billings, G. (2007). Pushing past the achievement gap: An essay on the language of deficit. The Journal of Negro Education, 316-323. 
Lankshear, C. (1997). Changing literacies. McGraw-Hill Education (UK).

Lazar, A. M. (2007). It's not just about teaching kids to read: Helping preservice teachers acquire a mindset for teaching children in urban communities. Journal of Literacy Research, 39(4), 411-443.

Lewison, M., Flint, A. S., \& Van Sluys, K. (2002). Taking on critical literacy: The journey of newcomers and novices. Language Arts, 79(5), 382-392.

Lewison, M., Flint, A. S., \& Van Sluys, K. (2008). Taking on critical literacy: The journey of newcomers and novices. Language arts, 79(5), 382-392.

Lincoln, Y. S., \& Guba, E. G. (1985). Naturalistic inquiry (Vol. 75). Sage.

Luke, A. (2012). Critical literacy: Foundational notes. Theory into practice, 51(1), 4-11.

Luke, A., \& Freebody, P. (1997). Shaping the social practices of reading. Constructing Critical Literacies: Teaching and Learning Textual Practice, 6, 460-475.

Marx, S., \& Pennington, J. (2003). Pedagogies of critical race theory: Experimentations with white preservice teachers. International Journal of Qualitative Studies in Education, 16(1), 91-110.

Mayring, P. (2014). Qualitative content analysis: theoretical foundation, basic procedures and software solution.

Merriam, S. B. (1998). Qualitative research and case study applications in education. Revised and expanded from. Jossey-Bass Publishers, 350 Sansome St, San Francisco, CA 94104.

Merriam, S. B. (2009). Qualitative Research: a guide to design and interpretation. San Francisco: Jossey-Bass. 
McDonough, P. M. (1997). Choosing colleges: How social class and schools structure opportunity. Suny Press.

McLaren, P. (1986). Postmodernity and the death of politics: A Brazilian reprieve. Educational Theory, 36(4), 389-401.

McLaren, P. (1995). Critical pedagogy and predatory culture: Oppositional politics in a postmodern era. Psychology Press.

McLaren, P. (2003). Critical pedagogy: A look at the major concepts. The critical pedagogy reader, 1 .

Mezirow, J. (1991). Transformative dimensions of adult learning. Jossey-Bass, 350 Sansome Street, San Francisco, CA 94104-1310.

Milner IV, H.R., Race, culture and researcher positionality: Working through dangers seen, unseen and unforeseen (2007) Educational Researcher, 36 (7), pp. 388-400

Moll, L. C. (Ed.). (1992). Vygotsky and education: Instructional implications and applications of sociohistorical psychology. Cambridge University Press.

Palmer, J. M., \& Larey, D. P. (2016). Pre-service Teachers' Leading and Teaching for Social Justice.

Paris, D. (2012). Culturally sustaining pedagogy: A needed change in stance, terminology, and practice. Educational Researcher, 41(3), 93-97.

Picower, B. (2009). The unexamined whiteness of teaching: How white teachers maintain and enact dominant racial ideologies. Race Ethnicity and Education, 12(2), 197215.

Price-Dennis, D. M. (2009). Practicing the promise of critical pedagogy: Case studies of three pre-service teachers mediating the meaning of race, equity, and social 
justice in middle school classrooms (Doctoral dissertation, The Ohio State University).

Purdie-Vaughs, V., \& Eibach, R. P. (2008). Intersectional invisibility: The distinctive advantages and disadvantages of multiple subordinate- group identities. Sex Roles, 59(5-6), 377-391. DOI: 10.1007/s11199- 008-9424-4

Reither, J. A. (1985). Writing and knowing: Toward redefining the writing process. College English, 47(6), 620-628.

Riley, K., \& Crawford-Garrett, K. (2016). Critical Texts in Literacy Teacher Education: Living Inquiries into Racial Justice and Immigration. Language Arts, 94(2), 94.

Rios, F., \& Lindley, L. (2004). Taking stands for social justice. Scholar-Practitioner Quarterly, 2(2), 89-106.

Rogers, R. (2002). Between contexts: A critical discourse analysis of family literacy, discursive practices, and literate subjectivities. Reading Research Quarterly, 37(3), 248-277.

Rogers, R. (2013). Cultivating diversity through critical literacy in teacher education. In Literacy teacher educators (pp. 7-19). SensePublishers.

Rose, D. G., \& Potts, A. D. (2011). Examining teacher candidate resistance to diversity: what can teacher educators learn?. International Journal of Multicultural Education, 13(2).

Saldana, J. (2016). Writing and Publishing Books in Qualitative Inquiry.

Seidl, B. L. (2007). Working with communities to explore and personalize culturally relevant pedagogies: "Push, double images, and raced talk." Journal of Teacher Education, 58(2), 168-182. 
Simon, R. (2013). Literacy teacher education as critical inquiry. In Literacy Teacher Educators (pp. 121-134). SensePublishers.

Sleeter, C. E. (2001). Preparing teachers for culturally diverse schools: Research and the overwhelming presence of whiteness. Journal of teacher education, 52(2), 94106.

Stanley, C. A. (2006). Coloring the academic landscape: Faculty of color breaking the silence in predominantly White colleges and universities. American Educational Research Journal, 43(4), 701-736.

Ullucci, K., \& Battey, D. (2011). Exposing color blindness/grounding color consciousness challenges for teacher education. Urban Education, 46(6), 1195 1225.

Ukpokodu, O. N. (2009). Pedagogies that foster transformative learning in a multicultural education course: A reflection. Journal of Praxis in Multicultural Education, 4(1), 4.

Van Dijk, T. A. (1993). Principles of critical discourse analysis. Discourse \& society, 4(2), 249-283.

Vygotsky, L. S. (1980). Mind in society: The development of higher psychological processes. Harvard university press.

Vygotsky, L. (1978). Interaction between learning and development. Readings on the development of children, 23(3), 34-41.

Wagner, N., Hassanein, K., \& Head, M. (2010). Computer use by older adults: A multidisciplinary review. Computers in human behavior, 26(5), 870-882. 
Wells, G. (1995). Language and the inquiry-oriented curriculum. Curriculum inquiry, 25(3), 233-269.

Williamson, P. (2013). Engaging literacy practices through inquiry and enactment in teacher education. In Literacy Teacher Educators (pp. 135-147). SensePublishers Wink, J. (2005). Critical pedagogy: Notes from the real world. New York, NY: Pearson/Allyn \& Bacon.

Yin, R. K. (2003). Case study research design and methods third edition. Applied social research methods series, 5 .

Zeichner, K., \& Hoeft, K. (1996). Teacher socialization for cultural diversity. Handbook of research on teacher education (pp. 525-547). 
APPENDICIES 


\section{APPENDIX A:}

\section{CIE Lesson Plan Example}

\begin{tabular}{|c|c|c|c|}
\hline CIE 2 & Disorienting Experience & $\begin{array}{l}\text { Disorienting Experience } \\
\text { Rational Discourse }\end{array}$ & $\begin{array}{l}\text { Critical Reflection } \\
\text { Blackboard Assignment }\end{array}$ \\
\hline $\begin{array}{l}\text { Resisting } \\
\text { Deficit } \\
\text { Perspectives } \\
\text { by } \\
\text { Exploring } \\
\text { Linguistic } \\
\text { Diversity }\end{array}$ & $\begin{array}{l}\text { Researcher will have PSTs, } \\
\text { conduct a running record while } \\
\text { she re-enacts the linguistic } \\
\text { reading behaviors of an African } \\
\text { American student who uses } \\
\text { AAVE. After coding and } \\
\text { analyzing the miscues based on } \\
\text { syntax, and grapho-phonic } \\
\text { proficiency, the researcher will } \\
\text { describe the nuanced syntactical } \\
\text { structures of AAVE in the } \\
\text { running record. Discussion will } \\
\text { center on linguistic diversity, } \\
\text { and who and what defines } \\
\text { appropriate language in the } \\
\text { classroom. }\end{array}$ & $\begin{array}{l}\text { In your collaborative } \\
\text { group please discuss the } \\
\text { following: } \\
\text { Imagine you are a third } \\
\text { grade classroom teacher, } \\
\text { and you conduct a running } \\
\text { record on a student who } \\
\text { uses AAVE as their first } \\
\text { language. } \\
\text { Would you allow } \\
\text { linguistic variation to be } \\
\text { counted as an error in a } \\
\text { running record? Why or } \\
\text { Why not? } \\
\text { How would you address } \\
\text { non-standard forms of } \\
\text { English in your } \\
\text { classroom? }\end{array}$ & $\begin{array}{l}\text { How can we honor students' home } \\
\text { language, when it may be divergent } \\
\text { from our own? } \\
\text { What biases do we bring to the } \\
\text { classroom, based on our intersectional } \\
\text { identities, and how can we resist } \\
\text { stereotyped ideations of reality? } \\
\text { What was the most challenging aspect } \\
\text { of this exercise? } \\
\text { Did you learn anything new about } \\
\text { yourself thought this activity? }\end{array}$ \\
\hline
\end{tabular}




\section{APPENDIX B:}

\section{Blackboard Critical Reflection Questions}

\begin{tabular}{|c|c|}
\hline \multicolumn{2}{|r|}{ CIE 1 Blackboard Critical Reflection Questions- Problem-Posing by Challenging the Text } \\
\hline 1. & Was there anything you liked or disliked about this activity? \\
\hline 2. & Did this activity challenge you in any way? \\
\hline 3. & How might this activity be challenging for elementary students? \\
\hline 4. & Did this activity help you think about literacy in a different way (good or bad)? \\
\hline 5. & What further questions might you have about Problem Posing or Critical Literacy? \\
\hline \multicolumn{2}{|r|}{$\begin{array}{c}\text { CIE } 2 \text { Blackboard Critical Reflection Questions- Counter Narrative by Talking Back to Multi-Media Text } \\
\text { Exploring Multiple Perspectives 3Hat Debate }\end{array}$} \\
\hline 1. & $\begin{array}{l}\text { Some people shared in class that it's hard to reconcile what we know as truth, and what we've been } \\
\text { socialized to believe as American citizens in relation to Muslims. As future educators do you think tackling } \\
\text { issues of xenophobia, racism, sexism, or discrimination is important in the elementary classroom? Why or } \\
\text { why not? }\end{array}$ \\
\hline 2. & $\begin{array}{l}\text { Reflect on the instructional/curricular elements of the } 3 \text { Hats activity. Did you find the } 3 \text { Hats structure to be } \\
\text { one that was easy to follow? Do you think you would use this structure in your future classroom? Please } \\
\text { provide pros and cons for this activity. }\end{array}$ \\
\hline 3. & Did this critical literacy activity help you think about literacy in a different way? \\
\hline 4. & Did this activity challenge you in any way? Please explain. \\
\hline 5. & What further questions might you have about the 3 Hats Debate critical literacy activity? \\
\hline \multicolumn{2}{|r|}{$\begin{array}{c}\text { CIE } 3 \text { Blackboard Critical Reflection Questions- Resisting Deficit Perspectives by Exploring Linguistic Diversity } \\
\text { through Running Records }\end{array}$} \\
\hline 1. & $\begin{array}{l}\text { What are your thoughts on the following quote? "While all children's spoken language differs from the } \\
\text { language of books, our challenge is intensified when children bring with them language patterns that are } \\
\text { significantly different from the language forms they experience in text" (Marie Clay) }\end{array}$ \\
\hline 2. & $\begin{array}{l}\text { Prior to our lesson today, how much thought had you given to language diversity in relation to reading and } \\
\text { reading assessment. }\end{array}$ \\
\hline 3. & $\begin{array}{l}\text { I shared as a beginning teacher; I would have marked all African American Language (AAL) markers as } \\
\text { errors during a running record. Did any portion of our discussion about language contradict the way in which } \\
\text { you viewed/view running records or reading assessments? }\end{array}$ \\
\hline 4. & $\begin{array}{l}\text { Did our discussion, or the short video clip challenge or change your thinking about what is considered "right" } \\
\text { or "wrong" language in the classroom? }\end{array}$ \\
\hline 5. & $\begin{array}{l}\text { Do you feel comfortable with students speaking AAL or a variation of non-standard English in your } \\
\text { classroom? Would you verbally correct students who used non-standard forms of English in your classroom? } \\
\text { Why or why not? }\end{array}$ \\
\hline 6. & $\begin{array}{l}\text { What are your thoughts on honoring students' home language in the classroom? Where do you draw the line } \\
\text { between cultural appreciation and grammatical syntactical error? }\end{array}$ \\
\hline 7. & her questions might you have about this topic? \\
\hline
\end{tabular}




\section{APPENDIX C:}

\section{CIE Learning Session Curriculum Example}

\section{Learning Session 1- 1/9/17}

CIE Focus: Intersectional Positionality

Instructional Goal(s): Introduce the concept of intersectionality, and the matrix of oppression (Collins, 2000) to ground the idea of honoring individuals' multi-privileged and oppressed identities.

Curriculum Used: Matrix of Oppression, Intersectional Identities Graphic Organizer (Appendix E), power point presentation

Learning Activities: Introduced concept by stating the multiple factors outside of just race, gender, and socioeconomic status influence achievement, understanding individuals outside of just a "single story" was emphasized in this lesson. Through a comparison of myself to President Trump, we looked beyond simply acknowledging our gender and our race, by exploring all of our intersected identities, and discussed as a group, which identities positioned us as privileged and oppressed. Next, students used the intersectional Positionality graphic organizer to identify six of their most pronounced identities, and then answered the 6 questions about these identities. Last students wrote a autobiographical reflection about one identity that was privileged and one that was oppressed based on the Matrix of Oppression framework passed out in class.

Real-Classroom Connection: A short vignette based on a Black elementary aged girl who lived in the surrounding (Portland) area was first used to get students to engage in moving beyond just seeing gender, skin color, and socioeconomic status, to imagine what other privileges and oppressions this little may experience based on her social positioning.

\section{Learning Session 2- 1/30/17}

CIE Focus: Critical Literacy Critique

Instructional Goal(s): Introduction of Critical Literacy, with an emphasis on challenging, and questioning through text-based critique, using the problem-posing method.

Curriculum Used: Time \& Newsweek Magazine Covers (Appendix F), Power Point, Problem-Posing 4 Square Graphic Organizer (Appendix G)

Learning Activities: Introduced the idea of critique by first identifying critically based questions that we should ask to move past literal interpretations of text (e.g. why does the 
author want you the reader to believe this, whose viewpoints are included/excluded from this text, etc). Next we discussed that "text" can be any medium that is used to convey a message, and thus visual text can be used as well. From here, two visual texts, in the form of magazine covers were shown. Using the four problem-posing questions presented in class students had to critique each text in small groups. We shared out our discussions in whole group format as well.

Real-Classroom Connection: This lesson centered on millennials and the ways in which society can positively and negatively frame this unique subset of the population. Students had to decipher ways to interpret both covers, which represented conflicting views. This assignment was foundational in helping students understand the utility of critical literacy practice, and the ways in which critique is used. Using socially charged visual text had binary purposes for this assignment. First, I thought the idea of millennials would be engaging and relative to students falling close to this age range. Secondly I wanted to show that critical literacy is not bound to just written text, and the practice of critique can be implemented in various modalities. By reinforcing the four problem-posing questions throughout the lesson, I helped students understand the practical classroom use of critical literacy in the classroom. 


\section{APPENDIX D}

\section{Cultural Diversity Awareness Inventory (CDAI)}

Please indicate how strongly you agree or disagree with the following statements by circling the appropriate letters following the statement.

$\begin{array}{ccccc}\begin{array}{c}\text { Strongly } \\ \text { Disagree }\end{array} & \text { Disagree } & \text { Neutral } & \text { Agree } & \begin{array}{c}\text { Strongly } \\ \text { Agree }\end{array} \\ \text { SD } & \text { D } & \text { N } & & \text { SA }\end{array}$

I Believe...

1. my culture to be different from some of the children Iserve.

2. it is important to identify immediately the ethnic group of the children I serve.

SD $\quad \mathbf{D} \quad \mathbf{N} \quad \mathbf{A} \quad \mathbf{S A}$

3. I would prefer to work with children and parents whose cultures are similar to mine.

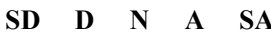

4. I would be uncomfortable in settings with people who speak non-standard English.

SD $\quad$ D $\quad$ N $\quad$ A $\quad$ SA

5. I am uncomfortable in settings with people who exhibit values or beliefs different from my own.

SD $\quad$ D $\quad$ N $\quad$ A $\quad$ SA

6. in asking families of diverse cultures how they wish to be referred to (e.g., Caucasian, White, Anglo) at the beginning of our interaction.

SD $\quad$ D $\quad \mathbf{N}$ A $\quad$ SA

7. other than the required school activities, my interactions with parents should include social events, meeting in public, places (e.g., shopping centers), or telephone conversations.

SD $\quad$ D $\quad$ N $\quad$ A $\quad$ SA

8. I am sometimes surprised when members of certain ethnic groups contribute to particular school activities (e.g., bilingual students on the debate team or Black students in the orchestra).

SD $\quad$ D $\quad$ N $\quad$ A $\quad$ SA

9. the family's views of school and society should be included in the school's yearly program planning.

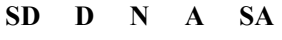

10. it is necessary to include on-going parent input in programplanning.

SD $\quad$ D $\quad \mathbf{N} \quad$ A $\quad$ SA

11. I sometimes experience frustration when conducting conferences with parents whose culture is different from my own.

SD $\quad$ D $\quad$ N $\quad$ A $\quad$ SA

12. the solution to communication problems of certain ethnic groups is the child's own responsibility.

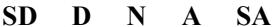

13. English should be taught as a second language to non-English speaking children as a regular part of the school curriculum.

SD $\quad$ D $\quad$ N $\quad$ A $\quad$ SA

14. when correcting a child's spoken language, one should role model without any further explanation.

SD $\quad$ D $\quad$ N $\quad$ A $\quad$ SA 


\section{APPENDIX E}

\section{Intersectionality Graphic Organizer}

\section{Intersectional Identilies}

Our social identities - whether they result in an experience of privilege or oppression -- $\quad$ are likely to shape how we see others and Please reflect on your identity or membership in any number of these groups.

\begin{tabular}{|c|c|c|}
\hline a. Race & b. Religion & c. Sexual Orientation \\
\hline d. Culture & e. National Origin & f. Language \\
\hline g. Gender & h. Ability (Disability) & i. Body Size Shape \\
\hline j. Sex & k. Socioeconomic Status/Class & I. Age \\
\hline
\end{tabular}

7-Minute Autobiography Exercise

1. Color the identity boxes which are most important to you.

2. Which identities were you more aware of?

3. Were the identities you are more aware of privileged or oppressed? Why do you think that is?

4. Which identities do you take for granted and not think about often?

5. From this exercise, can you identify one or two identities in which you think you should be more aware of as a teacher?

6. Chose two identities, which speak to your schooling experiences and development of self. 


\section{APPENDIX F}

\section{Magazine Cover Example}

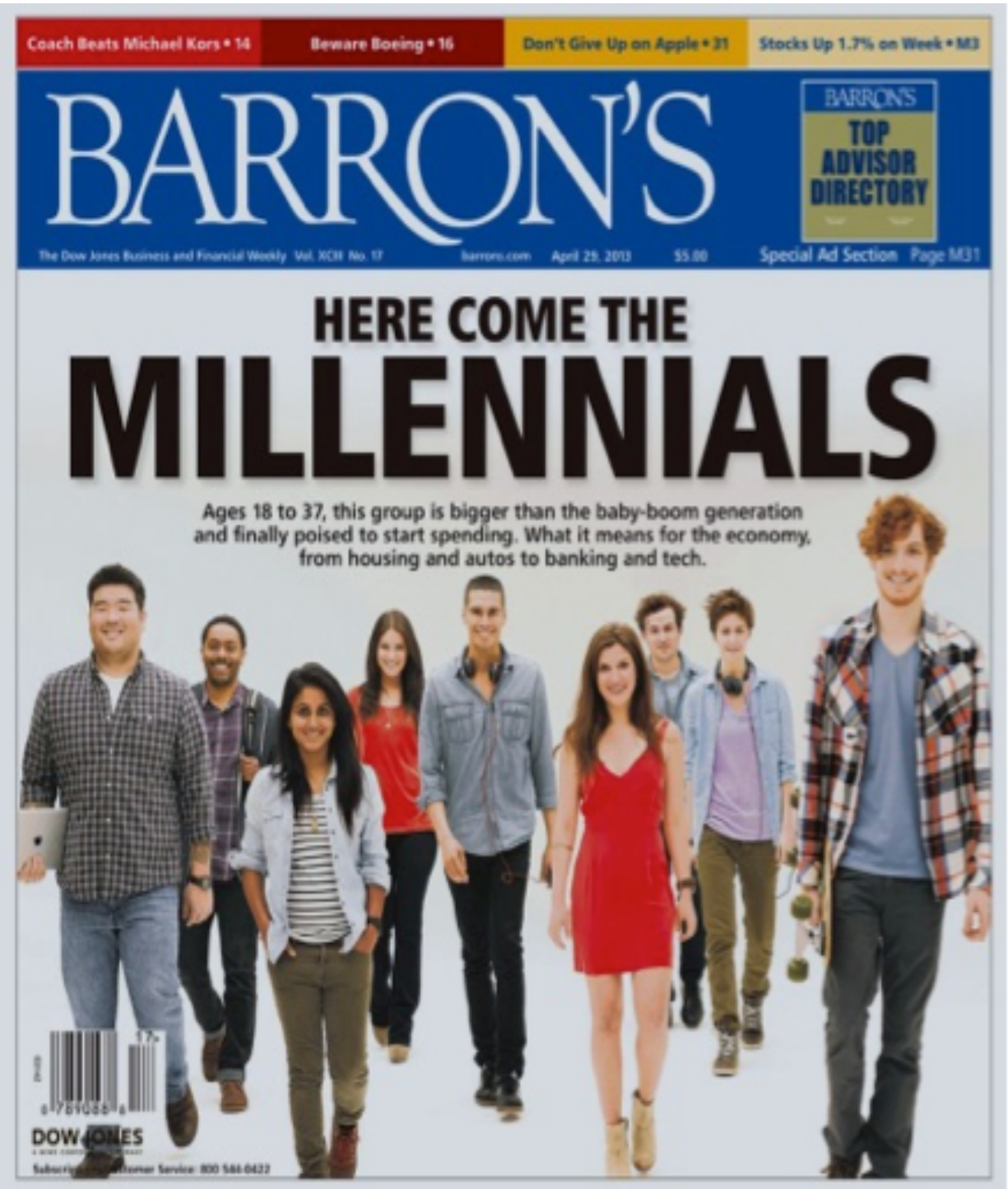




\section{APPENDIX G}

\section{Problem-Posing 4 Square Graphic Organizer}

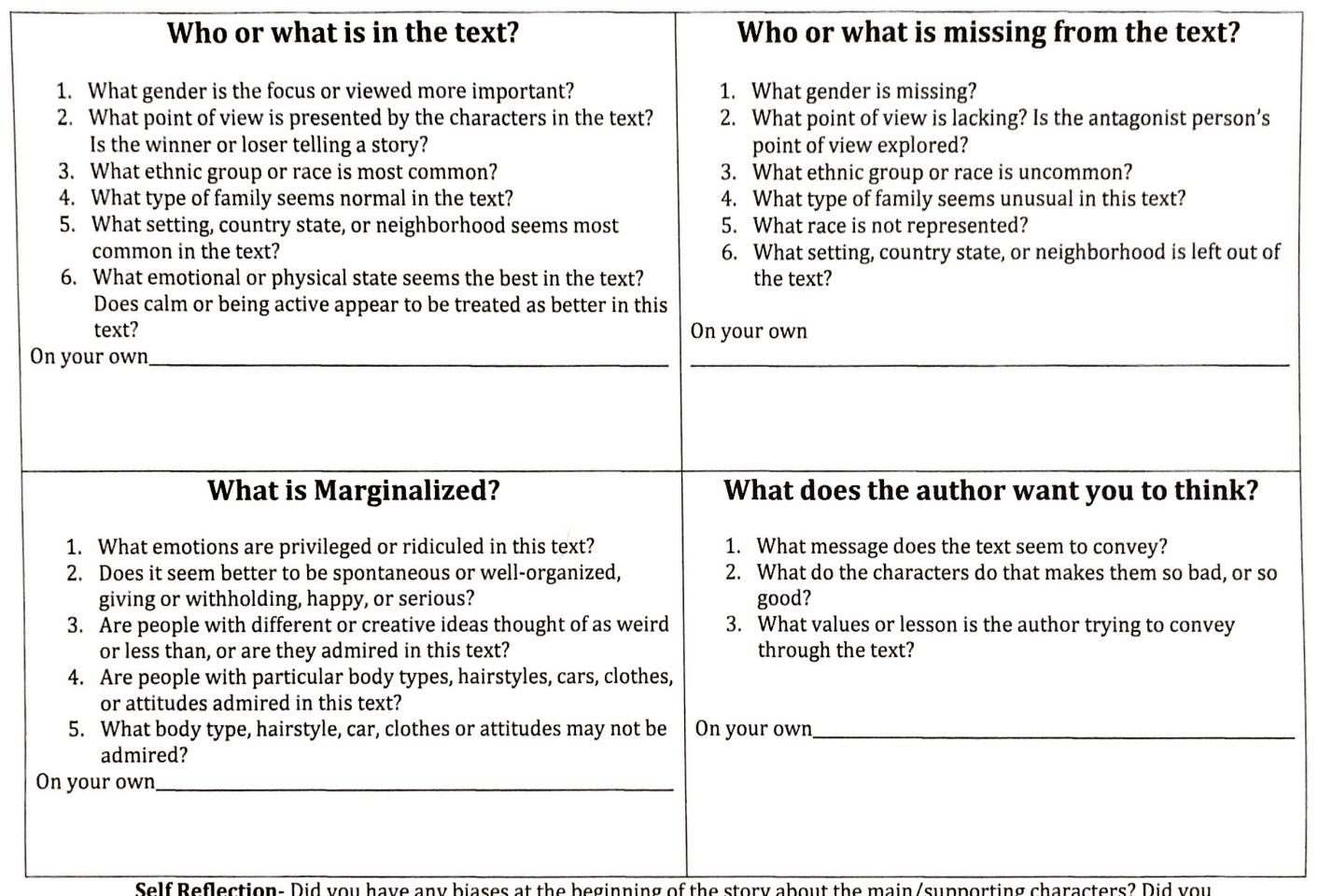

Self Reflection- Did you have any biases at the beginning of the story about the main/supporting characters? Did you perception of the main or supporting characters change by the end of the text? 


\section{APPENDIX H}

\section{3-Hats Debate Graphic Organizer}

\begin{tabular}{|l|l|}
\hline \multicolumn{2}{|c|}{} \\
\hline \multirow{2}{*}{$\begin{array}{l}\text { 1. Malala } \\
\text { "Muslim } \\
\text { Woman" }\end{array}$} & Taliban Member \\
& \\
\cline { 2 - 2 } & Nerspective Matrix \\
\cline { 2 - 2 } & Malala's Father \\
\hline $\begin{array}{l}\text { 2. Donald } \\
\text { Trump } \\
\text { "Muslim } \\
\text { Problems" }\end{array}$ & Muslim American \\
\cline { 2 - 2 } & Trump Supporter \\
& \\
\cline { 2 - 2 } & News Reporter \\
\hline
\end{tabular}




\section{APPENDIX I: \\ Critical-Intersectional Reflection Survey}

\section{Intersectional Positionality}

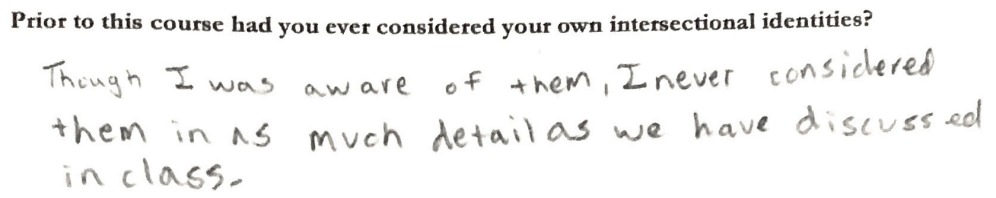

Prior to this course had you ever considered your own intersectional identities? Thiugh I was aware of them, Inever considered them in as much detailas we have discussed in class.

How did it feel to think about your identity as multi-privileged and multi-oppressed? It broadened my perspective, one day we had an activity to choose privileged or oppressed in each category.

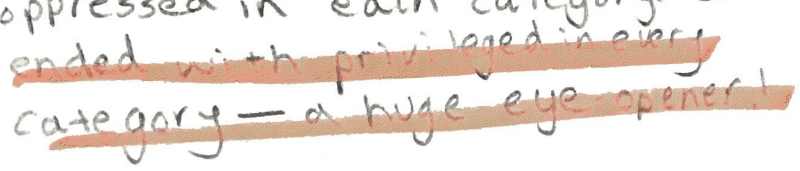

Can you use this way of viewing identity when you become a teacher? If so, how?

$$
\begin{aligned}
& \text { It think it will be nighly effective! I hope } \\
& \text { to make the conversations on identity } \\
& \text { as comfortable as possible for mystudents. }
\end{aligned}
$$




\section{Critical Literacy}

Based on the three Critical Literacy Activities facilitated by Mrs. Nightengale-Lee, please rank each based on the activity you gained the most from(1), and the activity you gained the least from (3).

\begin{tabular}{|l|l|c|}
\hline Lesson Title & Topic/Text & $\begin{array}{l}\text { Ranking } \\
\text { 1= Most Gained } \\
\text { 2= Gained } \\
\text { 3= Least Gained }\end{array}$ \\
\hline Problem Posing & $\begin{array}{l}\text { The Three Little Pigs \& the Somewhat Bad } \\
\text { Wolf }\end{array}$ & 3 \\
\hline $\begin{array}{l}\text { 3 Hats Multiple } \\
\text { Perspectives }\end{array}$ & Malala \& Donald Trump & 2 \\
\hline $\begin{array}{l}\text { Language } \\
\text { Variation \& } \\
\text { Running } \\
\text { Records }\end{array}$ & Bianca \& The Running Record & \\
\hline
\end{tabular}

Based on your number 1 ranking, briefly discuss why this experience resonated with you? (e.g. personally, instructionally, theoretically etc.)

$$
\begin{aligned}
& \text { This stction resonated with me personally. much of } \\
& \text { what we discussed was in question forme } \\
& \text { and it was nice to see that neither side } \\
& \text { was'twrong'? }
\end{aligned}
$$

Based on all three activities which one would you be willing to try in your own classroom?

$$
\begin{aligned}
& \text { I loved the video we watched on } \\
& \text { running recerd! }
\end{aligned}
$$

Do you have any takeaways from learning about critical literacy this semester?

$$
\begin{aligned}
& \text { overall, my perspective has been broadened } \\
& \text { if not exactly changed. It was largely } \\
& \text { beneficial }
\end{aligned}
$$

Additional comments, questions, suggestions or concerns 
APPENDIX J:

\section{CRR Coding Matrix}

\begin{tabular}{|c|c|c|}
\hline $\begin{array}{l}\text { Written } \\
\text { Indicators }\end{array}$ & Definition & Example \\
\hline Critique & $\begin{array}{l}\text { Individuals } \\
\text { question } \\
\text { themselves, } \\
\text { or a specific } \\
\text { status quo } \\
\text { instructional/ } \\
\text { curricular } \\
\text { practice. }\end{array}$ & $\begin{array}{l}\text { Prior to this lesson I had honestly only } \\
\text { thought of diversity in respect to where the } \\
\text { children in the story were from, what their } \\
\text { family structure looked like, different } \\
\text { language spoken, etc., rather than different } \\
\text { types of languages within one language. It } \\
\text { was interesting to think about if from a } \\
\text { different perspective that is so relevant to so } \\
\text { many students. (Allison CIE } 3 \text { Reflection) }\end{array}$ \\
\hline Resist & $\begin{array}{l}\text { Individuals } \\
\text { challenge } \\
\text { traditional } \\
\text { outlooks on } \\
\text { literacy or } \\
\text { education. }\end{array}$ & $\begin{array}{l}\text { The structure of the } 3 \text { Hats activity was easy } \\
\text { to follow. I do think I will use it my future } \\
\text { classroom for many reasons. Yes, some of } \\
\text { the topics are uncomfortable but it is } \\
\text { important to see what our students are } \\
\text { thinking during events that are trying. We } \\
\text { cannot just say "it's adult stuff"; that does not } \\
\text { instantly wipe the questions out of the kids } \\
\text { head nor does it stop the scenes from } \\
\text { appearing on television. (Josh, CIE } 2 \\
\text { Reflection) }\end{array}$ \\
\hline Re-Design & $\begin{array}{l}\text { Individuals } \\
\text { re-thinking } \\
\text { or re- } \\
\text { conceptualize } \\
\text { literacy in } \\
\text { new ways } \\
\text { that predicate } \\
\text { on critical } \\
\text { literacy. }\end{array}$ & $\begin{array}{l}\text { This activity helped me think about critical } \\
\text { literacy in a new and good way. Sometimes I } \\
\text { think we as teachers think of literacy as } \\
\text { analyzing writing and reading the text when } \\
\text { it is so much more than that. This had me } \\
\text { look at literacy in a way that incorporated } \\
\text { perspectives, writing, analyzing and so much } \\
\text { more. It pushed me to step outside of myself } \\
\text { and try stepping into others shoes which is } \\
\text { often hard for kids to do. Especially for little } \\
\text { kids, I think they struggle with seeing any } \\
\text { other perspective but their own; this activity } \\
\text { MAKES them do it. (Hailey, CIE } 2 \\
\text { Reflection) }\end{array}$ \\
\hline
\end{tabular}




\section{APPENDIX K \\ Blackboard Reflection- Initial Manual Coding Example}

might make it easier for them to form the opinions of the 3 Hats. I think the pros were that it made me step out of my comfort zone and try to step in someone else's shoes, it got to me think critically about other perspectives, and it was very informative while being fun. I think the cons definitely include things like parental pushback and I also think for little kids, if the activity was not described well enough, they would have a hard time understanding writing from three different perspectives.

$$
\text { re.conceptualizes literay }
$$

3. This activity helped me think about critical literacy in a new and good way. Sometimes I think we, as teachers, think of literacy as analyzing writing and reading the text, when ro $^{\circ}$ it is so-much more than that. This had me look at literacy in a way that incorporated perspectives, writing, analyzing, and so much more. It pushed me to step outside of myself and try stepping into others shoes, which is often hard for kids to do. Especially. for little kids, I think they struggle with seeing any other perspective but their own, this activity MAKES them do it.

4. This activity challenged me in many ways, primarily it challenged me because I had to look at a view point that is completely different than mine. I had to come up with a way to sound genuine in an opinion when my opinion is the polar opposite. It challenged me to think critically and sort of infer what people were thinking, even if it wasn't obviously said or pointed out:

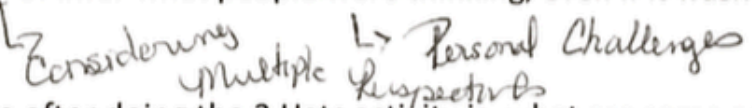

5. A question I might have after doing the 3 Hats activity is, what are some activities that might be good to do with young students before this activity? For younger students I really feel like they might struggle with the idea of having to write from three perspectives, what are some ways to prepare them for it?

\section{CIE 3}

1. My thoughts on the quote stem from my teacher perspective and classes that I have taken while in school. I have learned that we, as teachers, need to value differences in language because it helps us understand individual students funds of knowledge. 


\section{APPENDIX L}

\section{Discourse Analysis Initial Manual Coding Example}

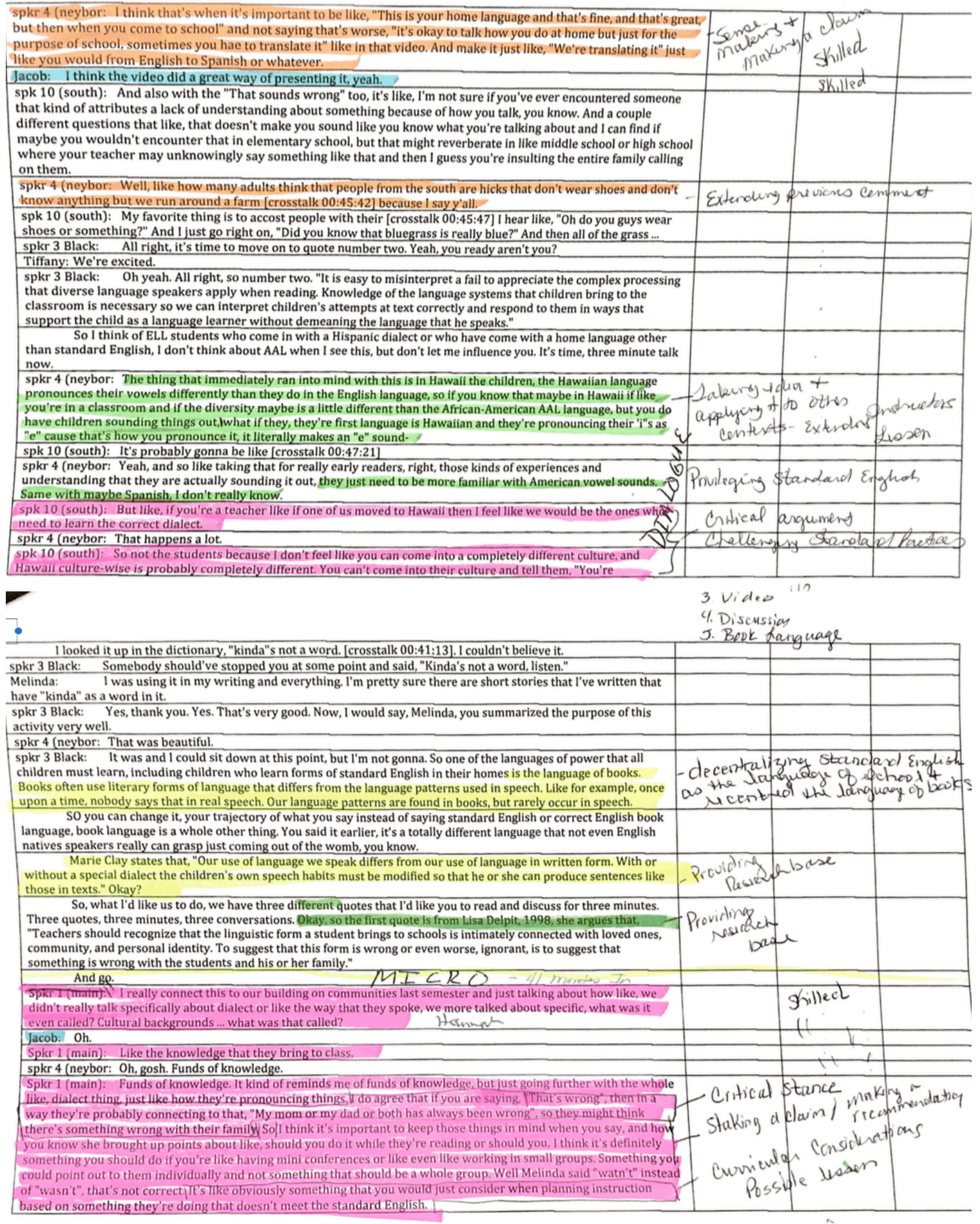




\section{APPENDIX M}

\section{Researcher Log Example}

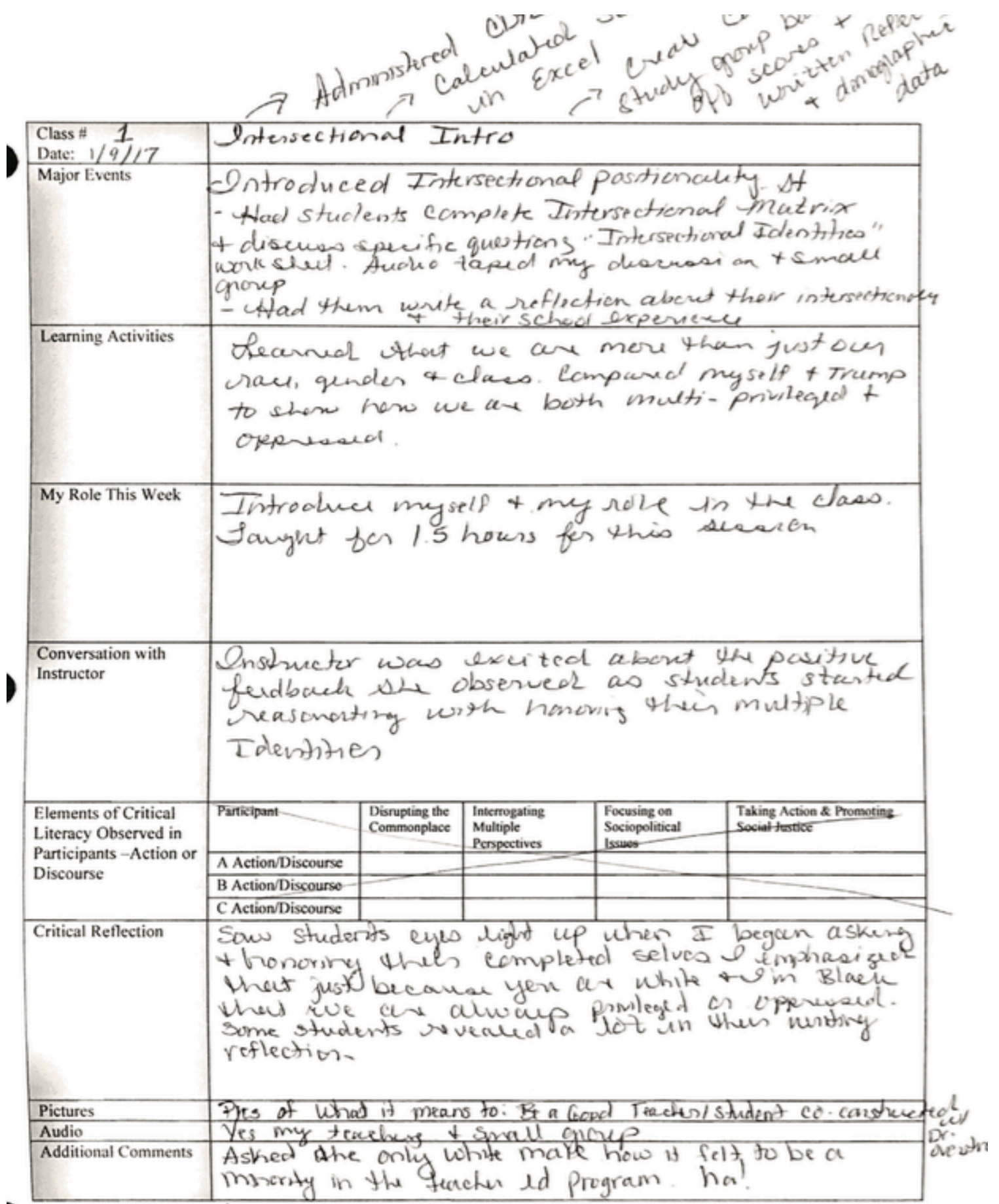

Interesting-thaland S Scare highen than meet an CDAI bat she has

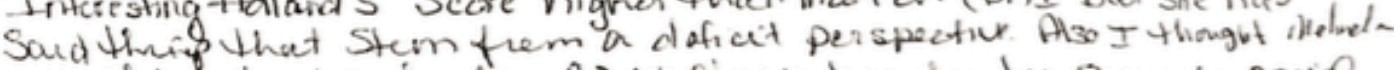

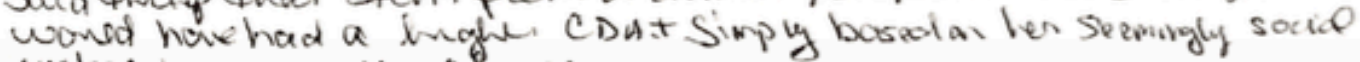
justice gave in tire claves. 
CURRICULUM VITAE

\section{Bianca Nightengale-Lee}

1905 South $1^{\text {st }}$ Street

College of Education and Human Development,

University of Louisville

Louisville, KY 40292,

Phone: 502-604-1199 • E-Mail: bianca.nightengale@louisville.edu

\section{EDUCATION:}

Ph.D. Curriculum \& Instruction, (December, 2017) University of Louisville, Louisville KY Areas of Emphasis: Critical Pedagogy, Teacher Preparation, Intersectional Positionality Dissertation Title: Educating Critically: Challenging the Familiar Contours of Literacy Teacher Education

Dissertation Chairs: Drs. Lori Norton-Meier \& Mikkaka Overstreet

M.Ed. Literacy Specialist, (May, 2012) University of Louisville, Louisville, KY

Program Components: 36-credit program includes theory instruction and researched classroom-based execution

B.S. Elementary Education (Dec., 2003) Eastern Michigan University, Ypsilanti, MI

Major: Literacy, Minor: Science

\section{Licensure \& Certification,}

State of Kentucky Teaching Licensure, P-5

Literacy Specialist Endorsement

Kentucky Educational Consultant Licensure

\section{RESEARCH:}

Graduate Research Assistantship, University of Louisville August, 2016-June 2017

Department of Early Childhood \& Elementary Education

- Large scale grant solicitation and composition, qualitative data collection and analysis for various research projects, trained in qualitative data analysis using NVIVO software- Supervisors: Drs. Amy Seely-Flint \& Michele Foster 
Graduate Research Assistantship, University of Louisville August, 2015-June 2017

Department of Educational Leadership, Evaluation, \& Organizational

Development

- Trained in survey development using Qualtrics Survey Platform, emphasis in qualitative and quantitative methodology, trained in Systematic Review of Literature format, assisted with curriculum development for qualitative courses- Supervisor: Dr. Meera Alagaraja

Local School Research Coordinator, SRI Research Group August 2016-present Olmstead Academy North Middle School, Louisville KY

- Coordinated on and off site data management for large-scale national research study investigating the National Writing Project College Ready Writers Program. Supervised teachers and 140 middle school students through data administration and data collection for the 2016-2018 school years.

\section{Research Assistant, Pacific Institute for Research \& Evaluation August 2015- March 2016}

- Conducted observational data collection, and analysis for regional study of pre-school teacher effectiveness using the Classroom Assessment Scoring System, over 30 hours of observations and a total of 7 data analysis reports written.

\section{Research Director, Goal Clarity Coach Leadership Academy, August 2015- April 2016}

- Designed, administered, and analyzed all data for the Goal Clarity Coach Leadership Academy, a partnership initiative between the Louisville Writing Project and Jefferson County Public Schools to support Goal Clarity Coach writing professional development proficiencies.

\section{Literacy Research Apprenticeship II, University of Louisville January 2015-April 2015}

- Conducted exploratory pilot study with Jefferson County Public Schools \& the Louisville Writing Project, designed to evaluate program effectiveness, data collection included survey development and dissemination along with interviews and observations, under the advisement of Dr. Lori Norton-Meier.

\section{Current Research Studies}

Urban Landscape as Metaphorical Text: Fostering Consciousness through a Socio- 
Spatial Interrogation of Equity \& Access in a Literacy Methods Course, University of Louisville- currently- Principle Investigator

Factors Inhibiting and Advancing Teacher Certification for Candidates of Color, University of Louisville- August 2016- Currently - Co-Principle Investigator

CAEP Standard 4 Teacher Education Program Evaluation \& Effectiveness, University of Louisville, August 2016- Currently- Co-Principle Investigator

\section{TEACHING:}

Visiting Assistant Professor, Berea College January 2018

Department of Educational Studies

Courses : EDS 150- Introduction to Education

EDS 347: Literacy Methods Primary: P-3

Part-Time Instructor, University of Louisville

August 2015-

Currently Department of Early Childhood \& Elementary Education

Courses: EDTP 311 -Writing Methods, P-5

EDTP 320 -Reading Methods, P-5

University Co-Teaching, University of Louisville

January 2014-May

2014

Department of Middle \& Secondary Education

Co-taught with Dr. Yuliya Ardasheva

Course: EDAP 620- Content Area Literacy

K-5 Teaching Experience

Instructional Coach, Jefferson County Public Schools 2015

August 2013-May

- Cultivate collaborative relationships with teachers utilizing the "Partnership Approach" Coordinate, and facilitate all weekly PLC meetings, where data was used to drive standards based instructional discussion Design engaging professional development experiences that are based on school, teacher, and student need (Topics: Formative Assessment, Thinking Stems, Vocabulary Acquisition, Number Talks, Critical Literacy, Differentiated Instruction) 


\section{Louisville Writing Project, Co-Director, University of Louisville June 2015- April 2016}

- Co-facilitated yearlong writing professional development for $\mathrm{k}$ 12 teachers, with an emphasis on lesson study, critical literacy, and standards based writing strategies, under the advisement of Jean Wolph.

- Taught $3^{\text {rd }}$ grade, established comprehensive and challenging standards based learning environment to meet the academic, intellectual, and social needs of all students, principal appointed team leader 3 consecutive years, member of the Instructional Leadership Team, and School Based Decision Making Council, principal appointed chair of the writing portion of the program review

\section{Elementary \& middle school Teacher, Detroit Public Schools August 2004- June 2008}

- Constructed comprehensive curriculum reflective of students' lives and cultural background, collaborated and served on School Improvement Team conceptualized and initiated school wide writing program "Young Authors

\section{PUBLICATIONS:}

Nightengale-Lee, B., Thomas, S., Compton, D., Joseph, B. (2017). More Than a Know it All Black Girl! Examining the experiences of African-American female pre-service teachers in predominately White spaces. Educational Studies. (In Press, 2018)

Nightengale-Lee, B. (2015). "Inquiry, Innovation, \& Action". Kentucky Department of Education: Kentucky Teacher, Volume 4, Issue 10.

Nightengale-Lee, B. (2014). "Thinking stems 2.0: A traditional strategy revamped". Kentucky Department of Education: Literacy Link, Volume 4, Issue 6.

Nightengale-Lee, B. (2013). "Multiple Perspectives: Looking at literacy through a critical lens". Kentucky Department of Education: Literacy Link, Volume 3, Issue 8. 


\section{Manuscripts in Review}

Nightengale-Lee, B., \& Overstreet, M. (2016). Mobilizing critical multicultural curricula in a literacy methods course. Teacher Education and Practice.

\section{Manuscripts in Progress}

Nightengale-Lee, B. (2017). Circumventing the Silence: Using a criticalintersectional framework to deconstruct privilege and oppression with White teacher candidates. Chapter in Norton-Meier, L, Overstreet, M (Eds.), Clinical Partnerships in Urban Elementary Settings: An Honest Celebration of the Messy Realities of Doing this Work. Sense Publishers (Invited)

\section{GRANTS AND AWARDS:}

2017 Kappa Delta PI Student Research Award- \$1,000 (Under Review)

2017 National Council of Teachers of English- Conference on English Education, Graduate Student Research Grant, \$2,500 (Under Review)

2017 Association of Teachers Educators Clinical Fellowship (selected)

2017 AERA Division B Curriculum Studies Vice-Presidential Graduate Student Seminar Liberating Dissertation Writing Competition- selected seminar participant (\$200)

2016 National Council of Teachers of English-Conference on English Education Research Initiative Grant (\$2,500 Funded)

2016 Holmes Scholar Fellowship Award- selected participant, college of education competition

2016-17 University of Louisville Grant Writing Academy Competition- selected participant, university wide competition

\section{REFFERED CONFERENCE PRESENTATIONS:}

Nightengale-Lee, B. (2018, March). Circumventing the Silence: Using a criticalintersectional framework to deconstruct privilege and oppression with White teacher candidates. Paper to be presented at the American Association of Colleges for Teacher Education (AACTE), Annual Meeting, Baltimore, MD.

Nightengale-Lee, B., Thomas, S., Compton, D., Joseph, B. (2017, September). More Than a Know it All Black Girl! Examining the experiences of African-American female pre-service teachers in predominately White spaces. Paper session presented at the 
Teacher Diversity Matters: National Symposium on Preparing, Recruiting, and Retaining Teachers of Color, Highland Heights, KY.

Nightengale-Lee, B. (2017, May). Educating Critically: Challenging the familiar contours of literacy teacher education. Poster presented at the Thirteenth Congress of Qualitative Inquiry, Urbana Champaign, IL.

Nightengale-Lee, B. (2017, April). A critical-intersectional framework in teacher education. Symposium session presented at the American Association for the Advancement of Curriculum Studies (AAACS), Annual Meeting, San Antonio TX.

Nightengale-Lee, B. Overstreet, M. (2017, March). A critical critique of methods curriculum in supporting teacher candidates' inquiry, action, and agency. Roundtable session presented at the American Association of Colleges for Teacher Education (AACTE), Annual Meeting, Tampa FL.

Nightengale-Lee, B, Clayton-Taylor. (2016, November). Hip Hop into Literacy: Hip hop in the elementary classroom. Symposium session presented at the National Council of Teachers of English (NCTE) Annual Meeting, Atlanta GA.

Nightengale-Lee, B. Overstreet, M. (2016, August) Hello from the Other Side: Teachers of color in a predominately white methods course. Symposium session presented at the Association of Teachers of English (ATE), Louisville, KY.

Nightengale-Lee, B. (2016, June) Looking at multiple perspectives in the elementary classroom. Panel session presented at the International Society of Language Studies Annual Conference, Normal IL.

Nightengale-Lee, B. (2016, April). Three Hats: Writing from multiple perspectives. Roundtable session presented at the Critical Digital Media Literacy Annual Conference, Savannah, GA.

Nightengale-Lee, B., Minter, T. (2016, March). Culturally responsive pedagogy \& practice. Symposium session presented at the National Reading Association of North Carolina, Raleigh, NC.

Clayton-Taylor, N, Nightengale-Lee, B. (2016, January). Grammar on FLEEK: Using hip-hop based education to teach grammar. Invited panelist at the Louisville Writing Project Annual Conference, Louisville KY.

Nightengale-Lee, B., Calloway, M., Elzey, C., Fuller, E., \& Hogue, S., (2015, November). GCC leadership academy program review. Roundtable session presented at the National Writing Project Conference. Minneapolis, MS. 
Nightengale-Lee, B., Putman, S., \& Vujaklija, A. (2014, July). LWP Technology Academy. University of Louisville, Louisville, KY.

Nightengale-Lee, B., (2013, March). Multiple Perspectives: Looking at literacy through a critical lens. Symposium session presented at the National Writing Project- Urban Studies, Birmingham AL.

\section{PROFESSIONAL SERVICE:}

Board Member, 2017-2018 AACTE Holmes Scholar Elected Board Member 2016-2018: Kentucky Council of Teachers of English (KCTE) Elected Board Member -Diversity \& Inclusion Chair

Reviewer, 2014: Literacy Research Association (LRA)-conference proposal reviewer

2014: American Education Research Association (AERA)conference proposal reviewer- Division D \& G

Conference Planning, 2017-18 AACTE Holmes Scholar Conference Committee 2016: Elevating \& Celebrating Effective Teaching and Teachers

(ECET2)- K-12 Planning Committee sponsored by The Bill \& Melinda Gates Foundation

\section{UNIVERISTY AND COLLEGE SERVICE:}

Invited Guest Lecturer, Critical Literacy \& Bias Exploration. Educational Foundations (undergraduate course), Berea College, August \& October 2017

Invited Presenter, Culturally Responsive Pedagogy (professional development training). Adjunct Faculty Retreat, University of Louisville, August 2017

Invited Guest Lecturer, Intersectional Positionality in the Classroom. Science \& Social Justice (graduate course), University of Louisville, June 2017

Faculty Search Committees (2) College of Education, Educational Leadership, Evaluation, \& Organizational Development search, 2016-17

Co-Creator \& Facilitator, Educators for Equity \& Social Justice Initiative, 2016present 
Board Member, Nystrand Center of Excellence University of Louisville, 2016present

President \& Founder, College of Education Black Graduate Student Association, 2016-2017

Invited Panelist, Minority Association of Graduate Students, Doctoral Student Symposium, 2016

Student Panelist, University of Louisville Doctoral Orientation, 2016

COMMUNITY ENGAGED SCHOLARSHIP:

Organization of Black Aerospace Pilots (OBAP) Summer Camp, Facilitator, 2017-present

Youth Ethics \& Skills (Y.E.S.) Community Based Educational Support Program, Board member \& volunteer, 2016-present

National Council of Teachers of English (NCTE), African-American Read-In, partnership with Atkinson Elementary, 2015, Organizer \& Facilitator, 2015

Chestnut Street YMCA, Board member \& volunteer, 2014-2015

\section{WORKSHOPS \& PROFESSIONAL DEVELOPMENT TRAINING:}

Allison, M., Nightengale-Lee, B. (2017, July). Writers Workshop Training (3 day training), Jefferson County Public Schools, Louisville, KY.

Clayton-Taylor, N, Nightengale-Lee, B. (2017, June). Engaging Students Through HipHop \& Literacy. Deeper Learning Conference, Jefferson County Public Schools, Louisville, KY

Nightengale-Lee, B. (2015 September). National Writing Project Writing Mini Unit Presentation (5 hour training), Kennedy Montessori Elementary School, Louisville, KY.

Nightengale-Lee, B. Clayton-Taylor, N., (2015 July). Culturally Responsive Pedagogy (6 hour training). Wheatley Elementary School, Louisville Ky.

Nightengale-Lee, B. (2015 July). Engage New York Math Curriculum Introduction \& Overview (3 hour training). Wheatley Elementary School, Louisville, KY 


\section{PROFESSIONAL MEMBERSHIPS:}

American Association of Colleges for Teacher Education (AACTE) Holmes Scholars

American Association of Colleges for Teacher Education (AACTE)

Literacy Research Association Member (LRA)

American Educational Research Association Member (AERA)

National Council of Teachers of English Member (NCTE)

Kentucky Council of Teachers of English Board Member (KCTE) 